\title{
Numerical Simulation of Air- and Water-Flow Experiments in a Block of Variably Saturated, Fractured Tuff from Yucca Mountain, Nevada
}

by E. M. Kwicklis, Falah Thamir ${ }^{1}$, R.W. Healy, and David Hampson ${ }^{2}$

1AMX International, Inc., Denver, Colorado

${ }^{2}$ EQE International, Evergreen, Colorado

\section{U.S. GEOLOGICAL SURVEY}

Water-Resources Investigations Report 97-4274

Prepared in cooperation with the NEVADA OPERATIONS OFFICE, U.S. DEPARTMENT OF ENERGY, under Interagency Agreement DE-Al08-97NV12033 


\title{
U.S. DEPARTMENT OF THE INTERIOR \\ BRUCE BABBITT, Secretary
}

\author{
U.S. GEOLOGICAL SURVEY
}

Thomas J. Casadevall, Acting Director

The use of firm, trade, and brand names in this report is for identification purposes only and does not constitute endorsement by the U.S. Geological Survey.

For additional information write to:

Chief, Earth Science Investigations Program

Yucca Mountain Project Branch

U.S. Geological Survey

Box 25046, Mail Stop 421

Denver Federal Center

Denver, CO 80225-0046
Copies of this report can be purchased from:

U.S. Geological Survey

Information Services

Box 25286

Federal Center

Denver, CO 80225 


\section{CONTENTS}

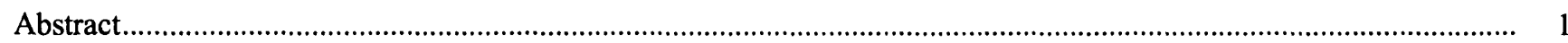

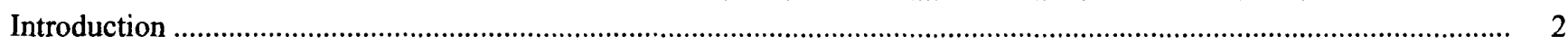

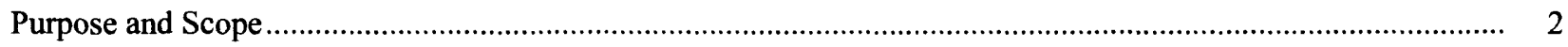

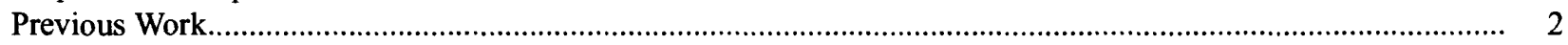

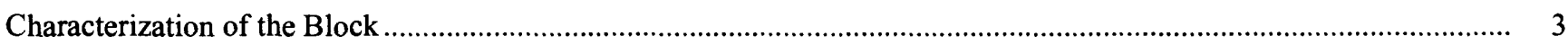

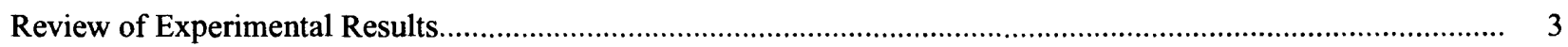

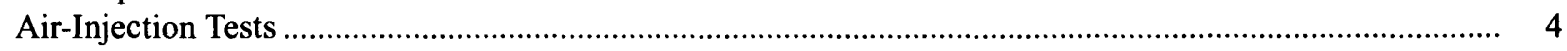

Moisture Redistribution Following Water Application ............................................................................ 4

Water Movement Under a Constant Applied Water Potential ................................................................. 12

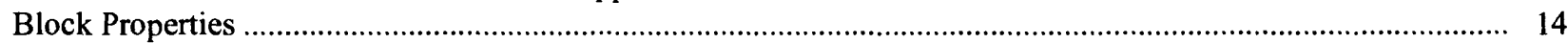

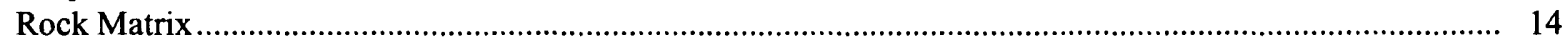

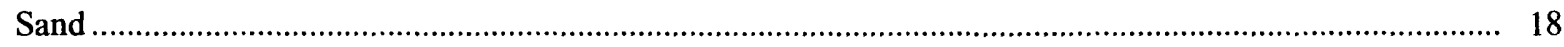

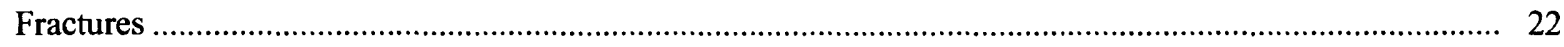

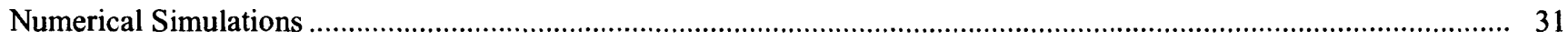

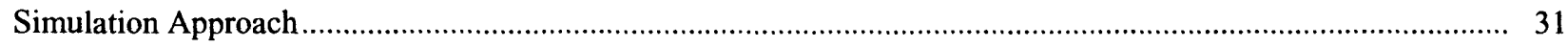

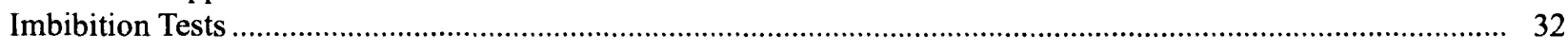

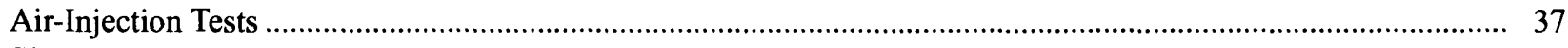

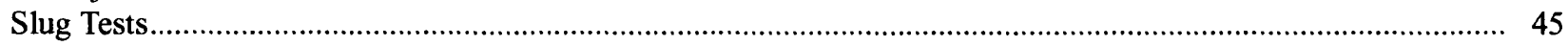

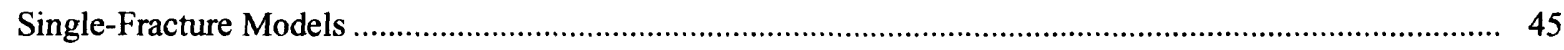

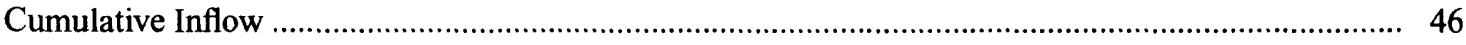

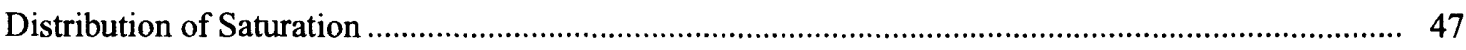

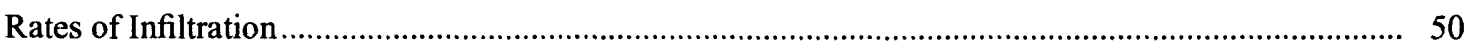

Equating Real to Hypothetical Fractures.................................................................................... 50

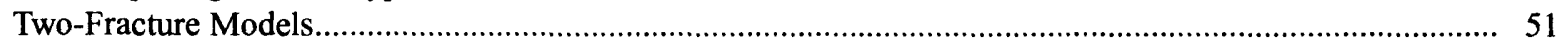

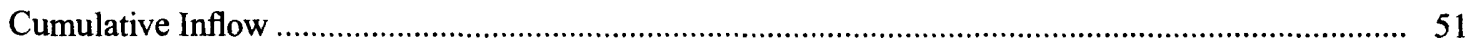

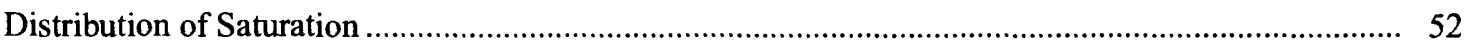

Sand Layer Matric Potentials .................................................................................................. 52

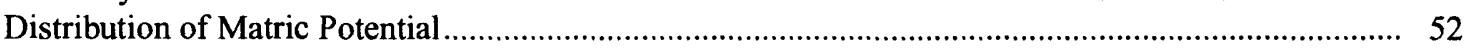

Analysis of Assumptions in this Modeling Approach........................................................................ 56

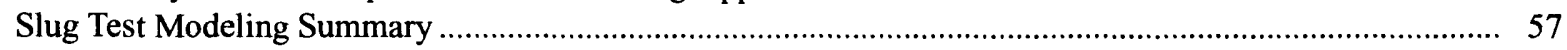

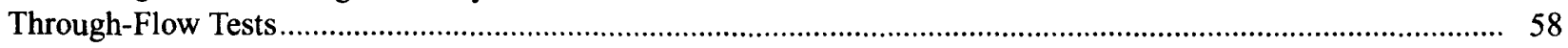

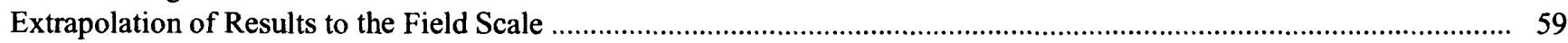

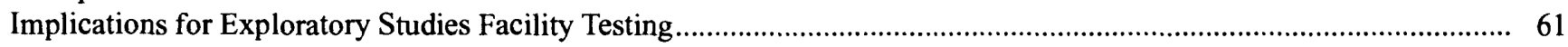

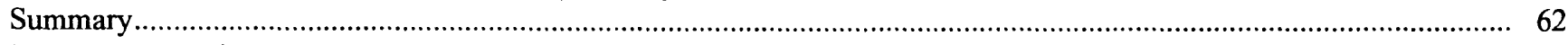

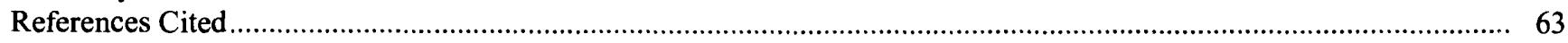

\section{FIGURES}

1. Sketch of the block showing fracture and borehole locations ...................................................................

2. Graphs showing results from air-injection tests: $(\mathrm{A})$ in boreholes $2 \mathrm{C}, 1 \mathrm{~F}, 3 \mathrm{~A}, 1 \mathrm{D}$, and $1 \mathrm{~A}$ from injection

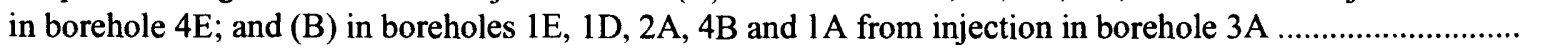

3. Sketch showing the experimental layout of the block with frame, Plexiglas enclosure, water sprayer, and sand layers.....

4-6. Graphs showing:

4. Matric potential response in the upper sand layer at 5 centimeters above the sand/rock interface during and after the addition of the first and second slugs of water..

5. Response of selected borehole psychrometers to the addition of the first and second slugs of water ......... 1

6. Water-flow rates for days 720 to 794: (A) inflow; and (B) outflow................................................. 13 


\section{FIGURES-Continued}

7-19. Graphs showing:

7. Matric potentials as measured by borehole tensiometer-transducer systems: (A) matrix boreholes;

(B) fracture boreholes in upper part of block; and (C) fracture boreholes in lower part of block

8. Water-flow rates for days 795 to 962 : (A) inflow; and (B) outflow

9. Flow rates through the block expressed as functions of: (A) average matric potential in the upper sand layer; (B) median borehole matric potential (matrix holes included); and (C) median borehole matric potential (matrix holes excluded)

10. Experimental saturation/matric potential data for rock matrix sampled from trimmed portions of the block, with fitted van Genuchten curve

11. Results of imbibition tests conducted in core samples taken from trimmed portions of the block showing apparent effects of entrapped air: (A) first series; and (B) second series

12. Fitted drying and estimated wetting moisture-characteristic curves for the rock matrix

13. Theoretical relative permeabilities to liquid $\left(\mathrm{k}_{\mathrm{rl}}\right)$ and gas $\left(\mathrm{k}_{\mathrm{rg}}\right)$ of rock matrix, as estimated from the Luckner functions using $\mathrm{S}_{\mathrm{Is}}=0.70$ (wetting) and $\mathrm{S}_{\mathrm{ls}}=0.95$ (drying)

14. Measured matric potential/water-saturation relation of sand packed to a similar bulk density as the upper sand layer

15. Matric potential/water-saturation data interpolated from wetting and drying curves of figure 14, with fitted van Genuchten function.

16. Theoretical hysteretic relations calculated by the aperture-scale numerical model VSFRAC for five stochastic realizations of a fracture with an average physical aperture of 100 micrometers for: (A) water saturation as a function of matric potential; and (B) relative permeability to water as a function of matric potential.

17. Theoretical relative water permeability/water saturation relations calculated by the aperture-scale numerical model VSFRAC for five stochastic realizations of a fracture with an average physical aperture of 100 micrometers for: (A) wetting conditions; and (B) drying conditions.

18. Average theoretical relations for 25-, 125-, and 250-micrometer fractures calculated for wetting conditions by aperture-scale numerical model VSFRAC on the basis of ten stochastic realizations: (A) water saturation as a function of matric potential; (B) water and air relative permeability as a function of matric potential; and $(C)$ water and air relative permeability as a function of water saturation

19. Theoretical relations calculated by the aperture-scale numerical model VSFRAC for a single realization of a 125-micrometer aperture fracture: (A) water saturation as a function of matric potential; and (B) air and water relative permeability as a function of water saturation

20. Aperture and phase distributions within the fracture characterized by the relations shown in figure 19:

(A) aperture distribution; (B) water and air distribution at a matric potential of -0.25 meter; and (C) water and air distribution at a matric potential of -0.15 meter.

21-25. Graphs showing:

21. Fit of the van Genuchten function to estimates of fracture properties calculated by the aperturescale numerical model VSFRAC: (A) saturation as a function of matric potential; and (B) water permeability as a function of matric potential

22. Normalized cumulative imbibition versus normalized time curves calculated using TOUGH2 for various values of $S_{l s}$ assuming: (A) $\alpha=\alpha_{d}$; and (B) $\alpha=\alpha_{w}=2 \alpha_{d}$.

23. Normalized cumulative imbibition versus normalized time data for unfractured cores grouped on the basis of the similarity to early time results calculated by TOUGH2: (A) $\mathrm{S}_{1 \mathrm{~s}}=0.70$; and (B) $\mathrm{S}_{1 \mathrm{~s}}=0.80 \ldots \ldots$.

24. Normalized cumulative imbibition versus normalized time curves calculated using TOUGH2 for $\mathrm{S}_{\mathrm{Is}}=0.80$ and assuming low permeability pumice fragments located at various distances from the bottom of the core

25. Normalized cumulative imbibtion versus normalized time data of cores containing a fracture either parallel to (S3) or transverse to (S14A) the core axis

26-28. Diagrams showing:

26. Simulated steady-state gas-pressure distribution during injection into borehole $1 \mathrm{~A}$.

27. Simulated steady-state gas-pressure distribution during injection into borehole $1 \mathrm{C}$.

28. Simulated steady-state gas-pressure distribution during injection into borehole 1D. 


\section{FIGURES-Continued}

29-33. Diagrams showing:

29. Simulated steady-state gas-pressure distribution during injection into borehole $2 \mathrm{~A}$

30. Simulated steady-state gas-pressure distribution during injection into borehole $2 \mathrm{C}$

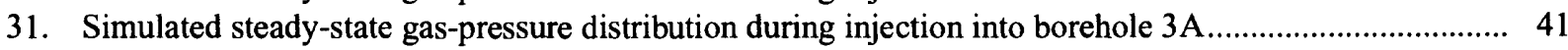

32. Simulated steady-state gas-pressure distribution during injection into borehole 4A.............................. 41

33. Simulated steady-state gas-pressure distribution during injection into borehole $4 \mathrm{E}$................................ 41

34-36. Graphs showing:

34. Calculated versus observed absolute gas pressures during injection tests, including: (A) monitoring and injection holes; (B) monitoring holes only; (C) monitoring holes located in fracture F1;

(D) monitoring holes located in fracture F2; (E) monitoring holes located in fracture F3;

(F) monitoring holes located in fracture F4; (G) monitoring holes located in fracture F5; and

(H) monitoring holes located in fracture F6.

35. Sensitivity of model estimates of cumulative inflow during the first 100-day redistribution period to fracture size...

36. Water permeability/matric potential relations used in the model for fractures, sand, and rock matrix ....... 47

37. Diagram showing simulated saturation distribution within an idealized block containing a single

25-micrometer fracture: (A) 1 day; (B) 5 days; (C) 10 days; (D) 25 days; (E) 50 days; and

(F) 100 days

38. Diagram showing simulated saturation distribution within an idealized block containing a single

125-micrometer fracture: (A) 1 day; (B) 5 days; (C) 10 days; (D) 25 days; (E) 50 days; and

(F) 100 days

39. Graph showing sensitivity of model estimates of rate of inflow to the block during the first 100-day

redistribution period to fracture size.

40. Graph showing model estimate of cumulative inflow during the first 100 -day redistribution period into an idealized block containing both a 25 - and 125 -micrometer fracture.

41. Diagram showing simulated saturation distribution within an idealized block containing both a 25and 125-micrometer fracture: (A) 1 day; (B) 5 days; (C) 10 days; (D) 25 days; (E) 50 days; and

(F) 100 days

42. Graph showing sensitivity of model estimates of sand layer matric potential during the first 100-day redistribution period to fracture size

43. Diagram showing simulated matric-potential distribution within an idealized block containing both a 25- and 125-micrometer fracture: (A) 1 day; (B) 5 days; (C) 10 days; (D) 25 days; (E) 50 days; and $(\mathrm{F}) 100$ days

44-46. Graphs showing:

44. Sensitivity of model estimates of cumulative inflow into the block during the first 100-day redistribution period to variations in sand properties

45. Sensitivity of model estimates of sand layer matric potential during the first 100 -day redistribution period to variations in sand properties

46. Comparison between measured and simulated water fluxes through the block as a function of matric potential. 


\section{TABLES}

1. Borehole termination locations and identification number of intercepted fractures.......................................... 6

2. Testing matrix for air-injection tests in the block ............................................................................... 7

3. Physical features of core samples used in imbibition tests................................................................... 18

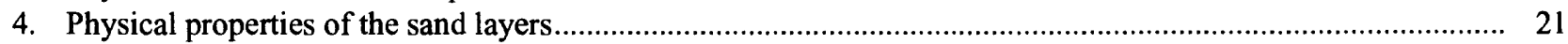

5. Aperture characteristics of hypothetical fractures considered by simulations in this report ............................... 23

6. Macroscopic hydrologic characteristics of hypothetical fractures considered by simulations in this

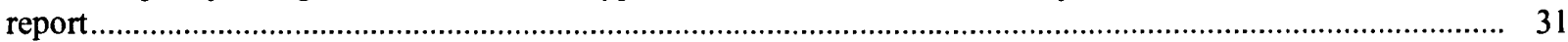

7. Summary of fracture properties based on calibration using air-permeability tests ............................................ 39

8. Comparison of measured and simulated gas pressures for air-injection tests ............................................... 44

9. Summary of effective transmissivities of fractures at matric potentials considered by the MAFIC simulations

\section{CONVERSION FACTORS}

\begin{tabular}{rll}
\hline Multiply & By & To obtain \\
bar & 14.50 & pound per square inch \\
kilopascal $(\mathrm{kPa})$ & 0.1450 & pound per square inch \\
meters of water (matric potential) & 1.4216 & pound per square inch \\
micrometer $(\mu \mathrm{m})$ & $3.937 \times 10^{-5}$ & inch \\
centimeter $(\mathrm{cm})$ & 0.3937 & inch \\
meter $(\mathrm{m})$ & 3.281 & foot \\
$\operatorname{liter}(\mathrm{L})$ & 0.2642 & U.S. gallon \\
cubic centimeter $\left(\mathrm{cm}^{3}\right)$ & $6.102 \times 10^{-2}$ & cubic inch \\
cubic centimeter per day $\left(\mathrm{cm}^{3} / \mathrm{day}^{2}\right)$ & $3.531 \times 10^{-5}$ & cubic foot \\
square $\operatorname{meter}\left(\mathrm{m}^{2}\right)$ & 10.764 & square foot \\
meter squared per second $\left(\mathrm{m}^{2} / \mathrm{s}\right)$ & $6.954 \times 10^{6}$ & U.S. gallon per day per foot \\
gram per cubic centimeter $\left(\mathrm{g} / \mathrm{cm}^{3}\right)$ & 62.43 & pound per cubic foot \\
\hline
\end{tabular}




\section{LIST OF SYMBOLS}

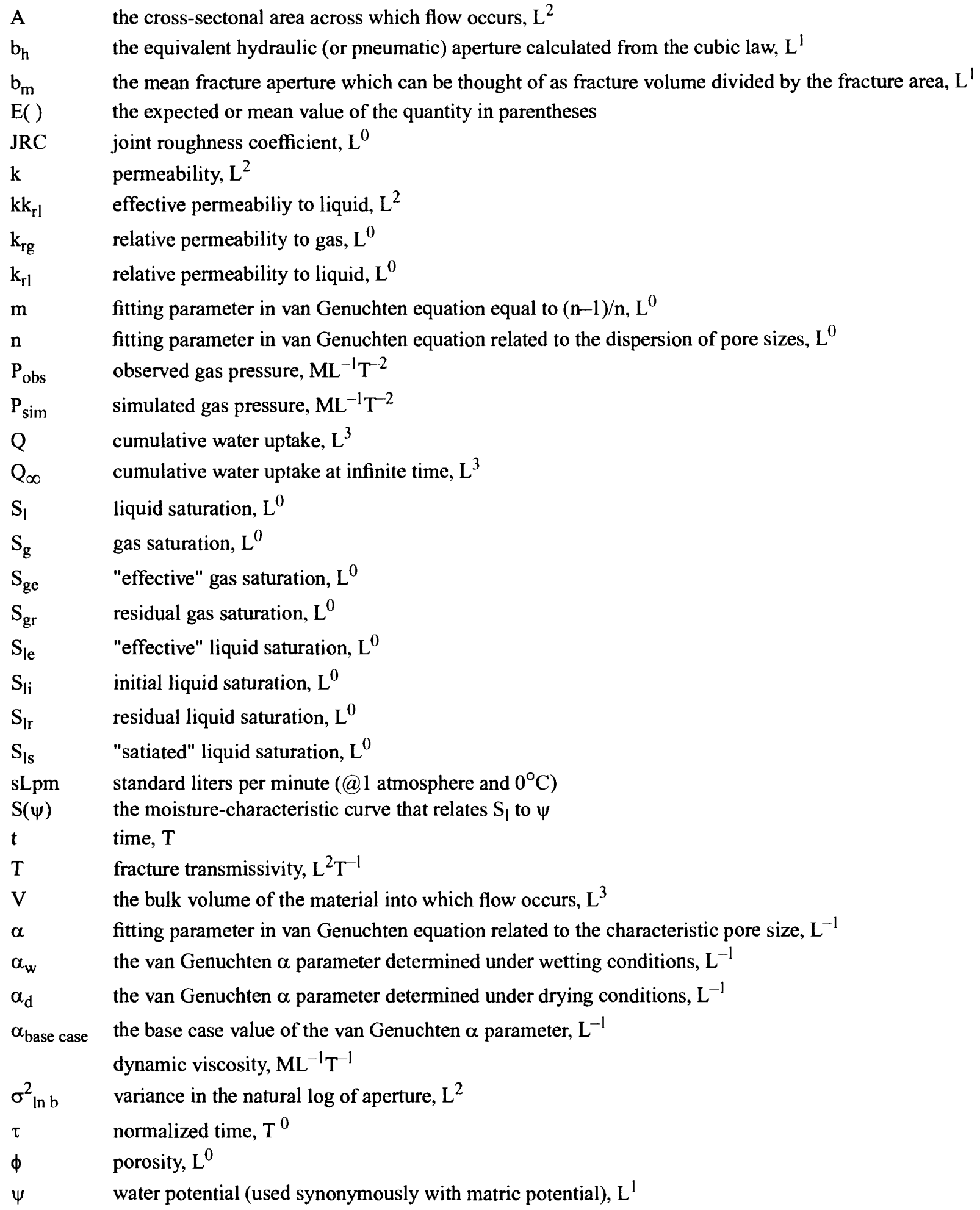




\title{
Numerical Simulation of Air- and Water-Flow Experiments in a Block of Variably Saturated, Fractured Tuff from Yucca Mountain, Nevada
}

\author{
By E.M. Kwicklis, Falah Thamir, R.W. Healy, and David Hampson
}

\section{ABSTRACT}

Numerical models of water movement through variably saturated, fractured tuff have undergone little testing against experimental data collected from relatively well-controlled and characterized experiments. This report used the results of a multistage experiment on a block of variably saturated, fractured, welded tuff and associated core samples to investigate if those results could be explained using models and concepts currently used to simulate water movement in variably saturated, fractured tuff at Yucca Mountain, Nevada, the potential location of a high-level nuclear-waste repository. Aspects of the experiment were modeled with varying degrees of success.

Imbibition experiments performed on cores of various lengths and diameters were adequately described by models using independently measured permeabilities and moisture-characteristic curves, provided that permeability reductions resulting from the presence of entrapped air were considered. Entrapped gas limited maximum water saturations during imbibition to approximately 0.70 to 0.80 of the fillable porosity values determined by vacuum saturation.

A numerical simulator developed for application to fluid flow problems in fracture networks was used to analyze the results of air-injection tests conducted within the tuff block through $1.25-\mathrm{cm}$-diameter boreholes. These analyses produced estimates of transmissivity for selected fractures within the block. Transmissivities of other fractures were assigned on the basis of visual similarity to one of the tested fractures. The calibrated model explained 53 percent of the observed pressure variance at the monitoring boreholes (with the results for six outliers omitted) and 97 percent of the overall pressure variance (including monitoring and injection boreholes) in the subset of airinjection tests examined.

Attempts to model moisture redistribution from a saturated sand layer overlying the block resulted in many insights into the factors affecting this process. Single-fracture models predicted that fractures whose permeability and capillary characteristics most closely matched that of the overlying sand would be most important to water uptake by the block. For large-aperture fractures, water uptake at early time was limited by the intrinsic permeability of the sand and, at later times, by the small relative permeability of the fracture. In the case of small-aperture fractures, water uptake was limited by the small intrinsic permeability of the fractures themselves. For large-aperture fractures, simulated sand layer matric potentials declined to near constant values as a result of capillary barrier effects at the sand/rock interface, indicating that similar declines in matric potential observed during the experiment may have been influenced by such processes. A two-fracture model indicated that capillary barrier effects associated with largeaperture fractures could hydraulically isolate portions of the block from the actively flowing fractures, resulting in a decrease in water uptake relative to the corresponding single-fracture 
models. Although these simulations provided considerable insight, none could simultaneously match all of the data for this period, which included measured matric potentials in both the overlying sand layer and rock matrix and estimated cumulative drainage from the sand at 100 days.

The through-flow tests provided an opportunity to compare model-based estimates of flux based on indirect indicators, such as intrinsic permeability and matric potential, with direct measurements of flux collected over a range of matric potentials. The steady fluxes predicted by using a fractured network model were generally in very close agreement with measured fluxes, thereby lending support to the validity of the measurements themselves, the analytical methods that were used to make those estimates, and the processes that were hypothesized as causing the decline in measured flow rates.

\section{INTRODUCTION}

Yucca Mountain, Nevada, is being characterized by the U.S. Geological Survey, in cooperation with the U.S. Department of Energy (Interagency Agreement DE-AI08-97NV12033) and its contractors, as a potential site for a high-level nuclear-waste repository. If found suitable, waste would be emplaced in the unsaturated zone within a thick sequence of tuffs with variable degrees of welding and fracturing. Prior to the recent interest in variably saturated, fractured tuff as a potential repository host rock, there was little investigation of the hydrologic behavior of such media in any detail. Hence, the methodology for characterizing and simulating water and solute movement in variably saturated, fractured tuff is not as mature as for other hydrologic environments. Although many aspects of flow in variably saturated fractured rock have been isolated and studied in detail, studies have not yet investigated if these characterization techniques and modeling concepts can be combined to explain flow behavior in real, relatively complex fracture systems. The need to test numerical models, as well as concepts, against experimental data continues in order for those models and concepts to be applied to the site with confidence.

\section{Purpose and Scope}

Recently data have become available from a laboratory experiment on a block of variably saturated, densely welded, fractured tuff from the Nevada Test Site (Thamir and others, 1993, 1994). The purpose of this experiment was to finalize the experimental design and analysis approach for an in-situ block test that would be performed in the Exploratory Studies Facility (ESF) at Yucca Mountain. The advantage of block tests is that they provide greater access for characterization and instrumentation and a larger degree of control over the boundary conditions compared with experiments in which the test volume remains unexcavated. The in-situ test, as well as the prototype test and analysis described in Thamir and others $(1993,1994)$, and in this report, is intended to provide an experimental basis to support or refute assumptions and results associated with models currently being used to help characterize flow within the unsaturated zone at Yucca Mountain. The purpose of this study is to investigate the following questions and to refine the testing and analysis strategies: (1) Can water flux through unsaturated, fractured rock be estimated through numerical modeling using indirect measurements of quantities such as intrinsic permeability and moisture status? (2) Does fracture transmissivity to water decrease abruptly with decreases in water (matric) potential (Montazer and Wilson, 1984; Wang and Narasimhan, 1985)? (3) What mechanisms govern water movement at the interface between unfractured, porous material and underlying fractures in welded tuff? and (4) Can the characterization techniques and modeling concepts developed over the past years be combined to explain water movement in real, relatively complex fracture systems?

\section{Previous Work}

Previous experimental work has focused on specific aspects of flow, such as flow within single fractures, flow within the rock matrix, or flow across the fracture-matrix interface. As will be apparent, previous experimental work has guided the design of the experiments done in the present study, as well as the subsequent analyses. Within single fractures, recent experiments on transparent fracture analogs or fracture replicas have attempted to visualize the distribution of fluid phases within single fractures or fracture analogs while simultaneously measuring the relation between phase permeabilities and phase saturations. In their 
two-phase flow experiments in transparent fracture replicas, Persoff and Pruess (1993) found significant phase interference between wetting and nonwetting fluids, so that the sum of the relative permeabilities can be much less than 1 . They observed irregular cycling in the gas inlet pressures as critical pore throats repeatedly blocked and cleared. Nicholl and others (1993a,b) used transparent fracture analogs (roughened glass) to investigate the potential for gravitational instabilities to break up coherent moisture fronts into smaller fingers that bypass much of the fracture plane. They found that these instabilities occurred during drainage, after the source of water had been removed, and also when the applied flux was less than the transmission capacity of the fracture under the existing gravitational gradient. Nicholl and others (1993a,b) also recognized the potential for flow paths to follow previously wetted structures, indicating that intermittent flow was likely to occur along the same pathways. Reitsma and Kueper (1994) measured the capillary pressure-liquid saturations of single, natural, rough-walled fractures. Their measured curves exhibited hysteretic behavior and relatively distinct air-entry pressures and were welldescribed by functional relations originally developed for porous media. The pneumatic properties of fractures in tuff and their relation to average physical apertures were presented in Schrauf and Evans (1986), who also presented techniques for identifying nonlinear flow behavior during air-injection tests.

Experiments dealing with imbibition into the tuff matrix show the need to consider complex pore structure that results from the presence of pumice inclusions (Peters and others, 1987). Foltz and others (1993) and Glass and others (1994) described experiments in which imbibition into the rock matrix from a waterfilled saw-cut was modeled. Glass and others (1994) found that their numerical model overestimated the observed saturations, which were imaged by X-ray techniques. They attributed their overestimates to the failure of their model to account for hysteresis in the measured moisture-characteristic curves and to the permeability reductions that accompany the presence of air entrapped during the wetting process.

Important to understanding fracture-matrix interactions is the role that fracture coatings may play on the exchange of fluids across that interface. Chekuri and others (1994) found that imbibition rates into cores through relatively thin iron and manganese oxide coatings were enhanced relative to imbibition through freshly fractured surfaces. This counterintuitive result was attributed to weathering along grain boundaries near the natural fracture surfaces. Conversely, Thoma and others (1992) compared the results of imbibition experiments through mineralized and freshly cut surfaces of four tuff samples and found that inferred permeability reductions of between 0.3 to $10^{-7}$ could result through mineralized surfaces relative to freshly cut surfaces. Their samples included those from both the surface and subsurface and different types of fracture mineralization (including manganese oxide, opaline silica, clay minerals, and possibly zeolites). The most substantial reduction in calculated permeability occurred through a coating that was identified as opaline silica.

Haldeman and others (1991) described an experiment to measure water and solute movement in a block of moderately welded tuff containing a single vertical fracture. That experiment used three pressure plates that permitted the boundary condition of the fracture and adjacent matrix half-blocks to be controlled independently. Modeling of the experiment produced estimates of the saturated fracture permeability and dispersivity. Other work in unsaturated fractured tuff relevant to the present study was reported by Rasmussen and others (1993). They compared air and water permeabilities determined on unfractured core samples tested under ambient and air-dried saturations, and in the field, by injecting air and water into the same packed-off intervals of borehole from which the cores were taken. Rasmussen and others (1993) observed that, in the fractured borehole intervals, permeabilities calculated using air or water were in close agreement, indicating that air was a good surrogate for water as a test fluid.

\section{CHARACTERIZATION OF THE BLOCK}

\section{Review Of Experimental Results}

Details of the experiment setup and design were reported previously, as were a partial set of rock properties and some preliminary results (Thamir and others, 1993, 1994). Only the most salient features of the experimental design will be repeated here, along with those results that seem most pertinent to the objectives of this study.

The block, which measured $81 \mathrm{~cm}$ in height with sides of 54 and $47 \mathrm{~cm}$, was cut from a boulder that was identified as part of the columnar unit of the Tiva Canyon Tuff of the Paintbrush Group of Tertiary age. In its present orientation, there appear to be two steeply dipping, roughly orthogonal fracture sets and a more 
shallowly dipping set (fig. 1). The block was drilled with $181.25-\mathrm{cm}$-diameter boreholes that were located either to intersect selected fractures or terminate in rock matrix. The locations of the borehole terminations and the identification number of fractures intercepted by the boreholes (if any) are listed in table 1. A miniature television camera ordinarily used for medical applications was used to verify the intersection of the borehole with the fractures, which were identified on the basis of their orientation and extrapolation of their traces from the sides, top, and bottom of the block.

Testing and characterization of the block proceeded in three stages. Prior to the application of any water, air-injection tests were conducted from boreholes within the block using miniaturized packer strings. The purpose of these tests was to determine if fracture continuity existed between the upper and lower surfaces of the block, and to provide a basis for estimating transmissivities of individual fractures within the block. In the next stage, a sand layer that had been placed on the upper surface of the block was fully saturated with water, and water redistribution from the sand into the block was monitored with psychrometers and tensiometers. This stage of the experiment provided information on hydrologic interactions that occur at the interface between porous materials and underlying fractured, welded tuffs. In the final stage, a specially designed system was used in which water was applied to the upper sand layer at rates that maintained prescribed matric potential conditions. Simultaneous measurements of near-steady flow through the block and measurements of matric potential within both the upper sand layer and the block were used to define the relation between flow rate and matric potential for the fracture network. The measured relation provided a basis for evaluating simulated estimates. Additionally, independent measurements of the hydrologic properties of the rock matrix and sand layer were made using small rock samples and sand columns packed to a similar bulk density as the upper sand layer.

\section{Air-Injection Tests}

Fracture continuity between boreholes of the initially air-dried block was investigated by injecting air at various flow rates into selected boreholes and monitoring associated pressure changes at other boreholes with pressure transducers. Miniature packer strings were used to isolate individual fractures either by straddling them or by packing off the bottoms of particular boreholes. The various combinations of injection and moni- toring holes that were investigated are summarized as the testing matrix in table 2 , which also lists the test identification number and the maximum flow rate injected during the test. Generally, various flow rates were used in the course of a test, and pressure equilibrium with a particular flow rate was achieved, except for matrix boreholes or especially tight fractures. The accuracy of the mass flow controllers used to control the flow rates was estimated to be approximately plus or minus 0.25 percent, and the accuracy of the transducers used to monitor gas pressure plus or minus 1 percent.

Examples of some test results are shown in figure 2. Different pressure ranges are used on the graphs to show details of the pressure response, which could be quite different among the injection hole and individual monitoring boreholes. Test results shown in figure 2(A) demonstrate that injection of air into fracture F5 through borehole $4 \mathrm{E}$ produced a measurable response in fracture $\mathrm{F} 5$ at borehole $2 \mathrm{C}$, as well as in fracture $\mathrm{F} 1$ at boreholes $1 \mathrm{~F}, 3 \mathrm{~A}$, and $1 \mathrm{D}$, suggesting that these fractures were open and that a continuous pathway exists from the upper to lower block surfaces along fractures $\mathrm{F} 1$ and $\mathrm{F} 5$. The response in fracture $\mathrm{F} 6$ at borehole 1A was detectable, but was considerably subdued compared with the other holes, possibly because fracture F6 was very narrow and appeared to be clay filled. A similar test performed by injecting air into fracture $\mathrm{F} 1$ at borehole $3 \mathrm{~A}$ (fig. 2B), indicated that open pathways existed within $\mathrm{F} 1$ between boreholes $3 \mathrm{~A}, 1 \mathrm{E}$ and $1 \mathrm{D}$, and between F1 and fractures F2 (borehole 2A) and F4 (borehole 4B). Again, the pressure response in borehole 1A (fracture F6) was greatly subdued compared with other boreholes. Based on these results as well as visual inspection of the fracture network (fig. 1), the pathway formed by fractures F1 and F5 is considered to be the principal pathway along which water can flow through the block. It is also clear, however, that heterogeneity within individual fractures exists. For example, when borehole $3 \mathrm{~A}$ serves as the injection hole, the response at borehole $1 \mathrm{E}$ was greater than at borehole $1 \mathrm{D}$, despite their location at comparable distances from the injection hole (fig. 2B).

\section{Moisture Redistribution Following Water Application}

After pneumatic testing, an approximately $10-\mathrm{cm}$ thick sand layer was placed over the upper surface 


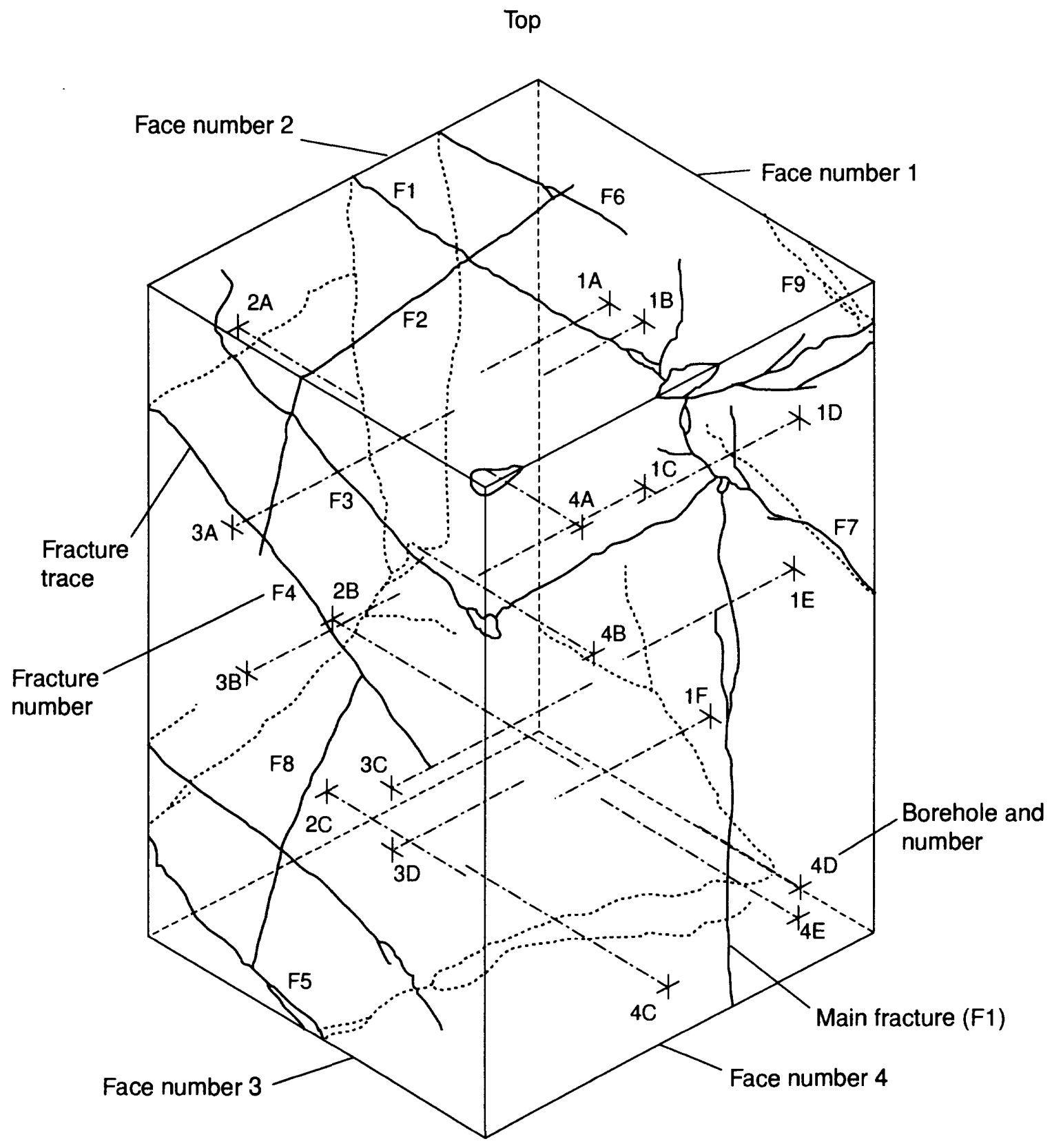

Figure 1. Sketch of the block showing fracture and borehole locations (modified from Thamir and others, 1993). Fractures in figure are identified by " $F$ " followed by a number (for example, fracture $F 5$ ) and boreholes by the number of the block face into which they were drilled, followed by a capital letter (for example, Borehole 1D). 
Table 1. Borehole termination locations and identification number of intercepted fractures

$[\mathrm{m}$, meter; Termination locations are calculated assuming faces 1 and 3 are located at $x=0.25 \mathrm{~m}$ and $\mathrm{x}=0.25 \mathrm{~m}$, faces 2 and 4 are at $\mathrm{y}=0.25 \mathrm{~m}$ and $\mathrm{y}=0.25$ $\mathrm{m}$, and that the top and bottom of the block are at $\mathrm{z}=0.40 \mathrm{~m}$ and $\mathrm{z}=0.40 \mathrm{~m}$, respectively. Borehole 1 A monitored fracture F6 during the air-injection tests, but functioned as a matrix monitoring borehole when measuring matric and water potentials]

\begin{tabular}{ccccc}
\hline $\begin{array}{c}\text { Borehole } \\
\text { identification number }\end{array}$ & $\begin{array}{c}\mathbf{X} \\
(\mathbf{m})\end{array}$ & $\begin{array}{c}\mathbf{Y} \\
(\mathbf{m})\end{array}$ & $\begin{array}{c}\mathbf{Z} \\
(\mathbf{m})\end{array}$ & $\begin{array}{c}\text { Monitored } \\
\text { fractures }\end{array}$ \\
\hline 1A & -0.066 & -0.152 & 0.187 & F6 \\
1B & -0.113 & -0.104 & 0.187 & F6 \\
1C & -0.021 & -0.101 & -0.019 & F1 \\
1D & -0.009 & 0.137 & 0.184 & F1 \\
1E & -0.020 & 0.136 & -0.013 & F1 \\
1F & -0.034 & 0.015 & -0.260 & F2 \\
2A & 0.126 & -0.072 & 0.297 & MATRIX \\
2B & 0.001 & 0.109 & -0.119 & F5 \\
2C & 0.002 & -0.047 & -0.340 & F1 \\
3A & -0.058 & -0.134 & 0.170 & MATRIX \\
3B & 0.040 & -0.109 & -0.005 & MATRIX \\
3C & -0.033 & 0.126 & -0.025 & MATRIX \\
3D & 0.072 & 0.126 & -0.102 & F3 \\
4A & 0.117 & 0.113 & 0.289 & F4 \\
4B & 0.099 & 0.007 & 0.127 & MATRIX \\
4C & 0.001 & -0.036 & -0.341 & MATRIX \\
4D & -0.142 & 0.120 & -0.297 & F5 \\
4E & -0.139 & -0.029 & -0.337 & \\
\hline
\end{tabular}

of the rock in order to provide a mechanism for controlling water potential along the upper boundary and to emulate the hydraulic behavior of either alluvium or unfractured nonwelded tuff. The block and sand layer were then completely encased in Plexiglas to minimize evaporation during hydraulic testing. The block rested on a second layer of sand, approximately $3.2 \mathrm{~cm}$ thick, which drained into a flask set on a scale that allowed the mass of outflow to be determined (fig. 3). Additional Plexiglas partitions isolated the space above the upper sand layer from the air in the annular space enclosing the block. Water (matric) potential $(\psi)$ within the upper sand layer was monitored by two tensiometer-transducer systems. The tensiometers were about $5 \mathrm{~cm}$ above the sand/rock interface. Water potential within the block was initially monitored by 18 thermocouple psychrometers emplaced within packed-off intervals of the boreholes. The accuracy of the psychrometers was estimated to be plus or minus $200 \mathrm{kPa}$ within the $-7,000$ to -100 kilopascals $(\mathrm{kPa})$ range. When water potentials within the block became larger than approximately $-85 \mathrm{kPa}$, the psychrometers were replaced by tensiometer-transducer systems for which the accuracy was estimated to be better than plus or minus $0.2 \mathrm{kPa}$.
Hydraulic testing began by introducing two slugs of water to the sand 100 days apart, each sufficient to saturate the upper sand layer. These were distinguished from each other by the addition of bromide and iodide tracers. Each slug was followed by periods during which water was permitted to redistribute from the sand layer to the block.

The first slug consisted of 10.0 liters (L) of water applied to saturate the sand over a 10 -hour period by means of a spray nozzle (fig. 3 ). Visual inspection showed that fracture traces along the sides of the block became wet to depths of several tens of centimeters during the first 4 or 5 days, also wetting the adjacent matrix. After the 10 -hour slug or 4 to 5 days, water movement along the fracture traces ceased, and the previously wetted zones around the fractures began to dry, leaving a rind of salt where the water evaporated. Although encased in Plexiglas, the lower part of the air-dried block may itself have been serving as a desiccant, adsorbing water vapor and resulting in a net transfer of water from the upper to the lower parts of the block.

A second slug was added approximately 100 days after the first slug, and 3.2 L of water was needed to resaturate the sand layer. Tensiometer measurements indicated that water did not start leaving the 
Table 2. Testing matrix for air-injection tests in the block

[sLpm, standard liter per minute; I, injection borehole; $M$, monitoring borehole; --., neither injection nor monitoring borehole]

\begin{tabular}{|c|c|c|c|c|c|c|c|c|c|c|c|c|c|c|c|c|c|c|c|c|}
\hline \multirow{2}{*}{$\begin{array}{l}\text { Injection } \\
\text { borehole }\end{array}$} & \multirow{2}{*}{$\begin{array}{c}\text { Test } \\
\text { identification } \\
\text { number }\end{array}$} & \multirow{2}{*}{$\begin{array}{l}\text { Maximum } \\
\text { injection } \\
\text { rate } \\
\text { (sLpm) }\end{array}$} & \multicolumn{18}{|c|}{ Borehole } \\
\hline & & & $1 \mathrm{~A}$ & 1B & $1 \mathrm{C}$ & 1D & 1E & $1 F$ & $2 A$ & $2 B$ & $2 \mathrm{C}$ & $3 A$ & 3B & $3 C$ & 3D & $4 \mathrm{~A}$ & 4B & $4 C$ & 4D & $4 \mathrm{EE}$ \\
\hline${ }^{1} 1 \mathrm{C}$ & P26391 K4 & 10.0 & M & --- & I & $\mathrm{M}$ & -- & -- & M & $\cdots$ & $\ldots$ & $M$ & -- & --- & -- & M & --- & -- & -- & -- \\
\hline${ }^{1} 1 \mathrm{D}$ & P26791K1 & 10.0 & M & -- & M & I & --- & -- & M & $\cdots$ & -- & M & -- & $\cdots$ & -- & M & -- & $\cdots$ & $\cdots$ & -- \\
\hline${ }^{1} 2 \mathrm{C}$ & $\mathrm{P} 26191 \mathrm{~K} 1$ & 7.0 & $M$ & -- & $\cdots$ & M & -- & M & $\cdots$ & -- & I & $\cdots$ & -- & -- & --- & --- & -- & -- & M & $M$ \\
\hline $2 \mathrm{C}$ & P26191K2 & 7.0 & M & -- & -- & M & --- & M & --- & --- & 1 & --. & --- & --- & --- & -- & --- & --- & $M$ & M \\
\hline $2 \mathrm{C}$ & $\mathrm{P} 26191 \mathrm{~K} 3$ & 6.0 & M & --- & --- & M & $-\cdots$ & $\mathrm{M}$ & --- & --- & I & M & -- & --- & --- & --- & -- & -- & -- & M \\
\hline $3 \mathrm{~A}$ & P33890K 3 & 10.0 & M & --- & --- & M & M & --- & M & $\cdots$ & --- & 1 & -- & --- & --- & $\cdots$ & M & -- & --- & -- \\
\hline $3 \mathrm{~A}$ & P35290K 3 & 10.0 & M & --- & --- & $M$ & M & $\cdots$ & M & --- & -- & 1 & --- & --- & --- & --- & M & $\cdots$ & $\cdots$ & $\cdots$ \\
\hline${ }^{1} 3 \mathrm{~A}$ & P35290K4 & 10.0 & M & --- & --- & $M$ & -- & -- & --- & -- & -- & I & -- & --- & --- & --- & --- & M & M & M \\
\hline $3 \mathrm{~A}$ & P35290K6 & 10.0 & -- & --- & M & M & -- & $\cdots$ & --- & -- & $\cdots$ & I & -- & -- & M & -- & --- & -- & -- & -- \\
\hline $3 \mathrm{~A}$ & P35290K 7 & 10.0 & $\cdots$ & --- & M & M & $\cdots$ & M & --- & --- & M & I & -- & M & -- & --- & -- & --- & -- & --- \\
\hline $3 \mathrm{~A}$ & $\mathrm{P} 25391 \mathrm{~K} 1$ & 10.0 & $\mathbf{M}$ & $\ldots$ & -- & M & M & --- & $M$ & --- & $\cdots$ & I & --- & $\cdots$ & --- & --- & M & $\cdots$ & -- & $\cdots$ \\
\hline $3 \mathrm{~A}$ & $\mathrm{P} 25391 \mathrm{~K} 2$ & 10.0 & M & M & M & $\cdots$ & $\cdots$ & M & --- & --- & -- & 1 & $\cdots$ & -- & -- & -- & $\cdots$ & $-\cdots$ & -- & -- \\
\hline $3 \mathrm{~A}$ & P25391K3 & 10.0 & -- & -- & M & M & -- & -- & $\cdots$ & $\cdots$ & $\cdots$ & 1 & --- & $\cdots$ & -- & -- & -- & M & M & M \\
\hline $3 \mathrm{~A}$ & $\mathrm{P} 25491 \mathrm{~K} 1$ & 10.0 & M & --- & M & M & --- & -- & --- & $M$ & --- & 1 & -- & --- & -- & M & --- & -- & -- & -- \\
\hline $3 \mathrm{~A}$ & P25491K2 & 10.0 & M & --- & $\mathrm{M}$ & -- & --- & --- & --- & $\cdots$ & M & I & --- & $M$ & M & --- & $\ldots$ & $\cdots$ & -.- & $\cdots$ \\
\hline $3 \mathrm{~A}$ & $\mathrm{P} 25491 \mathrm{~K} 3$ & 10.0 & M & -- & M & --- & --- & $-\cdots$ & $\cdots$ & $\cdots$ & M & $I$ & M & -- & M & $\cdots$ & -- & -- & -- & -- \\
\hline
\end{tabular}

' Indicates that this test was used to calibrate fracture transmissivity of fracture intersected by the injection borehole.

sand until 2 days after the second slug had been added. Water along the fracture traces moved to greater depths compared with the first slug, presumably because smaller lateral water-potential gradients resulted in less water uptake of fracture water by the matrix during the second application.

Wetting and partial drainage of the sand over the first 100 days caused the upper sand layer to compact from 102 to 94 millimeters ( $\mathrm{mm}$ ) in thickness, so that the initial pore volume decreased from 10.8 to $8.7 \mathrm{~L}$. Whether the sand was initially only partially saturated as a result of the entrapment of air bubbles, or whether the sand had partially compacted even as water was being applied to it, was not determined. In any case, $4.5 \mathrm{~L}$ of water $(10.0 \mathrm{~L}+3.2 \mathrm{~L}-8.7 \mathrm{~L})$ had drained from the sand into the block by 100 days, and $5.5 \mathrm{~L}$ of water remained in the compacted sand layer at that time, prior to the addition of the second slug.

Examination of the tensiometer data collected from the upper sand layer shows that matric potentials decreased rapidly after addition of the two slugs, indicating that water was leaving the sand layer (fig. 4). The time-varying changes in matric potential were used in combination with the estimated moisture-characteristic curve of the sand to calculate the rates of drainage from the sand. Thus, periods of rapid decline in matric potential can be correlated with the periods during which rates of drainage were high and water moved rapidly along the fracture traces. Conversely, periods of slow decline indicate that relatively smaller amounts of water were leaving the sand. These can be correlated with periods during which water movement 
A.
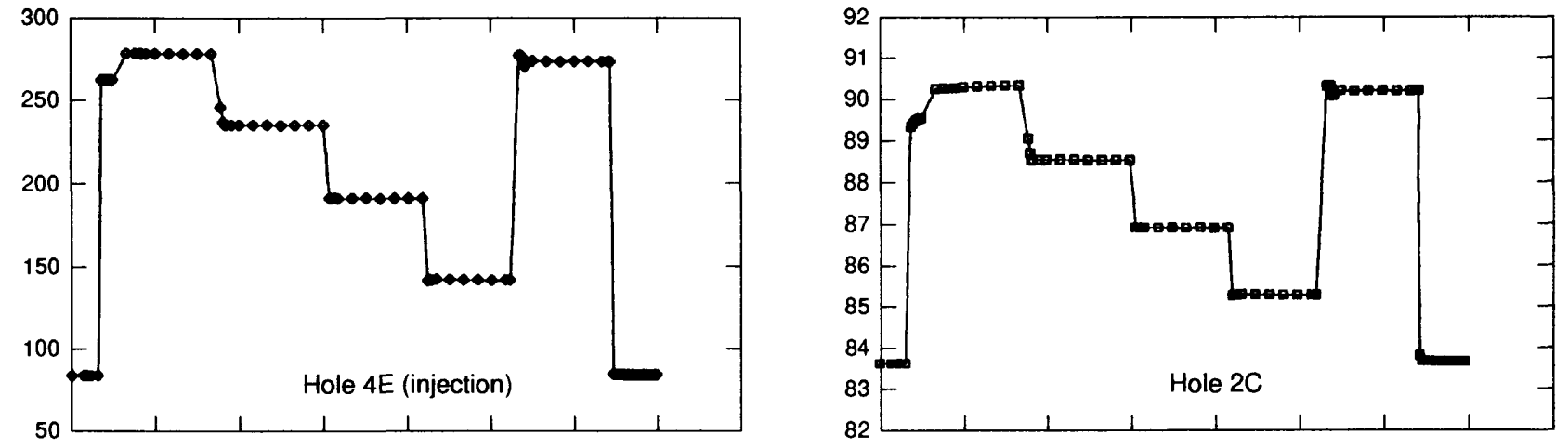

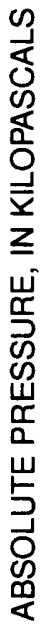
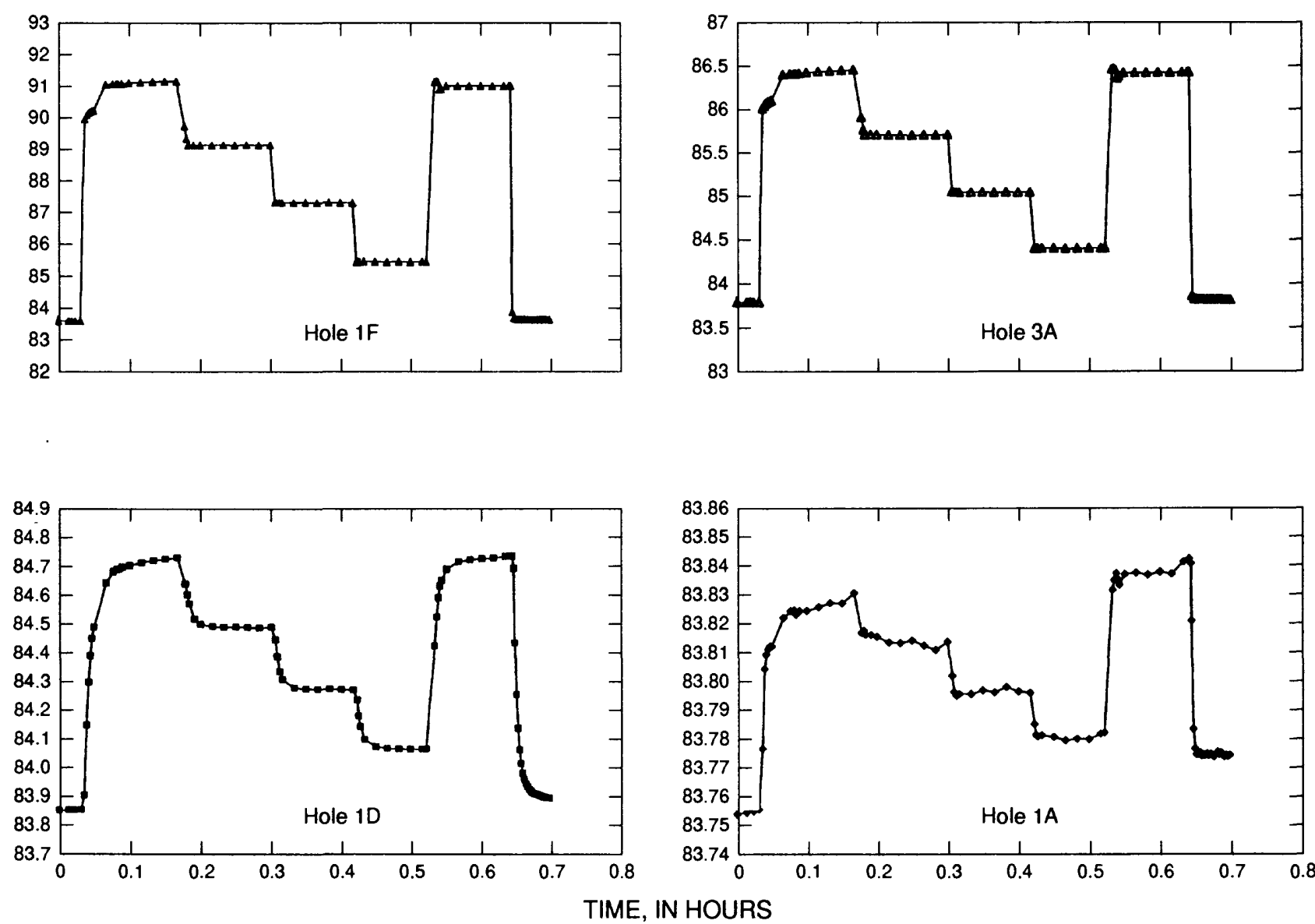

Figure 2. Results from air-injection tests: $(A)$ in boreholes $2 C, 1 F, 3 A, 1 D$, and $1 A$ from injection in borehole 4E; and $(B)$ in boreholes 1E, 1D, 2A, 4B, and $1 \mathrm{~A}$ from injection in borehole $3 \mathrm{~A}$.

8 Numerlcal SImulatlon of Alr- and Water-Flow Experlments in a Block of Varlably Saturated, Fractured Tuff from Yucca Mountain, Nevada 
B.
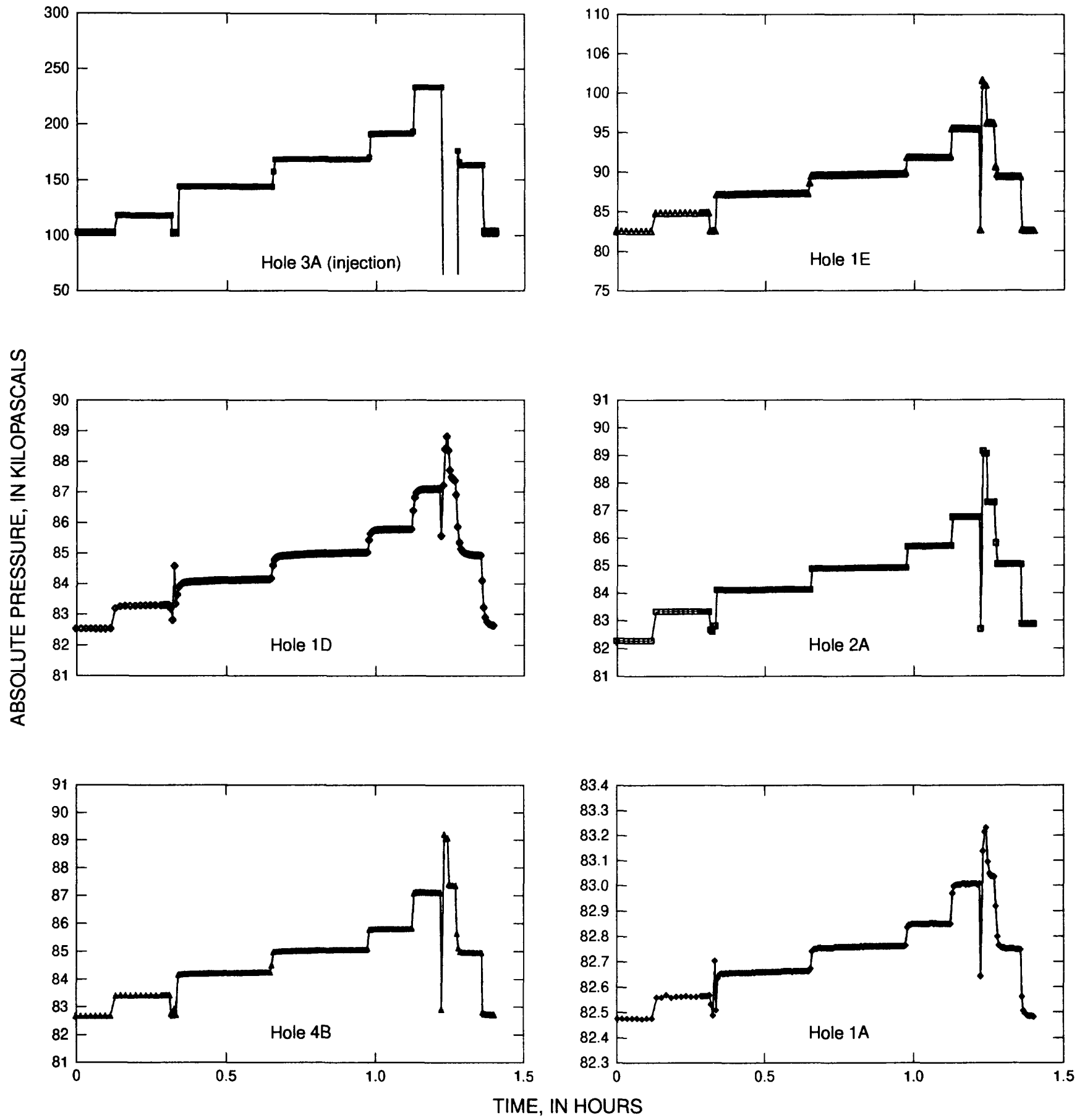

Figure 2. Results from air-injection tests: $(A)$ in boreholes $2 C, 1 F, 3 A, 1 D$, and $1 A$ from injection in borehole $4 E$; and $(B)$ in boreholes 1E, 1D, 2A, 4B, and $1 \mathrm{~A}$ from injection in borehole $3 \mathrm{~A}$.-Continued 


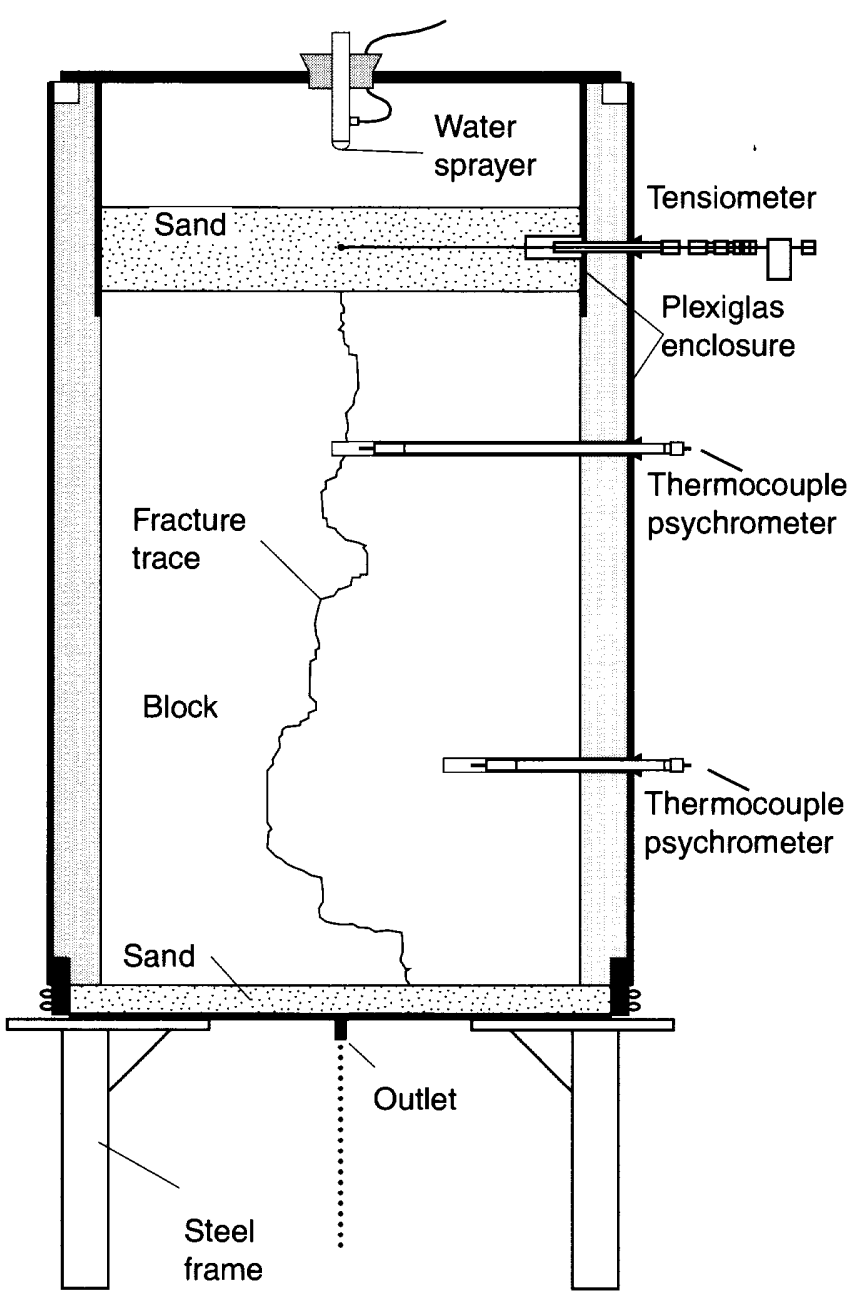

Figure 3. Sketch showing the experimental layout of the block with frame, Plexiglas enclosure, water sprayer, and sand layers (modified from Thamir and others, 1993).

along the fracture traces slowed and salt buildup indicative of evaporation began.

Data in figure 4 indicate that after the first slug of water was added, the matric potentials decreased much more slowly after the matric potential at the sand/rock interface has decreased to approximately $-10 \mathrm{~cm}$. This relatively slight suction at the interface may be sufficient to prevent water from entering fractures within the block except at relatively small rates. Saturation/ matric potential data collected for the sand with tempe cells indicate that saturation in the sand is greater than 90 percent (Thamir and others, 1993; fig. 4), indicating it is not desaturation of the sand that results in the implied decrease in flow rates. Also, matric potentials following the addition of the second slug appear to slowly approach a value of approximately $-10 \mathrm{~cm}$, which is about 3 to $4 \mathrm{~cm}$ greater than the final value following application of the first slug. The slightly larger values following application of the second slug may reflect diminished imbibition rates of an already substantially wet matrix.

Psychrometer data collected during this period show, as expected, that instruments in the upper part of the block were the first to respond (fig. 5). The sequence of responses may be explained in terms of the fracture network geometry and from what can be inferred from a qualitative analysis of the air-injection data. The psychrometer in borehole 2A (fracture F2) responded first, after the application of the first slug at day 10 , followed by the psychrometer in borehole $4 \mathrm{~A}$ (fracture F3) at about day 45 and in borehole 4B (fracture F4) at about day 115 . The psychrometer in borehole 4B appeared to respond to the second, rather than the first, water application, which is the sequence of wetting one might expect if flow was occurring through the fracture network. The psychrometer in borehole $3 \mathrm{~A}$ (fracture F1) did not respond to the first pulse until about day 75, and the psychrometer in borehole 1D (fracture F1) did not respond until about day 90 . The psychrometer in borehole 1D responded late compared with that in $3 \mathrm{~A}$ because, although located at nearly identical elevations, borehole 1D may terminate in an area of locally wide aperture, as suggested by the analyses of the air-injection data (see the following paragraphs). The psychrometers in boreholes 1A (fracture F6) and 1B (fracture F6) are among the last in the upper part of the block to respond. Fracture F6 was determined from visual inspection and from the air-injection tests to be relatively tight. Boreholes $3 \mathrm{~A}, 1 \mathrm{~A}, 1 \mathrm{~B}$, and $1 \mathrm{D}$ all terminate at comparable elevations and allow comparisons to be made of the relative rates of water movement along different fractures or through the matrix. Boreholes $2 \mathrm{~A}$ and $4 \mathrm{~A}$ were located about $10 \mathrm{~cm}$ higher than those boreholes and so may not be directly comparable.

It is interesting to note that the psychrometers in boreholes 4A (fracture F3) and 4B (fracture F4) all responded within days to the addition of the secondslug at day 110 , indicating that the second pulse moved both farther and faster than the first. Visual inspection confirmed that water did move farther than was observed following application of the first slug. Deeper penetration of moisture after application of the second slug probably occurred because the rock matrix had already been substantially wetted by the first slug. Therefore, matrix imbibition of fracture water was probably not as 


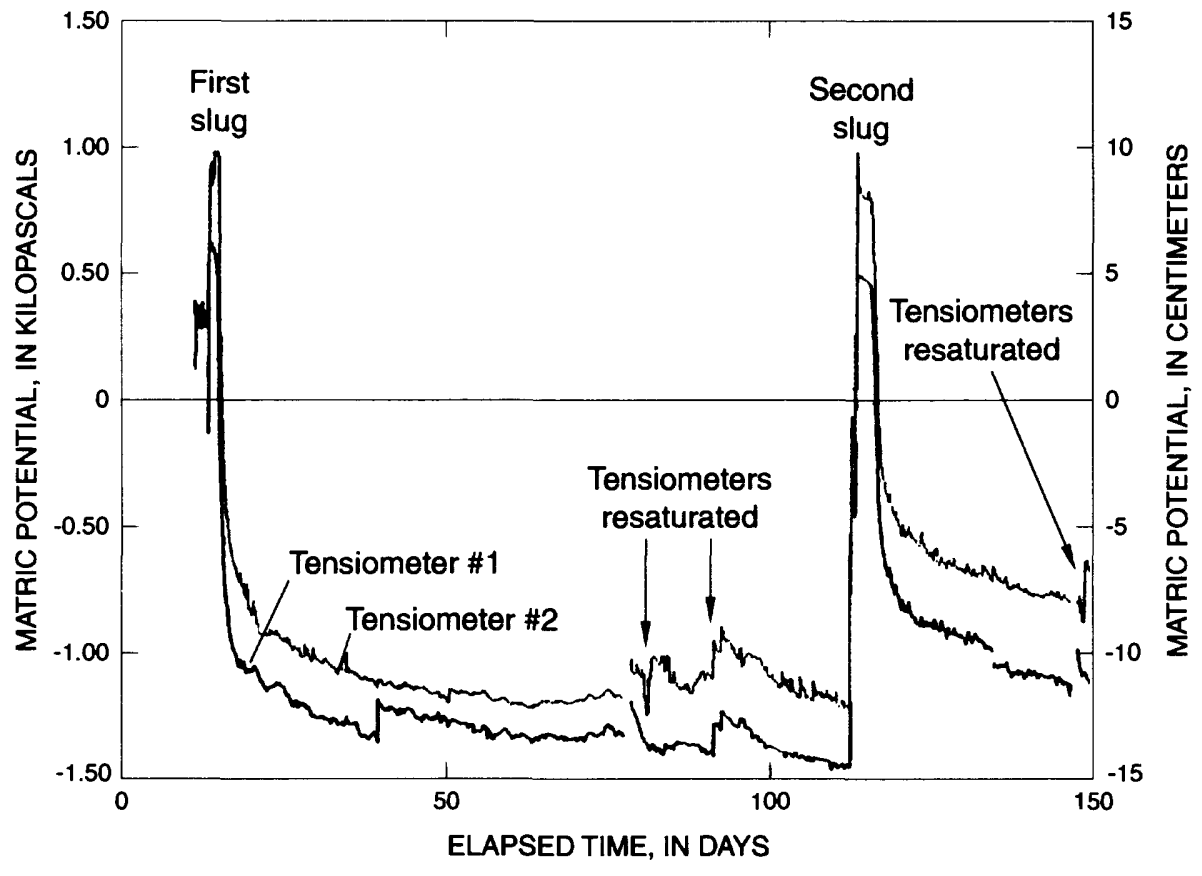

Figure 4. Matric potential response in the upper sand layer at 5 centimeters above the sand/rock interface during and after the addition of the first and second slugs of water (modified from Thamir and others, 1993). Number of days indicates elapsed time since the onset of monitoring. The first slug of water was added on day 10.

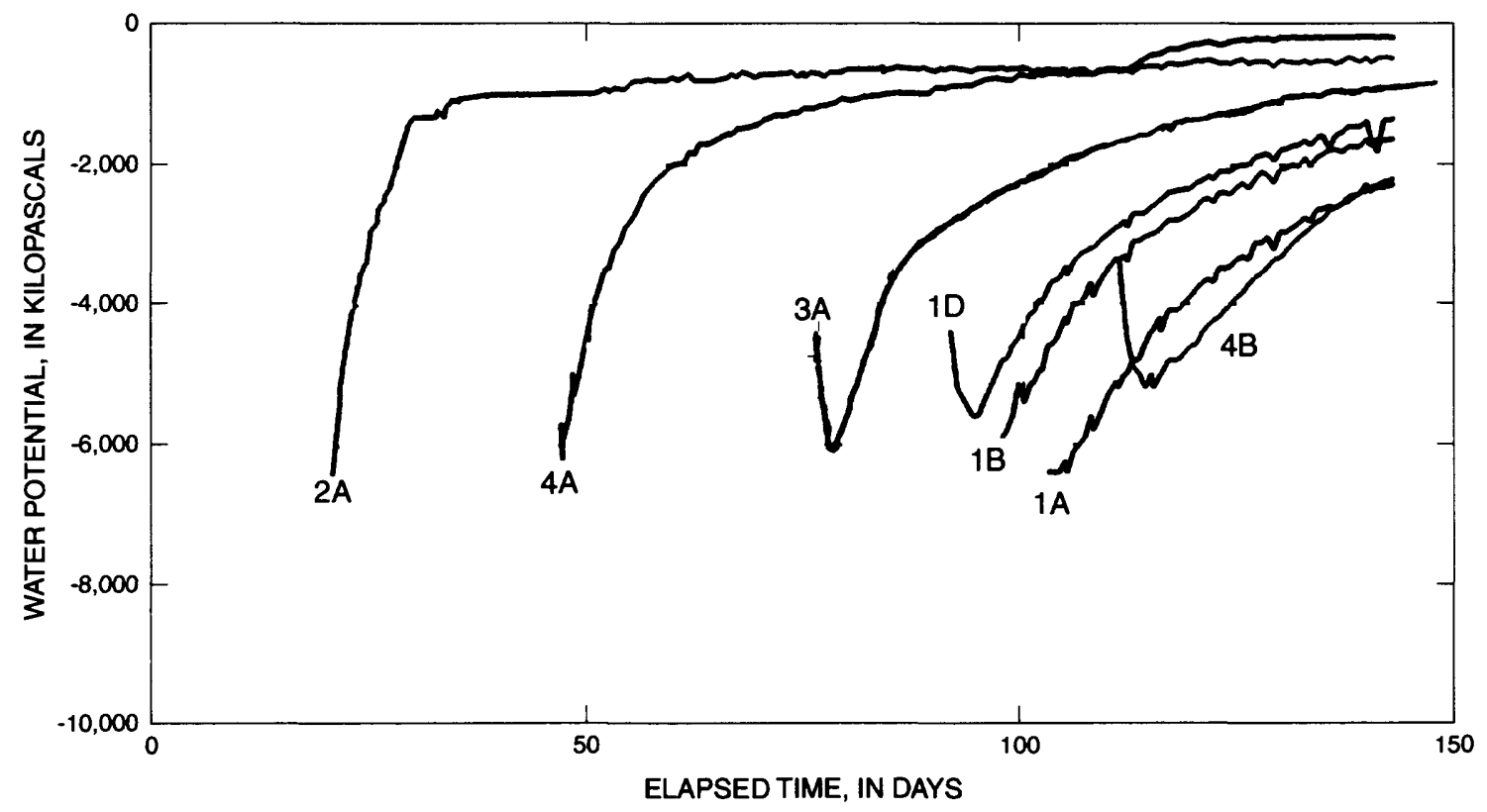

Figure 5. Response of selected borehole psychrometers to the addition of the first and second slugs of water (modified from Thamir and others, 1993). Number of days indicates elapsed time since the onset of monitoring. 
great as it had been following application of the first slug, which had been applied to an air-dried block. It is possible that the apparently deeper penetration of moisture following the application of the second slug may also be related to the displacement of water that remained in the fractures after the application of the first slug.

\section{Water Movement Under a Constant Applied Water Potential}

This stage of the experiment was intended to examine the dependence of water-flow rates through the block on the water potential at the upper sand/rock interface. The experimental design required that the block be saturated under a positive water pressure and that water potentials at the sand/rock interface be decreased in a stepwise manner, with steady water-flow rates recorded at each step. To accomplish these objectives, a system was designed that used information from the sand layer tensiometers to adjust flow rates from the spray nozzle so that prescribed water potentials could be maintained in the sand layer. Rates of inflow and outflow were determined gravimetrically.

As described in Thamir and others $(1993,1994)$, ponded conditions within the upper sand layer were maintained for more than a year without outflow from the block. During this time, flow into the block was erratic, and inflow rates were very low or zero (Thamir and others, 1994, fig. 4). However, psychrometers continued to show a general wetting trend (Thamir and others, 1994, fig. 5) indicating continued uptake of water at small rates. It was not until 20 days after a second round of air-injection tests had been completed that ponded water in the upper sand layer began to drain and outflow was first observed at the base of the block (Thamir and others, 1994). This period of testing remains the most difficult to explain, but the absence of outflow initially was probably because of the presence of entrapped air within the fractures, as evidenced from the short-term variability in rates of inflow, the relative sensitivity of these rates to ponding depth (which may have compressed or dislodged air bubbles from critical pore throats), and the fact that quasi-steady flow through the block was ultimately established for water potentials less than zero. That air injected into a fracture could dislodge entrapped air is a counterintuitive result. Although the processes that actually occurred on a pore scale were not observed, it is possible that the injected air raised the water pressure in the fracture so that entrapped air ahead of the water was pushed into and through critical pore throats. The injected air then escaped from the fracture along the sides of the block. Aerobic bacteria also may have also clogged fractures to some degree. The absence of outflow probably cannot be attributed to matrix imbibition of water moving through fractures because water inflow into the fractures along the upper surface was also very low during this period. In the absence of entrapped air, matrix imbibition would have enhanced water movement into the fractures by sustaining initially steep water-potential gradients.

After the initial breakthrough of water into the bottom sand layer, water inflow rates were automatically adjusted to maintain constant prescribed water potentials in the upper sand layer, as measured by replicate pairs of tensiometer-transducer systems. One pair was placed over fracture $\mathrm{F} 1$ and the other over an unfractured part of the block. During an approximately 70-day period, prescribed (average) water potentials were decreased slightly from -10 to $-12 \mathrm{~cm}$, and inflow and outflow rates decreased approximately 45 percent from $390 \mathrm{~cm}^{3} /$ day to $210 \mathrm{~cm}^{3} /$ day (fig. 6). Inflow and outflow rates appeared to be in relatively close agreement, although inflow rates were somewhat erratic, and outflow may have been blocked periodically by air entrapment either in the fractures themselves or in the lower sand layer (Thamir and others, 1994). Constant flow rates were not observed for particular water potentials, presumably because insufficient time had been allotted to establish such equilibrium. The possibility that clogging by bacteria caused the decline in flow rates attributed to the change in boundary conditions cannot be completely ruled out. However, monitoring of bacteria concentrations in the outflow during this phase of the experiment showed no correlation with flow rates.

The tensiometer responses in selected boreholes during this same time period are shown in figure 7 . The matric potential in the rock matrix (borehole $4 \mathrm{C}$ ) near fracture F5, which is considered to be a major conducting fracture, is larger (less negative) than those boreholes farther from the main conducting fractures (boreholes 2B and 3B), indicating that water potential equilibrium was not completely achieved at this time (fig. 7A). However, these differences are considered relatively small in view of the fact that, in the initial airdry state, matric potentials were estimated to be much smaller, on the order of $-2 \times 10^{5} \mathrm{kPa}$, based on the relative humidity of the laboratory air. Figure 7B shows that tensiometers in three boreholes that terminate in 

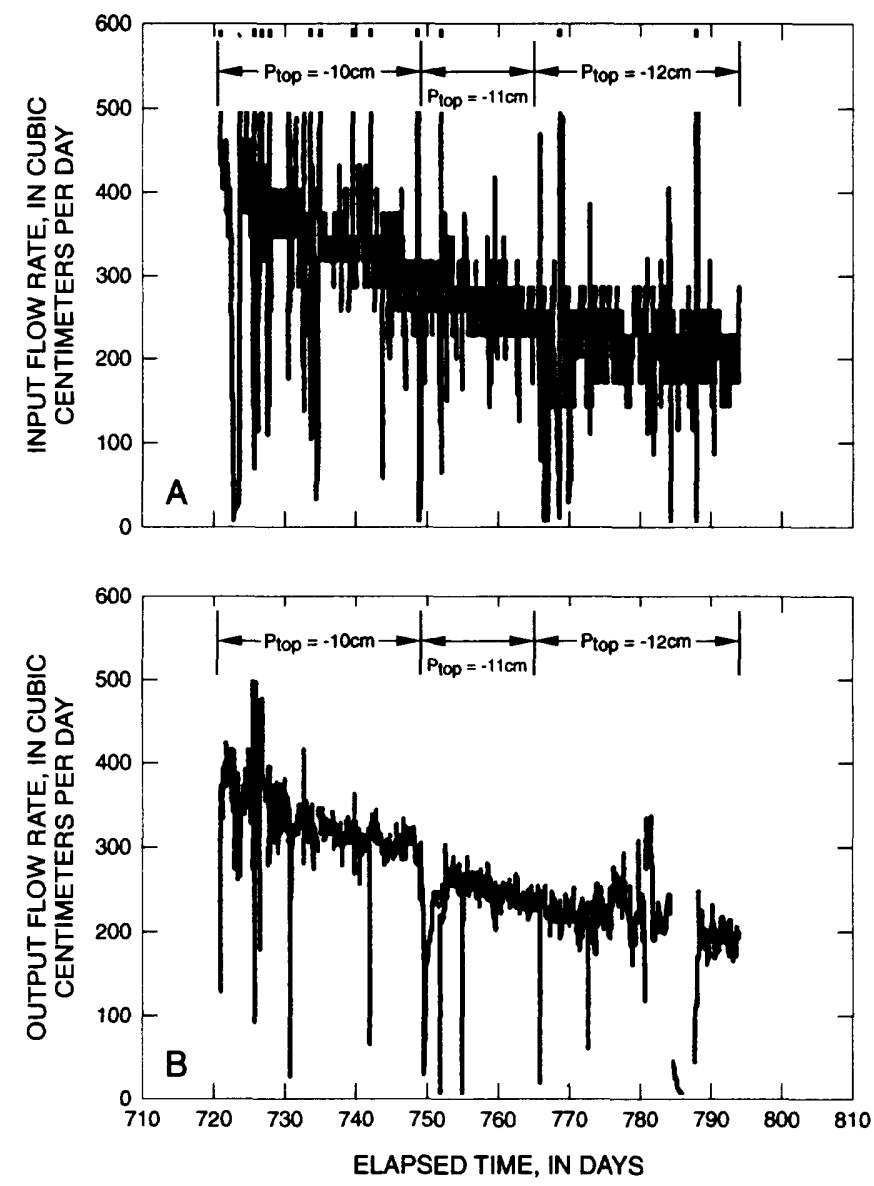

Figure 6. Water-flow rates from days 720 to 794 : (A) inflow; and (B) outflow (from Thamir and others, 1994). Number of days indicates elapsed time since the onset of monitoring.

fracture F1 (boreholes 3A, 1C, and 1D) had positive matric potentials despite the fact that along the upper sand/rock interface a negative matric potential was maintained. Matric potential in borehole $1 \mathrm{E}$ was negative and displayed a trend that reflected the changingboundary condition in the upper sand layer. The matric potentials measured in boreholes that monitored fracture F5 all displayed a cyclic behavior (fig. 7C) in which the transitions from negative to positive matric potentials could be correlated with temporary interruptions in outflow (Thamir and others, 1994). The abrupt buildup and slow dissipation of positive matric potentials in the lower part of the block, with only short-term disturbance in outflow, suggests that in spite of their emplacement against the fracture face, the tensiometers
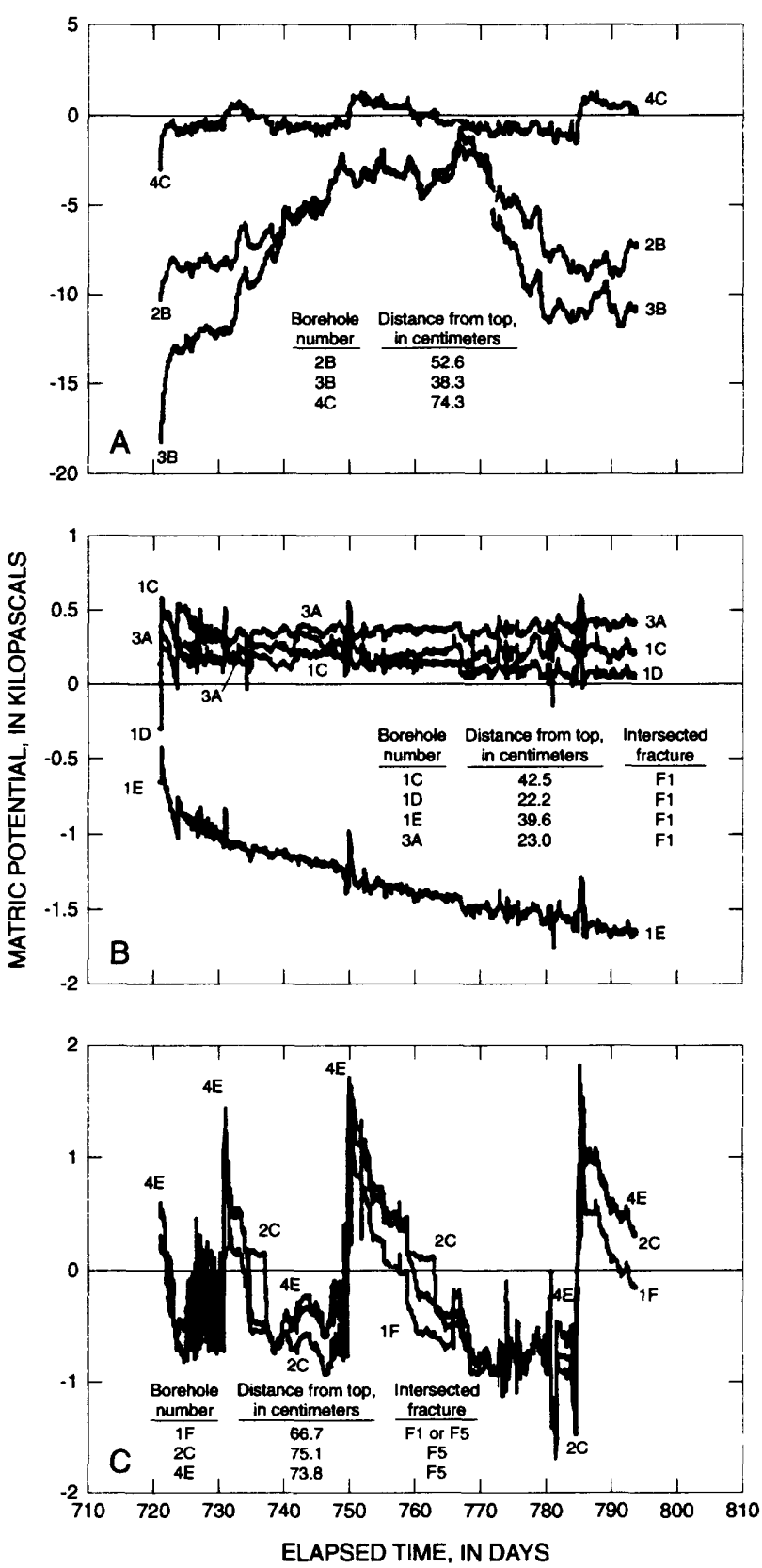

Figure 7. Matric potentials as measured by borehole tensiometer-transducer systems: (A) matrix boreholes; (B) fracture boreholes in upper part of block; and (C) fracture boreholes in lower part of block (from Thamir and others, 1994). Elapsed time refers to the number of days since monitoring began. 
were responding to changes in potential in the rock matrix. Low-permeability rock near saturation would have a small storage capacity, and therefore water pressures would be expected to change abruptly with the further addition of small amounts of moisture. These positive pressures would bleed off slowly by seepage along the block sides or back into the fractures. The maximum matric potentials appear to be limited by the corresponding water pressures at which entrapped air at the base of the block would be forced through the underlying sand layer (Thamir and others, 1993, fig. 4). In any case, because the tensiometers in the upper part of the block do not exhibit similarly cyclic behavior, the response of the tensiometers in the lower part of the block may be attributable to boundary effects, and may not reflect phenomena inherently related to water movement in fractures.

Flow rates through the block have been recorded for average sand layer matric potentials of about -12 to $-21 \mathrm{~cm}$ in increments of $-1 \mathrm{~cm}$ (fig. 8). Although, as observed earlier, variability in inflow and outflow rates occurs at each prescribed potential, there does appear to be a strong relation between flow rates through the block and matric potential in the upper sand layer.

The flow rates recorded in figures 6 and 8 were used to construct a relation between flow rate and the average matric potential, as recorded by the tensiometer-transducer systems in the sand layer (fig. 9A). The flow rates at each matric potential were variable and appeared, in most cases, to be adjusting still when the boundary conditions were changed. The predominant flow rates observed immediately prior to a subsequent step decrease in matric potential (figs. 6,8 ) were used to construct figure 9 because these rates were assumed to best approximate the fully equilibrated flow rates. The data for the seven largest matric potentials shown in figure 9 were visually extrapolated in log-linear space to predict a flow rate of approximately $1,800 \mathrm{~cm}^{3} /$ day at a matric potential of $0 \mathrm{~cm}$, which represents fully saturated flow conditions. Based on the cross-sectional area of the block perpendicular to flow and an assumed unit gradient, the corresponding permeability of the block is $8.37 \times 10^{-15} \mathrm{~m}^{2}$.

Similar relations were determined between flow rate and the median water pressure, as calculated from the borehole tensiometer measurements. These relations were determined both with (fig. 9B) and without (fig. 9C) the matrix boreholes present in order to allow for the possibility that the interiors of the blocks might be much drier than the fractures or block surfaces and therefore might not reflect the conditions required for water to flow in the fractures. Despite some scatter, both figures suggest similar behavior. Flow rates decrease with decreasing water potentials in the range of 0 to $-1.5 \mathrm{kPa}(0$ to $-15.0 \mathrm{~cm}$ water $)$. Figures $9 \mathrm{~B}$ and 9C increase confidence that the relation defined in figure $9 \mathrm{~A}$ is indicative of the rock properties and that the observed decrease in flow rates is not a result of partial desaturation of the sand.

\section{Block Properties}

The hydrologic properties of the block are described in this section based on the experiments described in Thamir and others $(1993,1994)$ and on additional experiments conducted for this study.

\section{Rock Matrix}

Hydrologic properties for the welded tuff matrix were determined from core samples (diameter= $1.27 \mathrm{~cm}$ ) taken from trimmed portions of the boulder from which the block was cut. Intrinsic permeability $(k)$ and porosity $(\phi)$ measured on four of these samples are given in Thamir and others (1993, table 1). The geometric mean permeability of these four samples is $1.24 \times 10^{-18} \mathrm{~m}^{2}$. Moisture characteristic data were obtained from three additional core samples by starting with water-saturated samples and allowing the samples to progressively dry. At each stage of drying, sample saturation was determined gravimetrically. Water potential corresponding to that saturation was determined from the water activity and temperature of the sample using Kelvin's equation (Edlefsen and Anderson, 1943) The composite data from these samples were fit $\left(r^{2}=0.982\right)$ by functions developed by van Genuchten (1980) (see fig. 10):

$$
S_{l e}=\left(1+(\alpha \psi)^{n}\right)^{-m}
$$

where

$$
S_{l e}=\left(S_{1}-S_{l r}\right) /\left(S_{l s}-S_{l r}\right)
$$

Equation 1 is the moisture characteristic function $[\mathrm{S}(\psi)]$, which describes the relation between saturation and water potential $(\psi)$. The values for fitting parameters of this function are $S_{1 r}=0.0, S_{1 s}=0.95, \alpha=1.8686 \times$ $10^{-3} \mathrm{~m}^{-1}, \mathrm{n}=1.4832$ and $\mathrm{m}=0.32578$, where $S_{\mathrm{le}}$ is 

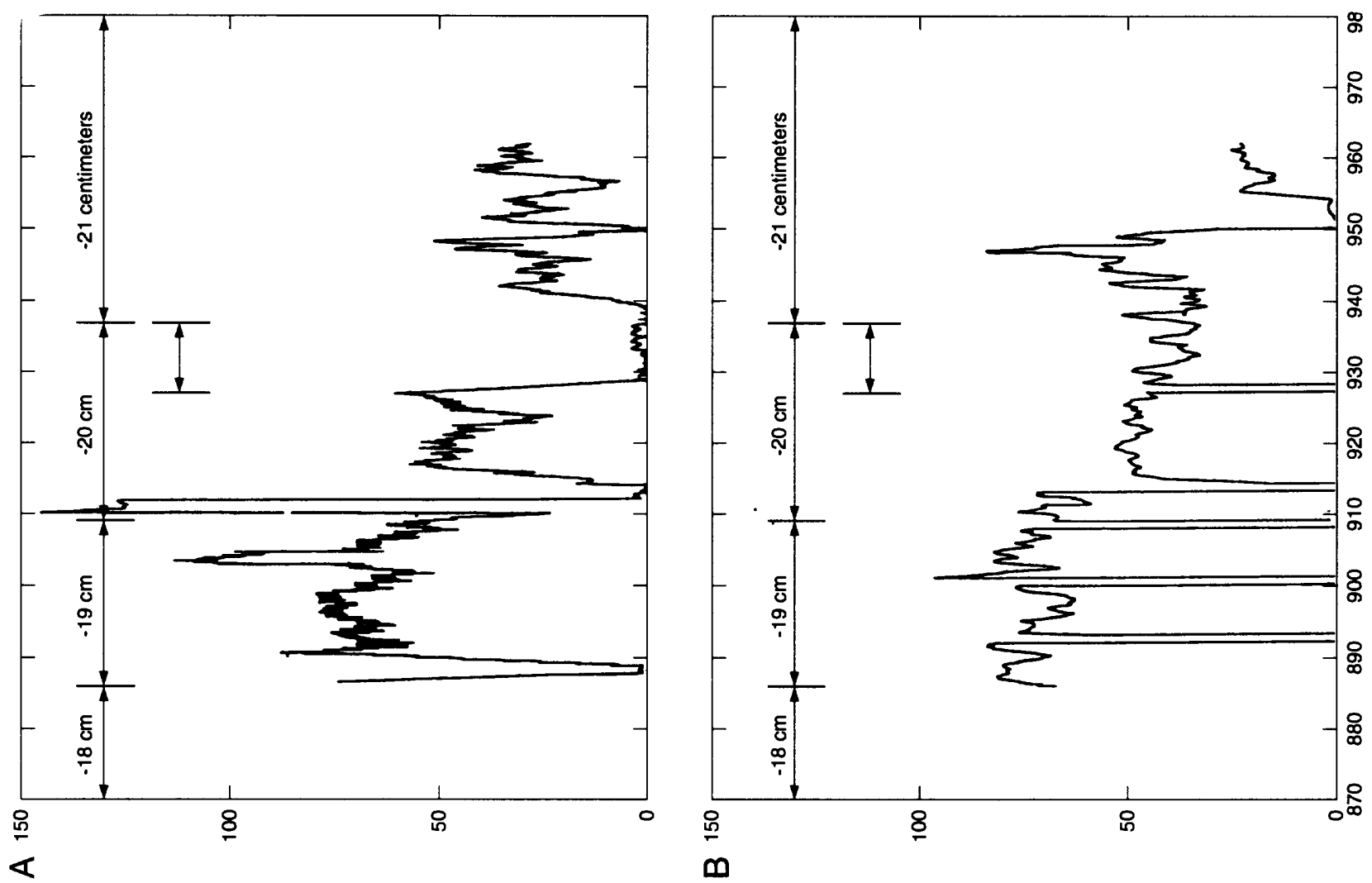

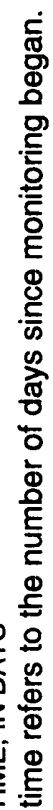
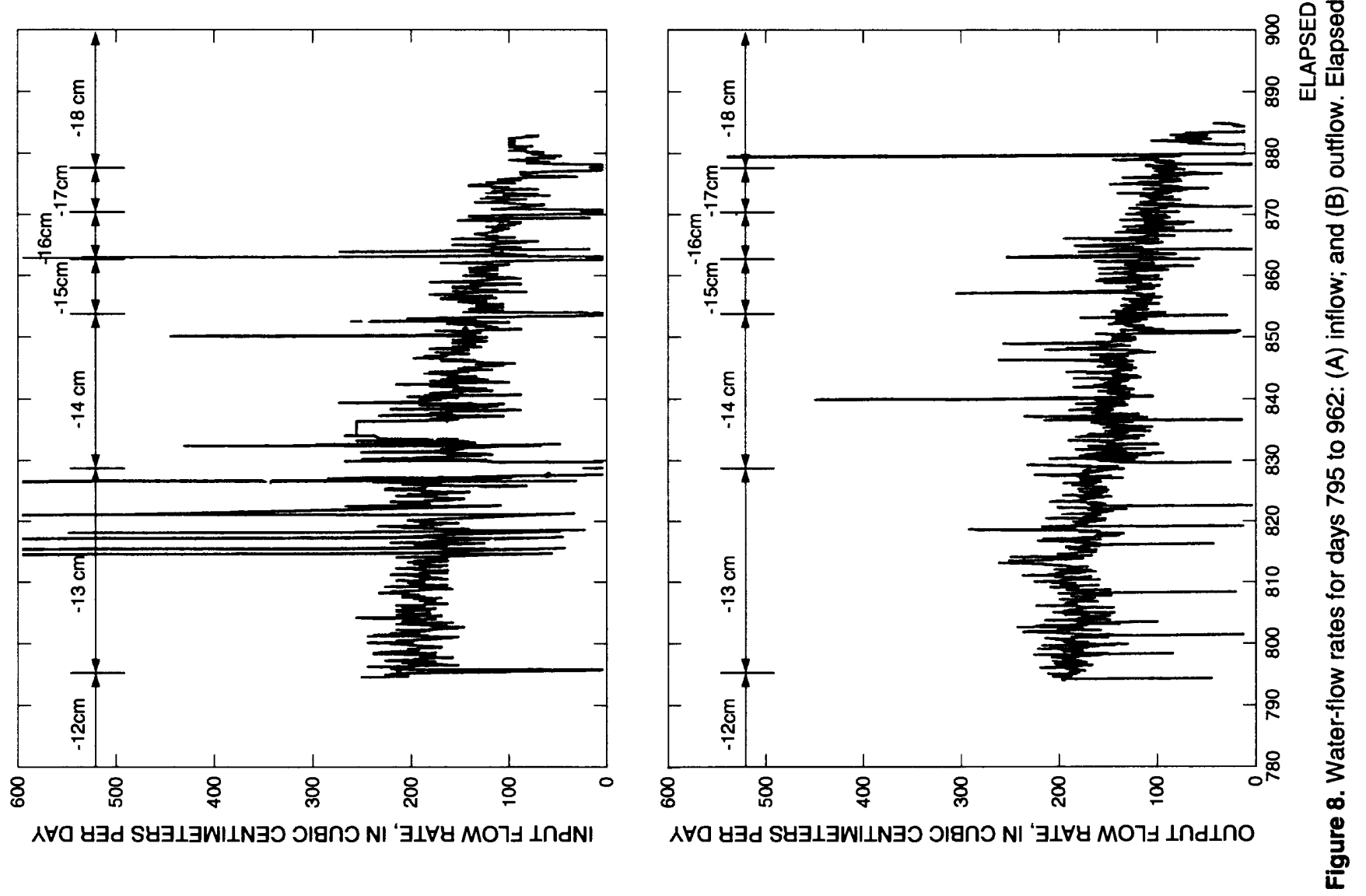

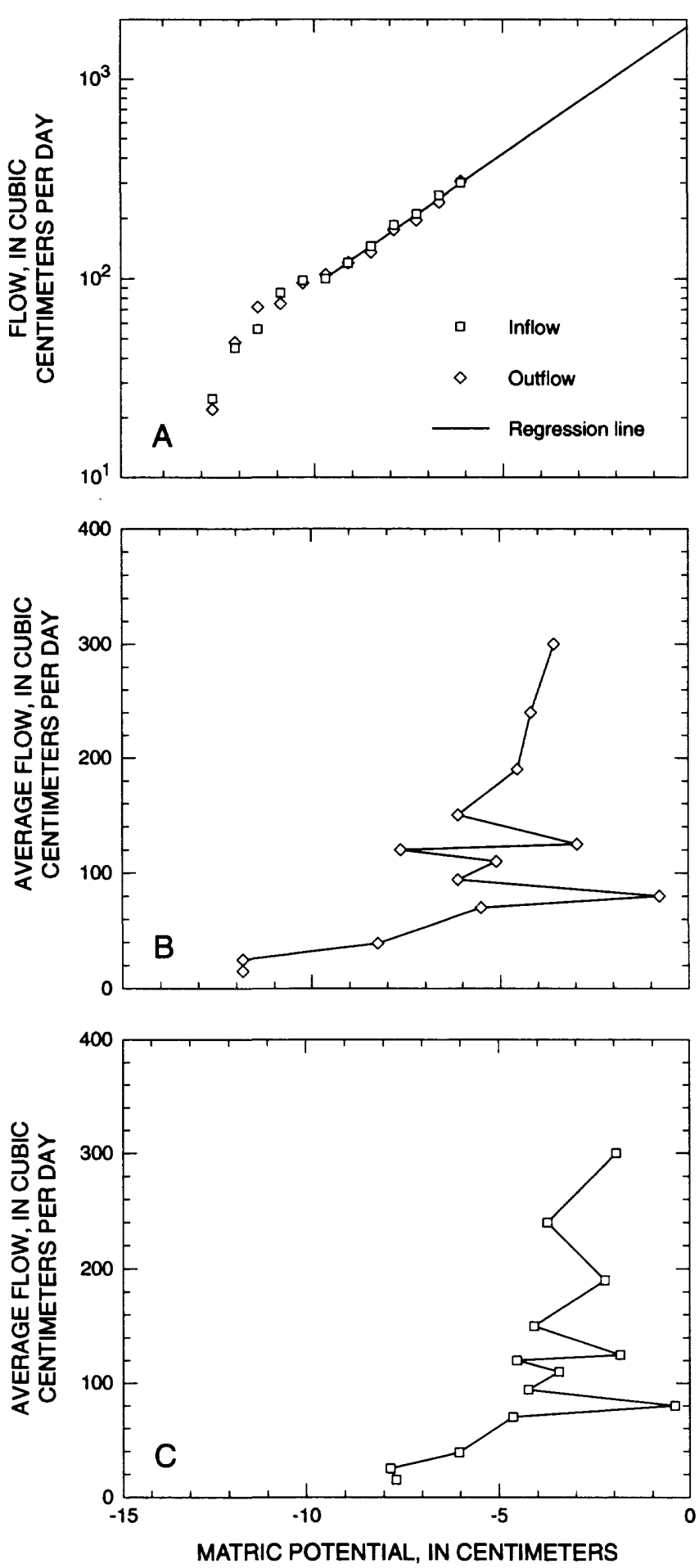

Figure 9. Flow rates through the block expressed as functions of: (A) average matric potential in the upper sand layer; (B) median borehole matric potential (matrix holes included); and (C) median borehole matric potential (matrix holes excluded). "effective" water saturation, $S_{1}$ is water saturation, $S_{\mathrm{lr}}$ is residual water saturation, $S_{1 \mathrm{~s}}$ is "satiated" or maximum field saturation, $\alpha$ is a scaling parameter related to the characteristic pore size, and $\mathrm{n}$ is a measure of the dispersion of those pore sizes around the characteristic pore size. The assumption is made that $m=1-1 / n$. The pore size information described by the parameters of the moisture-characteristic curve $[\mathrm{S}(\psi)]$ was used to predict the relative permeability to liquid water $\left(\mathrm{k}_{\mathrm{rl}}\right)$ as a function of $S_{l e}$ :

$$
\mathrm{k}_{\mathrm{rl}}=\mathrm{S}_{\mathrm{le}}^{0.5}\left[1-\left(1-\mathrm{S}_{\mathrm{le}}^{1 / \mathrm{m}}\right)^{\mathrm{m}}\right]^{2}
$$

Relative permeability to gas (air) $\left(\mathrm{k}_{\mathrm{rg}}\right)$ as a function of $S_{1}$ was calculated using the functions of Luckner and others (1989), which extend those of van Genuchten to include expressions for $\mathrm{k}_{\mathrm{rg}}$.

$$
\mathbf{k}_{\mathrm{rg}}=\mathrm{S}_{\mathrm{ge}}{ }^{0.33}\left[1-\left(1-\mathrm{S}_{\mathrm{ge}}{ }^{1 / \mathrm{m}}\right)^{\mathrm{m}}\right]^{2}
$$

and

$$
S_{g e}=\left(1-S_{g r}-S_{1}\right) /\left(1-S_{g r}\right)
$$

where $S_{\text {ge }}$ is "effective" gas saturation, and $S_{g r}$ is residual gas saturation.

Several series of imbibition experiments on 2.2to $7.1-\mathrm{cm}$-long cores sampled from the trimmed portions of the block (Ciesnik and others, 1994) indicate potential errors are associated with employing the moisture-characteristic curve $[\mathrm{S}(\psi)]$ developed for drying conditions in numerical models intended to capture wetting behavior of the initially air-dried block. In these experiments, fillable porosity was first determined for these samples by flushing the air in the samples with $\mathrm{CO}_{2}$ and saturating the samples under a vacuum. After oven-drying the samples under a vacuum, the samples were rewet either by submersion in a tank of water or by allowing water to be imbibed through one end of the cores. Dimensions and porosity of these cores are listed in table 3 . When rewet by submersion, these samples reached an average maximum saturation of 0.896 after 425 hours, with a standard deviation of 0.018 (Ciesnik and others, 1994). This relatively uniform response, reflected by the small standard deviation, contrasted sharply with the results of those experiments in which water was imbibed through one end. Figures $11 \mathrm{~A}$ and $11 \mathrm{~B}$ show the results from 


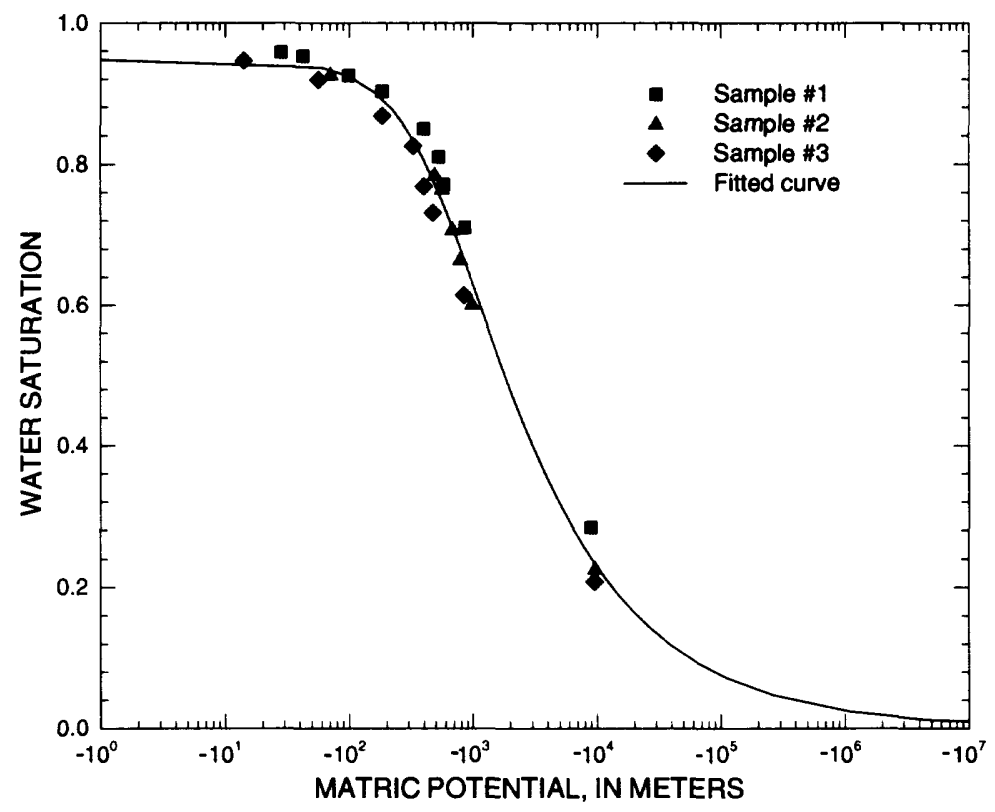

Figure 10. Experimental saturation/matric potential data for rock matrix sampled from trimmed portions of the block, with fitted van Genuchten curve.

two series of experiments in which the amount of water imbibed was gravimetrically determined as a function of time. Imbibition into these cores in many cases appears to have stopped after 100 hours in the first series of tests and after 325 hours in the second series. These results indicate that during wetting of initially dry core, the value of $S_{1 s}$ can be substantially less than 1. The values of $S_{1 \mathrm{~s}}$ suggested by the response of the 14 cores shown in the second series (fig. 11B) range between 0.39 and 0.90 , with an average of 0.666 and a standard deviation of 0.180 . The imbibition experiments were conducted in a Plexiglas glovebox in which a beaker of water was placed, ensuring that humidity within the glovebox was maintained near 100 percent. Therefore, it is unlikely that the failure of the samples to achieve greater saturation was caused by evaporation from the sample surfaces. There is considerable variability both among samples and between replicate trials on the same sample. Some of the variability among samples can be explained by the presence of vertical (sample 3) or horizontal (sample 14a) fractures in the cores or possibly by the differences in orientation of the cores with respect to the compaction foliation. Flow directions in cores 1 through $7 \mathrm{~b}$ and $15 \mathrm{a}$ were perpendicular to foliation, whereas the flow direction was parallel to foliation in cores $8,9,10,14 \mathrm{a}$, and $14 \mathrm{~b}$. Furthermore, in this series of experiments there is a weak correlation $\left(r^{2}=0.25\right)$ between maximum achievable saturation and core length. Still, the variability among the imbibition experiments is surprising given the relatively small variability in the $\mathrm{k}$ and $S(\psi)$ data and the relatively uniform response in the submersion experiments.

Because the $S(\psi)$ curve developed under drying conditions appears to be inadequate to model the results of the imbibition experiments, and by inference, the wetting behavior of the block rock matrix, an $S(\psi)$ curve was estimated for wetting conditions. This curve was developed by modifying selected parameters associated with the fitted $S(\psi)$ curve. Based on a rule-ofthumb suggested by Luckner and others (1989), it was assumed that the value of $\alpha$ for wetting $\left(\alpha_{\mathrm{w}}\right)$ is twice the value of $\alpha$ for drying $\left(\alpha_{d}\right)$, or $\alpha_{w}=3.7373 \times$ $10^{-3} \mathrm{~m}^{-1}$. This value for $\alpha_{\mathrm{w}}$ is twice the value obtained for $\alpha_{d}$ by fitting equation 1 to the saturation/water potential data shown in figure 10. Also, based on the results of modeling the imbibition experiments (see section "Numerical Simulations-Imbibition Tests), values of $S_{l s}=0.70$ and $S_{g r}=0.3$ at $0.0 \mathrm{~m}$ tension were chosen as being representative values for wetting conditions. With other parameters of the van Genuchten function left unchanged, the wetting curve shown in figure 12 was calculated. 
Table 3. Physical features of core samples used in imbibition tests

[From Ciesnik and others, $1994 . \mathrm{cm}$, centimeter; $\mathrm{cm}^{3}$, cubic centimeter; $\mathrm{g} / \mathrm{cm}^{3}$, gram per cubic centimeter]

\begin{tabular}{cccccc}
\hline $\begin{array}{c}\text { Sample } \\
\text { number }\end{array}$ & $\begin{array}{c}\text { Length } \\
(\mathbf{c m})\end{array}$ & $\begin{array}{c}\text { Diameter } \\
\mathbf{( c m )}\end{array}$ & $\begin{array}{c}\text { Bulk volume } \\
\left(\mathbf{c m}^{\mathbf{3}}\right)\end{array}$ & $\begin{array}{c}\text { Bulk density } \\
\left(\mathbf{g} / \mathbf{c m}^{\mathbf{3}}\right)\end{array}$ & $\begin{array}{c}\text { Porosity } \\
\text { (percentage) }\end{array}$ \\
\hline 1 & 2.25 & 2.52 & 10.20 & 2.298 & 7.8 \\
2 & 4.24 & 2.52 & 20.00 & 2.300 & 7.7 \\
3 & 5.64 & 2.52 & 27.73 & 2.310 & 7.3 \\
4 & 5.89 & 2.52 & 28.10 & 2.307 & 7.6 \\
5 & 5.46 & 2.52 & 27.60 & 2.317 & 7.1 \\
6 & 5.40 & 2.52 & 26.31 & 2.308 & 7.4 \\
$7 \mathrm{~A}$ & 2.88 & 2.52 & 12.70 & 2.492 & 8.1 \\
$7 \mathrm{~B}$ & 3.11 & 2.52 & 15.02 & 2.315 & 7.1 \\
8 & 2.72 & 2.52 & 13.50 & 2.304 & 7.6 \\
9 & 6.07 & 2.52 & 29.83 & 2.315 & 7.2 \\
10 & 5.83 & 2.52 & 28.77 & 2.310 & 7.4 \\
$14 \mathrm{~A}$ & 7.10 & 4.14 & 94.02 & 2.333 & 7.2 \\
$14 \mathrm{~B}$ & 7.07 & 4.14 & 93.81 & 2.335 & 7.1 \\
$15 \mathrm{~A}$ & 3.05 & 4.14 & 37.27 & 2.521 & 7.8 \\
\hline
\end{tabular}

To account for the permeability reductions that result from air entrapment, the fitting parameters of the functions of van Genuchten (1980) and Luckner and others (1989) were determined in a somewhat unconventional manner. As described above, the moisturecharacteristic function (equation 1) was calculated with $\mathrm{S}_{1 \mathrm{~s}}=0.70$ based on the assumption that liquid saturation $\left(\mathrm{S}_{1}\right)$ equal 0.70 at $0.0 \mathrm{~m}$ tension. However, the $\mathrm{k}_{\mathrm{rl}}$ versus $S_{1}$ function was calculated assuming $S_{1 s}=1.0$, so that $k_{r l}$ was defined over a range of saturations from 0 to 1 . As shown in figure 13 , the $k_{r g}$ versus $S_{1}$ function defined for the wetting case (using $\mathrm{S}_{\mathrm{gr}}=0.30$ ) limits the maximum achievable saturation to 0.70 because the decrease of air permeability to zero at this value prevents the further escape of air. Thus, although $\mathrm{k}_{\mathrm{rl}}$ has been defined for $S_{1}>0.70$, its maximum attainable value is limited to $\mathrm{k}_{\mathrm{rl}}\left(\mathrm{S}_{1}=0.70\right)$ or approximately 0.03 .

\section{Sand}

Some properties of the upper and lower sand layers from the experiment in Thamir and others (1993, 1994) are listed in table 4. For each property, two values are listed for the upper sand layer, representing initial conditions and those that existed after consolidation following drainage of the first slug of water. In general, moisture-characteristic curves can be measured under conditions in which the medium goes from a state of complete saturation to complete dryness (sometimes called the principal drainage curve or main desorption curve), or conditions in which the medium goes from a state of complete dryness to complete wetness (sometimes called the principal wetting curve or main sorption curve). When a partially drained material is rewetted, or a partially water-filled material is drained, the saturation/water potential relation follows an intermediate curve as it moves from one principal curve to the other. These intermediate curves are known as scanning curves (Hillel, 1980). Partial S $(\psi)$ curves were developed for both wetting and drying conditions, as shown in figure 14 (Thamir and others, 1993, 1994). These curves, which represented part of the principal drainage curve and a wetting scanning curve, were measured with a tempe cell after packing the sand to bulk density similar to that listed for "upper initial" conditions in table 4 from the experiment in Thamir and others $(1993,1994)$. Matric potential within the sand was adjusted by changing the length of a water column in a tube hung from the base of the tempe cell. Water saturation of the sand was determined simultaneously on the basis of the quantity of water which drained or was taken up by the sand through that tube, which terminated in a graduated cylinder partially filled with water. Although measurements for repeated cycles did not overlap exactly, the differences between cycles are relatively small, and hysteretic behavior was clearly exhibited. 

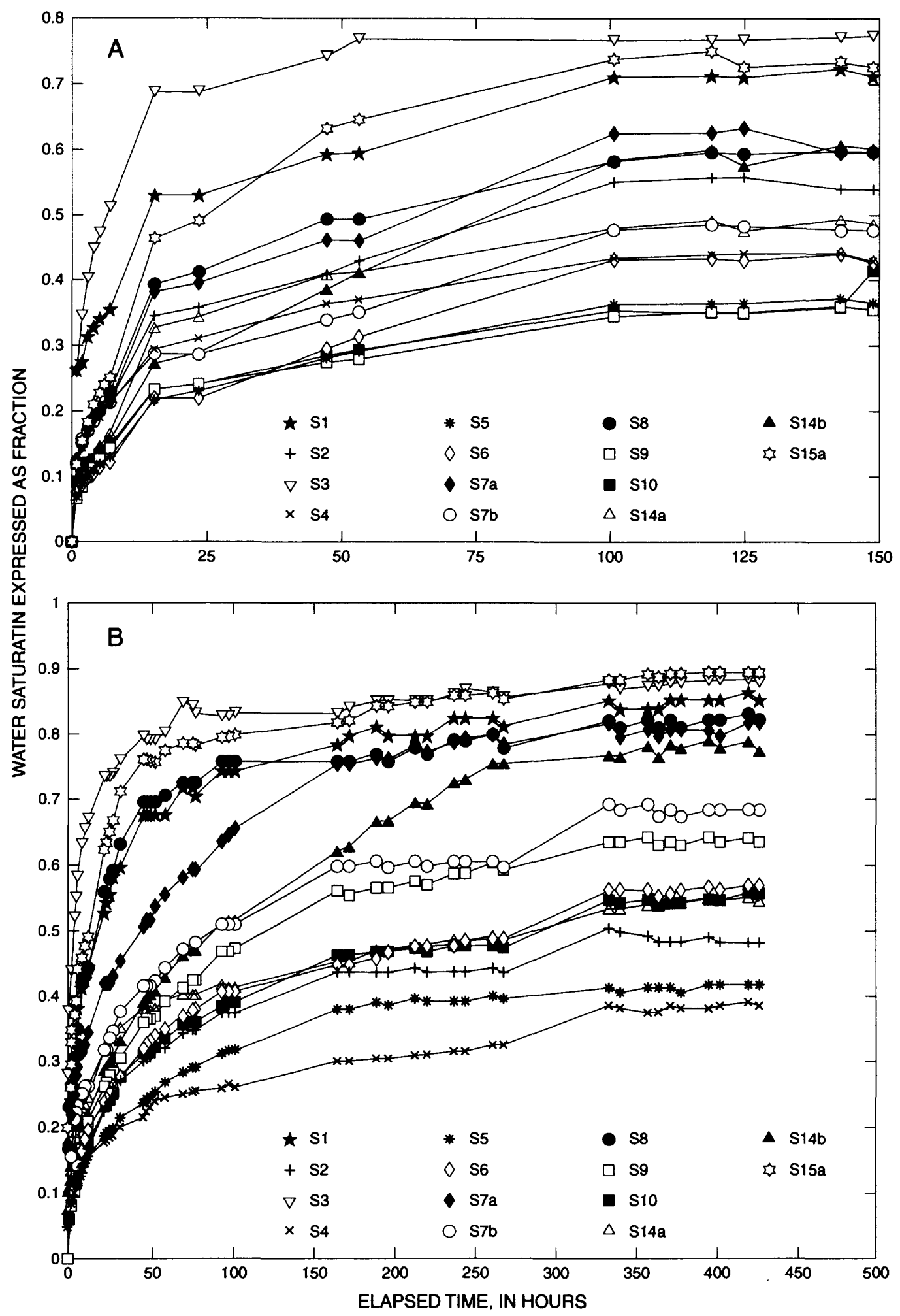

Figure 11. Results of imbibition tests conducted in core samples taken from trimmed portions of the block showing apparent effects of entrapped air: (A) first series; and (B) second series (modified from Ciesnik and others, 1994). 


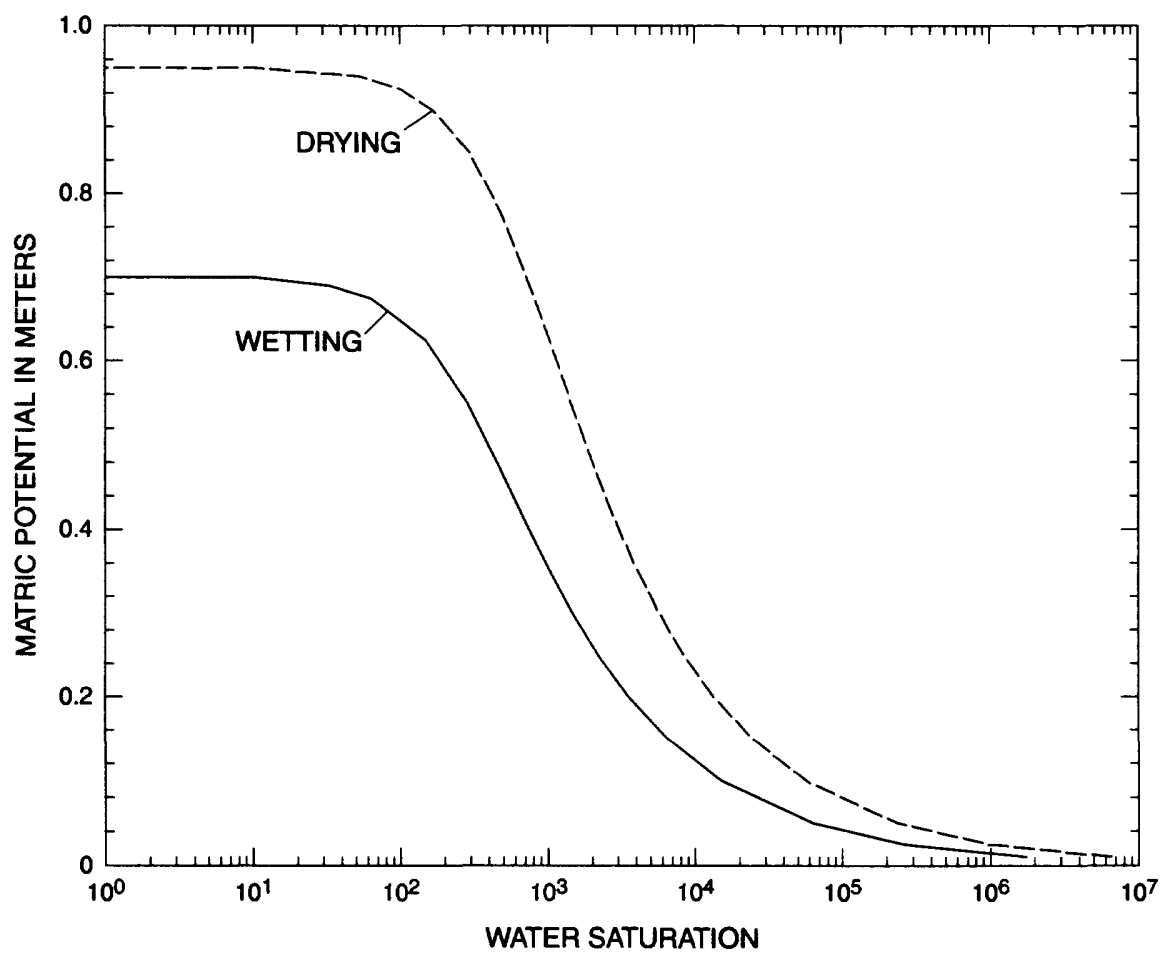

Figure 12. Fitted drying and estimated wetting moisture-characteristic curves for the rock matrix.

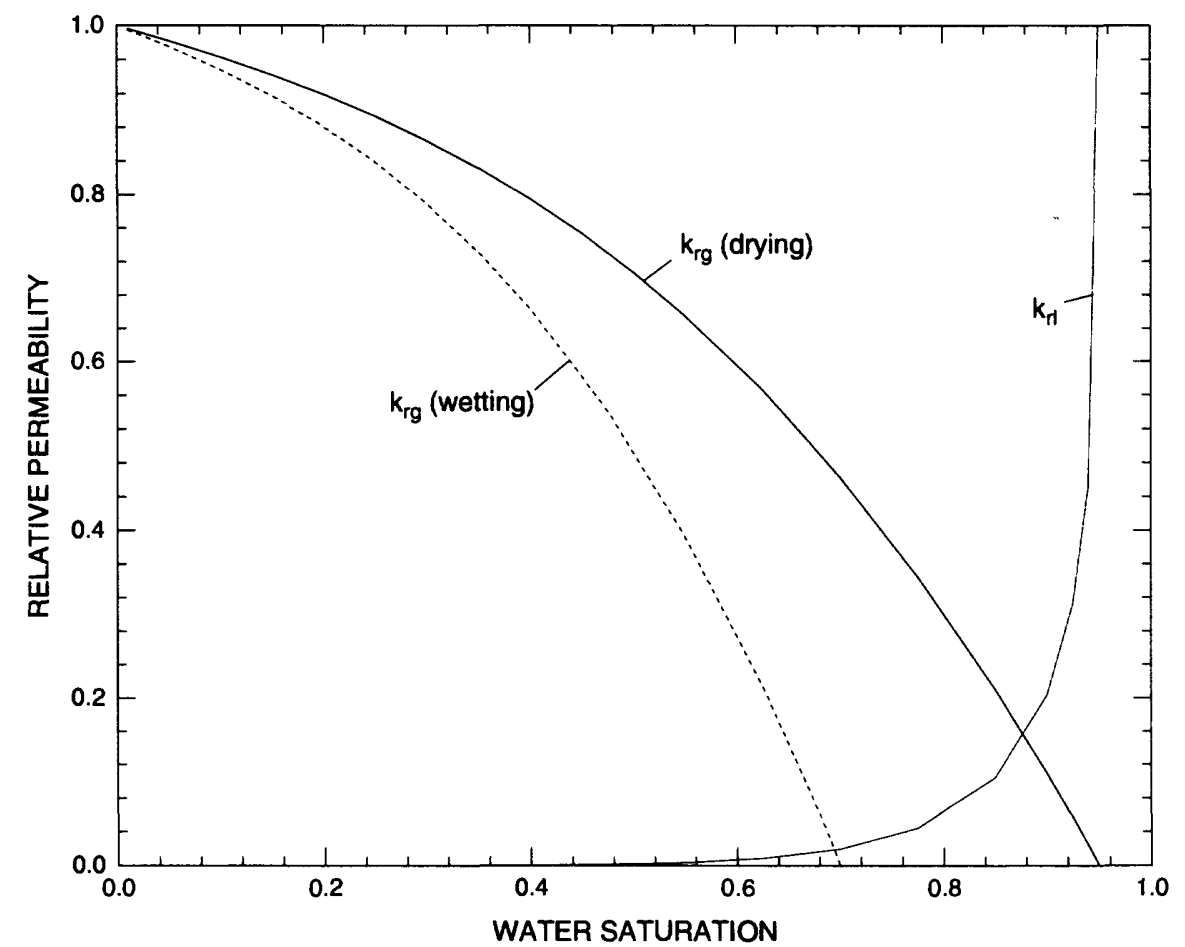

Figure 13. Theoretical relative permeabilities to liquid $\left(k_{\mathrm{r}}\right)$ and gas $\left(\mathrm{k}_{\mathrm{rg}}\right)$ of rock matrix, as estimated from the Luckner functions using $S_{\mathrm{IS}}=0.70$ (wetting) and $S_{\mathrm{IS}}=0.95$ (drying). 
Table 4. Physical properties of the sand layers

[From Thamir and others, $1994 . \mathrm{mm}$, millimeter; $\mathrm{g} / \mathrm{cm}^{3}$, gram per cubic centimeter; $\mathrm{cm}^{3}$, cubic centimeter]

\begin{tabular}{lcccc}
\hline $\begin{array}{c}\text { Sand } \\
\text { layer }\end{array}$ & $\begin{array}{c}\text { Thickness } \\
(\mathbf{m m})\end{array}$ & $\begin{array}{c}\text { Bulk density } \\
\left(\mathbf{g} / \mathbf{c m}^{\mathbf{3}}\right)\end{array}$ & $\begin{array}{c}\text { Porosity } \\
\text { (as fraction) }\end{array}$ & $\begin{array}{c}\text { Pore volume } \\
\left(\mathbf{c m}^{\mathbf{3}}\right)\end{array}$ \\
\hline Upper (initial) & 102 & 1.57 & 0.41 & 11.0 \\
Upper (final) & 94 & 1.70 & 0.36 & 8.9 \\
Lower & 32 & 1.74 & 0.34 & 3.9 \\
\hline
\end{tabular}

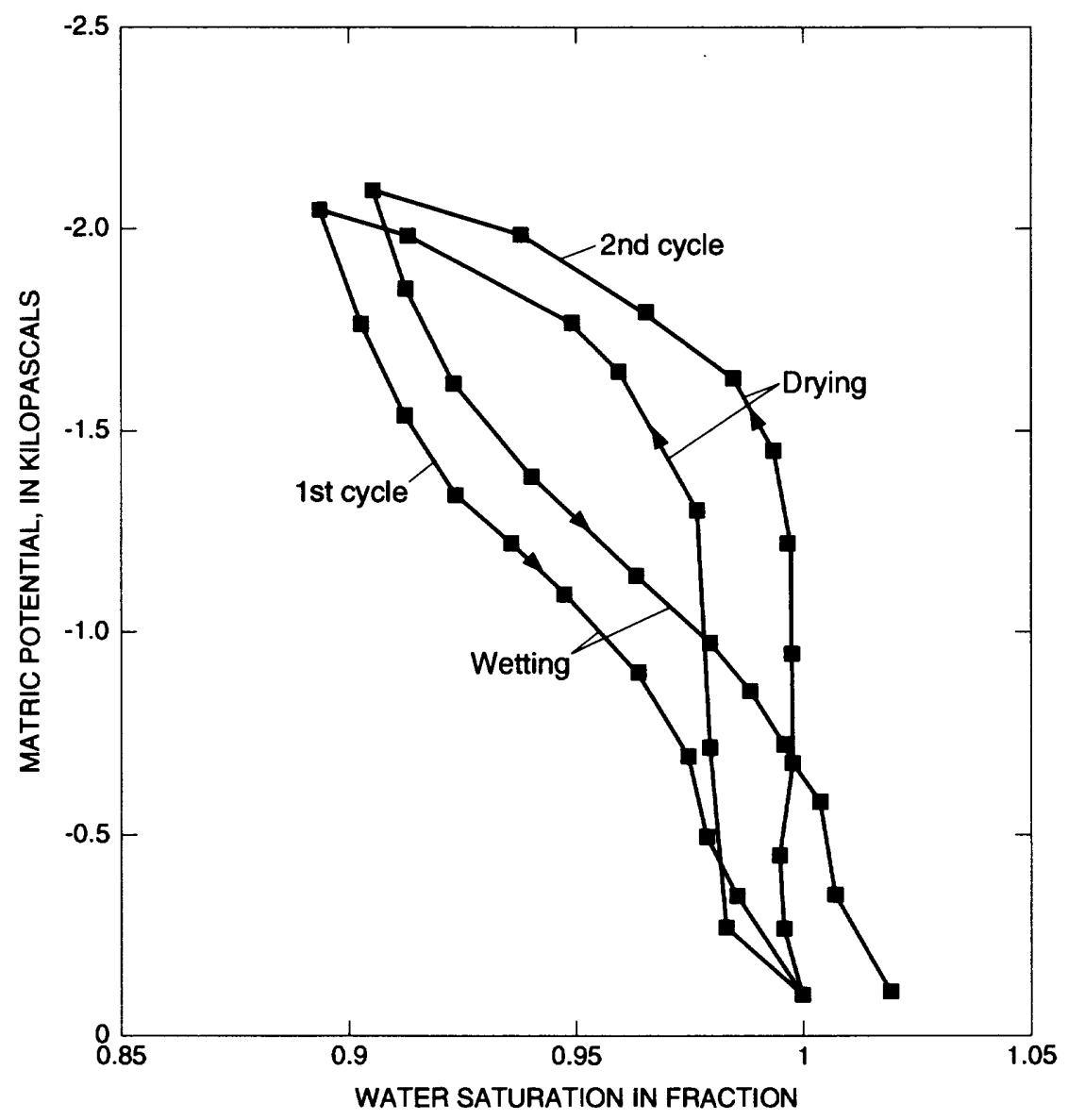

Figure 14. Measured matric potential/water-saturation relation of sand packed to a similar bulk density as the upper sand layer (from Thamir and others, 1994). The figure shows replicate drying and wetting curves for the sand.

Data from the two principal drainage curves were visually interpolated and fitted with the van Genuchten function (fig. 15). Saturations were not measured at water potentials smaller than approximately $-2.0 \mathrm{kPa}(-20 \mathrm{~cm})$. Based on the tensiometer response following application of the first two slugs of water, this value was the lower limit of water potentials expected to be induced in the upper sand layer. The fitting parame- ters were $S_{1 s}=0.995, S_{l r}=0.0, n=6.34042$, and $\alpha=3.4520 \mathrm{~m}^{-1}$. Permeability of the sand layer overlying the block in the experiment in Thamir and others (1993, 1994)was estimated from measurements on sand layered to a similar initial density using a falling head permeameter. Based on a single sample, the permeability of the sand layer overlying the block was estimated as $\mathrm{k}=2.321 \times 10^{-11} \mathrm{~m}^{2}$. 


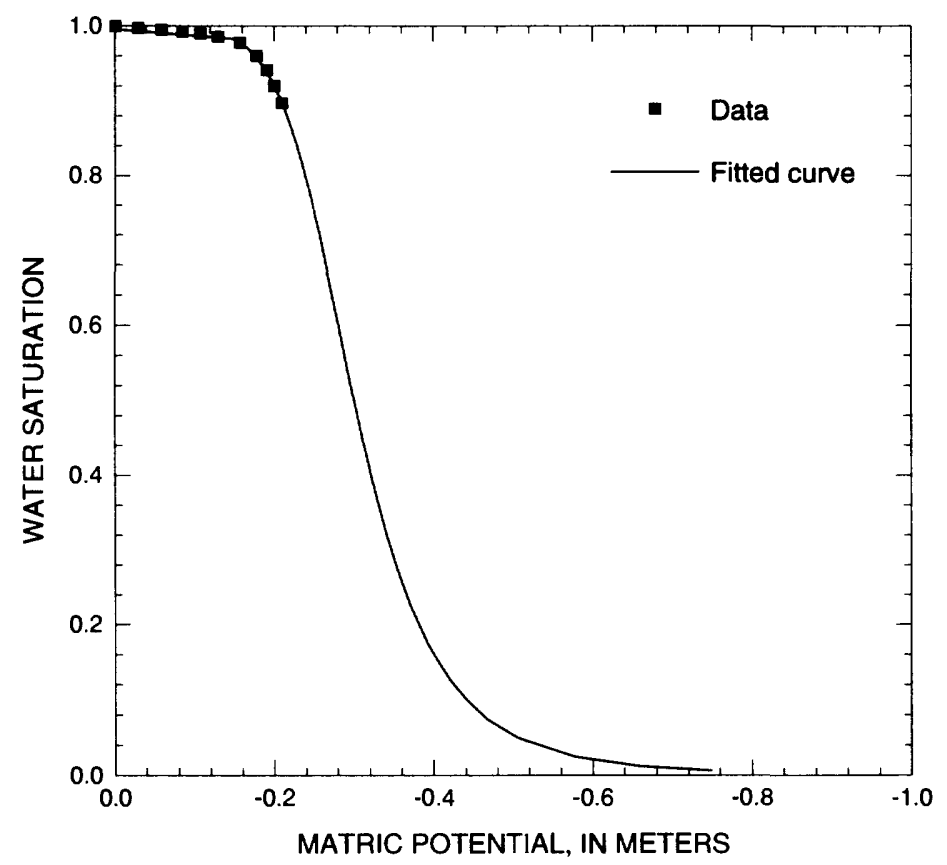

Figure 15. Matric potential/water-saturation data interpolated from wetting and drying curves of figure 14, with fitted van Genuchten function.

\section{Fractures}

No data are presently available on the unsaturated hydrologic properties of individual fractures within the experimental block. Indeed, there is little, if any, experimental data of this type available from other sources. Therefore, for this report, it is necessary to rely on the use of hypothetical fracture properties developed in accordance with current theory on water movement through variably saturated fractures. The following paragraphs describe the assumptions and methods by which these properties were developed.

Current conceptual and numerical models of partially saturated or two-phase flow between rough fracture surfaces treat flow as analogous to that in a heterogeneous confined aquifer, with transmissivity variations controlled by the values of local aperture according to the cubic law (Pruess and Tsang, 1990; Kwicklis and Healy, 1993). In these models, the capillary rise law for parallel plates determines which constant aperture cells in the finite difference mesh are drained or filled by water. The particular model used to develop fracture properties for this report, VSFRAC (Variably Saturated FRACture model; Kwicklis and Healy, 1993), also applies an accessibility criterion to determine if continuous air- or water-filled pathways are available from the active flow boundaries to those fracture cells predicted to drain or fill on the basis of the capillary-rise criteria. The application of an accessibility criterion allows hysteretic relations between fracture permeability, saturation, and matric potential to be calculated. However, this accessibility criterion was applied only to the "invading" phase. The displaced phase is assumed to be able to move at all phase saturations in order to generate relative permeability curves for the invading phase over a broader range of saturations than would otherwise be possible with the model. This was done to compensate for the fact that certain processes not considered by the model (diffusion of entrapped air through water, removal of residual water as vapor) might, over time, remove an unknown portion of the trapped phase. Also, because the model does not consider the effects of gravity, buoyancy of the gas phase and gravitational drainage of the liquid phase are not considered at this scale.

Given an aperture field, VSFRAC solves the governing flow equations for the liquid and gas phases in a deterministic manner (Kwicklis and Healy, 1993). If the aperture distribution for a fracture has been measured, that aperture distribution can be supplied directly to VSFRAC, which calculates the resulting phase distributions and flux rates at user-specified values of matric potential. In this case, the results are com- 
pletely deterministic. If details about the aperture field within a fracture are not available, some assumptions must be made about its spatial structure. The geometric model presently used in conjunction with VSFRAC assumes that aperture within an individual fracture is lognormally distributed and varies spatially within the plane of the fracture in a way that can be characterized by a spherical variogram. The aperture field is thus characterized in a statistical manner by its mean $\left(b_{m}\right)$, variance $\left(\sigma_{\ln b}^{2}\right)$ and a measure of its spatial correlation structure, which in this case is the range of the variogram. Obviously, in the absence of fracture-specific information, other assumptions and fracture descriptors are possible. Numerical techniques such as the "turning-bands" method used in this study allow different aperture fields to be generated from the same set of fracture descriptors. These different aperture fields, referred to as "realizations," are based on the statistics of the distribution, yet differ in their details and therefore possess different flow properties.

Although estimates of mean aperture for individual fractures in the block are available from analysis of the air-injection tests (see "Numerical Simulations Air-Injection Tests" section), no information is available concerning $\sigma_{\ln b}^{2}$ or the spatial structure of aperture. It will be assumed that the importance of $\sigma^{2}{ }_{\ln b}$ is secondary relative to $b_{m}$. It will be further assumed in this section that apertures are spatially correlated over a range that is one-tenth times the dimensions of the flow field to ensure that flow behavior has been simulated for a statistically representative portion of the fracture. This assumption effectively eliminates the potential for high or low transmissivity conduits ("channels") to exist uninterrupted across a fracture. Table 5 lists the values of $b_{m}$ of hypothetical fractures whose unsaturated hydrologic behavior will be discussed in the following paragraphs. Also listed in table 5 are the mean $(u)$ of the natural logarithm $(\ln b)$ and variance $\left(\sigma_{\ln b}^{2}\right)$ of the associated lognormal aper- ture distribution assumed for these values of $b_{m}$, and the values of aperture corresponding to the 95 -percent confidence limits of the lognormal distribution, $\mathrm{e}^{(u-2 \sigma)}$ and $\mathrm{e}^{(\mathrm{u}+2 \sigma)}$. The latter are given to indicate the range of apertures associated with the values of $\sigma^{2} \ln b$ assumed for these fractures.

Limited sensitivity analyses concerning the impact of assumed aperture variance have been reported. Pruess and Tsang (1990) and Kwicklis and others (1993) found that for a given mean aperture, increases in aperture variance decreased the ratio between hydraulic and mean physical aperture, in part because more numerous small-aperture regions occur that can restrict flow. Also, with increases in aperture variance, the range in water potentials over which the fracture drains or fills becomes broader and hysteresis becomes more pronounced (Kwicklis and others, 1993; Healy and Kwicklis, 1991).

To illustrate the capabilities of the model and suggest the range of hydraulic responses that are possible for identical fracture descriptors, five stochastic realizations of a fracture with an average physical aperture of $100 \mu \mathrm{m}$ were generated, and the water saturation and relative permeability versus matric potential curves were calculated under both wetting and drying conditions (figs. 16A and 16B). Individual realizations are labeled according to the hydraulic aperture, $b_{h}$, calculated under single-phase conditions. Hysteretic behavior is apparent in both the saturation/matric potential (fig. 16A) and relative water permeability/ matric potential (fig. 16B) relation. The irregular behavior obtained for some realizations may be understood by the so-called "ink-bottle effect" (Hillel, 1980, p. 79), which is used to explain hysteresis in porous media (that is, the tension at which large-aperture segments of the fracture drain is determined by the airentry matric potential of surrounding smaller aperture segments that isolate them from the active flow boundaries).

Table 5. Aperture characteristics of hypothetical fractures considered by simulations in this report $\left[b_{m}\right.$, mean aperture; $\mu \mathrm{m}$, micrometer; $u$, the mean of the natural logarithm of $b ; \sigma_{\ln b}^{2}$, the variance of the natural logarithm of $b ; b, a p e r t u r e ; \sigma_{\ln b}$, the standard deviation of the natural logarithm of $b ; \mathbf{e}=2.718]$

\begin{tabular}{|c|c|c|c|c|}
\hline $\begin{array}{c}b_{m} \\
(\mu \mathrm{m})\end{array}$ & $\mathbf{u}$ & $\sigma_{\ln b}^{2}$ & $\begin{array}{c}b=e^{u-2 \sigma} \ln b \\
(\mu \mathrm{m})\end{array}$ & $\begin{array}{c}b=e^{u=2 \sigma} \ln b \\
(\mu \mathrm{m})\end{array}$ \\
\hline 2.5 & 0.88 & 0.0667 & 1.44 & 4.1 \\
\hline 125.0 & 4.33 & 1.0000 & 10.28 & 561.2 \\
\hline 250.0 & 4.95 & 1.1400 & 16.69 & $1,194.4$ \\
\hline
\end{tabular}



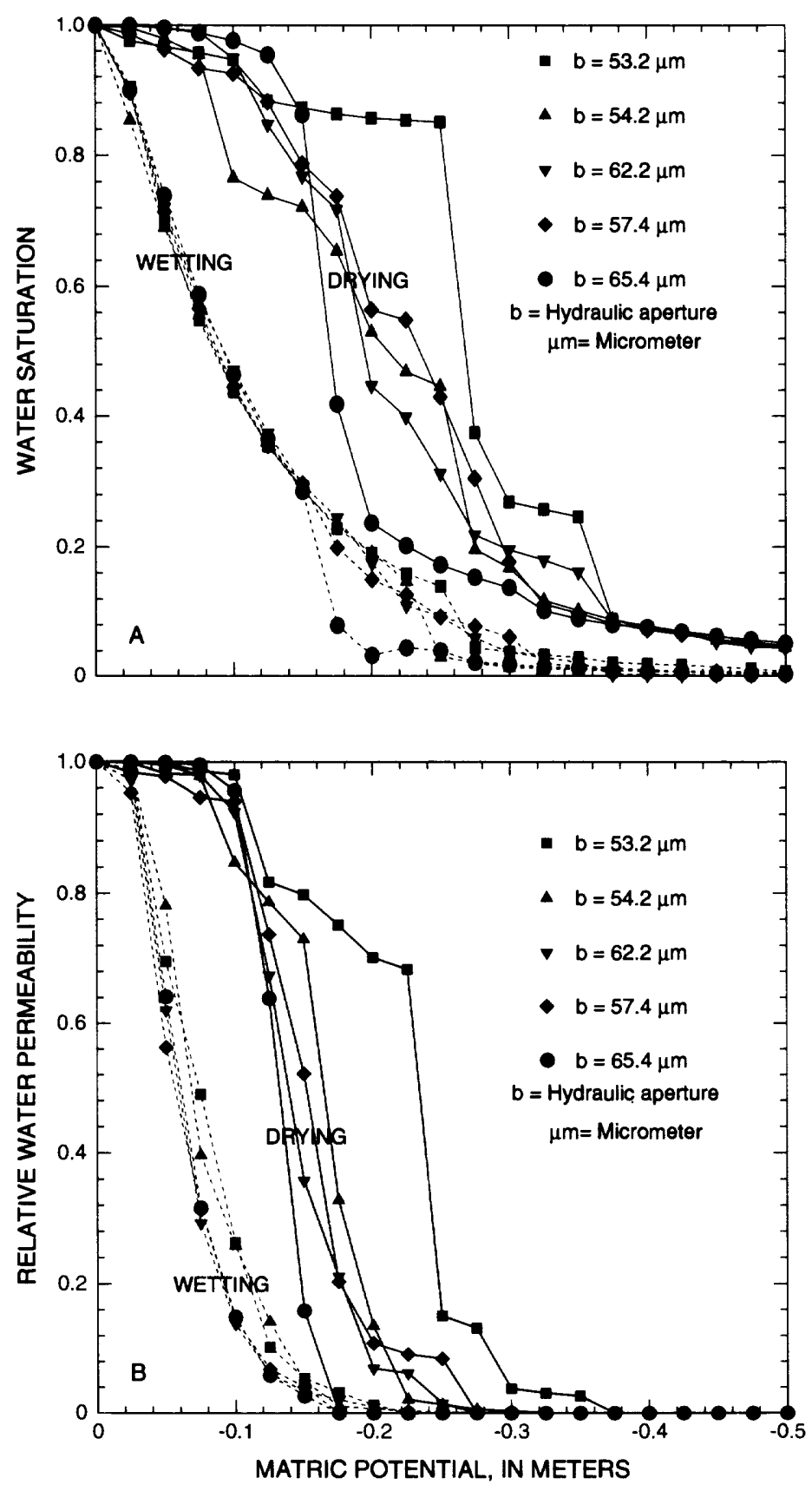

Figure 16. Theoretical hysteretic relations calculated by the aperture-scale numerical model VSFRAC for five stochastic realizations of a fracture with an average physical aperture of 100 micrometers for: (A) water saturation as a function of matric potential; and (B) relative permeability to water as a function of matric potential. 
A comparison of the relative water permeability/ saturation relation for these same realizations also suggests hysteretic behavior (figs. 17A and 17B). For a given saturation, relative water permeability appears to be larger under wetting conditions. Although volumetrically significant, the large-aperture regions are not areally extensive and so, when the fractures are wetting, do not contribute much to flow as they fill with water (saturation greater than 0.80 ). During drying, however, the surrounding, more areally extensive, but volumetrically less significant, small-aperture fracture segments must also drain when these large aperture segments drain, so that a great deal of the fracture area simultaneously becomes unavailable for liquid flow.

Shown in figures $18 \mathrm{~A}, 18 \mathrm{~B}$, and $18 \mathrm{C}$ are the water saturation/matric potential, relative permeability/ matric potential, and relative-permeability/water saturation relations developed under wetting conditions for fractures with mean physical apertures of 25, 125, and $250 \mu \mathrm{m}$. These are the average relations developed from 10 different stochastic realizations of the aperture field for a given mean aperture. Unlike analogous relations observed for individual realizations, where behavior could be far from smooth, the averages are very regular. Figure $18 \mathrm{~A}$ shows that as the mean physical aperture decreases, the range of matric potentials over which the fracture fills becomes broader. However, the model simulations predict that on average, none of the fractures considered is significantly saturated when the matric potential is less than $-1 \mathrm{~m}$. Figure $18 \mathrm{~B}$ shows the relative permeabilities to water and air as a function of matric potential. For a given average aperture, there is only a very small range of matric potential over which both air and water have nonzero relative permeabilities. The matric potential at which air permeability decreases to zero and water permeability increases to nonzero values becomes larger as the mean aperture size increases. For $25-\mu \mathrm{m}$ fractures, these matric potentials are between -0.5 and $-0.75 \mathrm{~m}$. For $250-\mu \mathrm{m}$ fractures, the analogous matric potentials are greater than $-0.1 \mathrm{~m}$. Relative permeabilities to water and air can also be expressed as a function of water saturation (fig. 18C). There are no clear-cut trends among the different size fractures when permeabilities are expressed in this way. Gas permeabilities decrease to zero at liquid saturations of between 0.2 and 0.4 , suggesting that, during wetting, entrapped air saturations of between 0.6 to 0.8 will prevent complete filling of the fractures by water. Thus, although water permeability is calculated by the model for saturations up to 1.0 , those portions of the curves above liquid saturations of 0.2 to 0.4 may never be realized.

To illustrate how aperture distribution within the plane of a fracture can theoretically control the distribution of air and water and their relative permeabilities, one realization of a stochastically generated aperture field $\left(b_{m}=125 \mu \mathrm{m}\right)$ will be considered. The water saturation/matric potential and relative permeability/water saturation relations developed for this realization under wetting conditions (figs. 19A and 19B) show that water permeability emerges at a water saturation of approximately $0.06(\psi=-0.275 \mathrm{~m})$ and air permeability is extinguished at a water saturation of $0.21(\psi=$ $-0.15 \mathrm{~m}$ ). A comparison of the aperture distribution for this realization (fig. 20A) with the corresponding phase distribution at $\psi=-0.25 \mathrm{~m}$ (fig. 20B) shows that although the air phase is continuous along several wide aperture pathways connecting the inflow (left) and outflow (right) boundaries, water is confined to the narrowest aperture regions of the fracture and is only connected along a single pathway in the upper part of the flow field. Conversely, by $\psi=-0.15 \mathrm{~m}$ water can move along additional narrow aperture pathways, but air has become discontinuous between the inflow and outflow boundaries. The pathways followed by water around the pockets of entrapped air are confined to the narrowest aperture regions and, at $\psi=-0.15 \mathrm{~m}$, are sufficiently tortuous to reduce the water relative permeability to only 0.003 . If no other mechanisms for removal of the entrapped air existed, it is difficult to imagine that the void geometry would permit filling of remaining airfilled pore space. Diffusion of the entrapped air through the water or fluid exchange through an adjacent porous matrix, processes not considered by this model, are two possible mechanisms.

Additional simulations were performed for a fracture with an average aperture of $2.5 \mu \mathrm{m}$. To facilitate the incorporation of these results and those for the $25-, 125-$ and $250-\mu \mathrm{m}$ fractures into other numerical models, the predicted saturation/matric potential and relative liquid permeability/matric potential relations output from the aperture-scale numerical model VSFRAC were fit with functions developed by van Genuchten (1980) and Luckner and others (1989). For each mean fracture aperture, the fitting process identified parameters that would simultaneously optimize the fit to both the moisture characteristic and relative permeability results generated by VSFRAC. Figures $21 \mathrm{~A}$ 


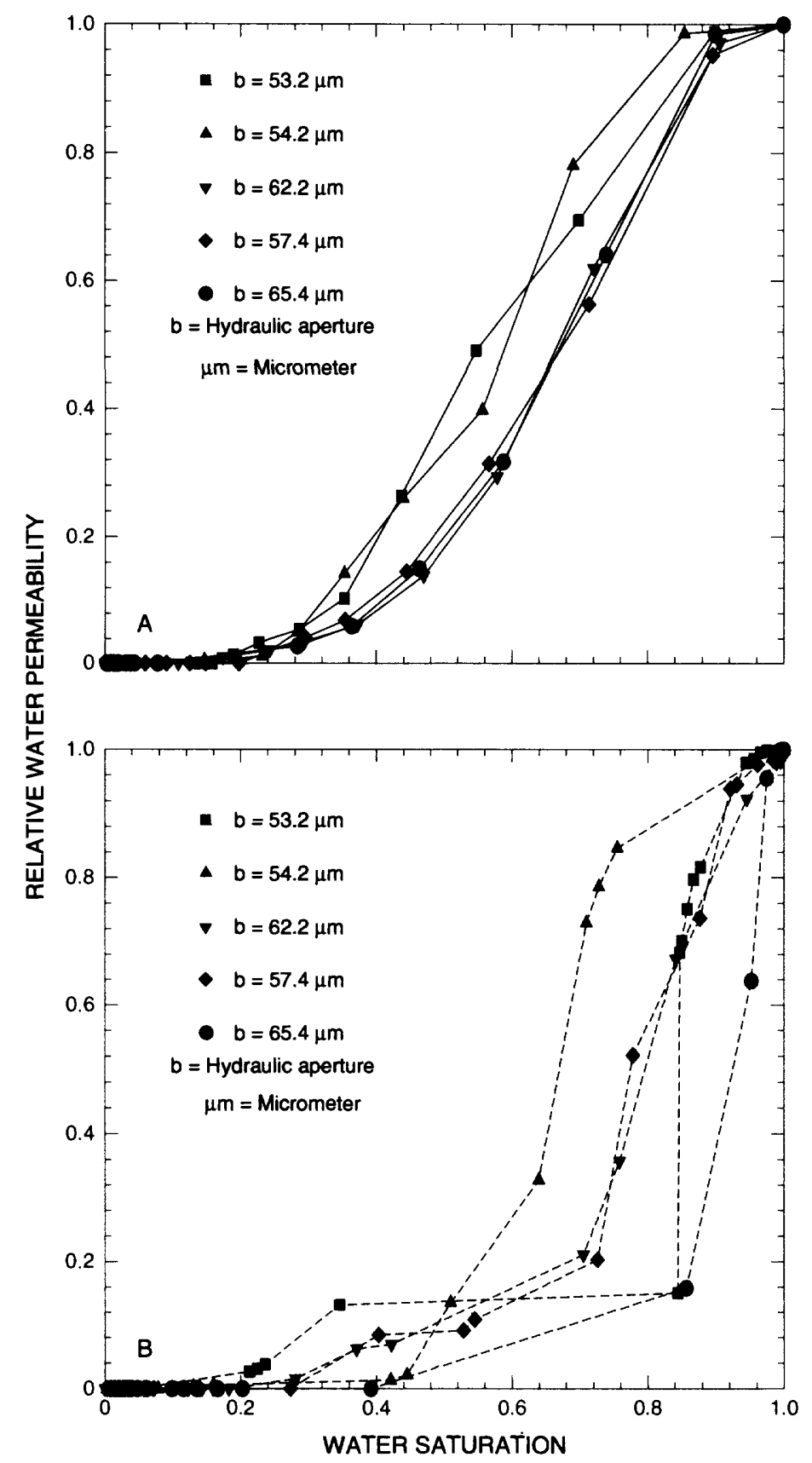

Figure 17. Theoretical relative water permeability/water saturation relations calculated by the aperture-scale numerical model VSFRAC for five stochastic realizations of a fracture with an average physical aperture of 100 micrometers for: $(A)$ wetting conditions; and (B) drying conditions. 

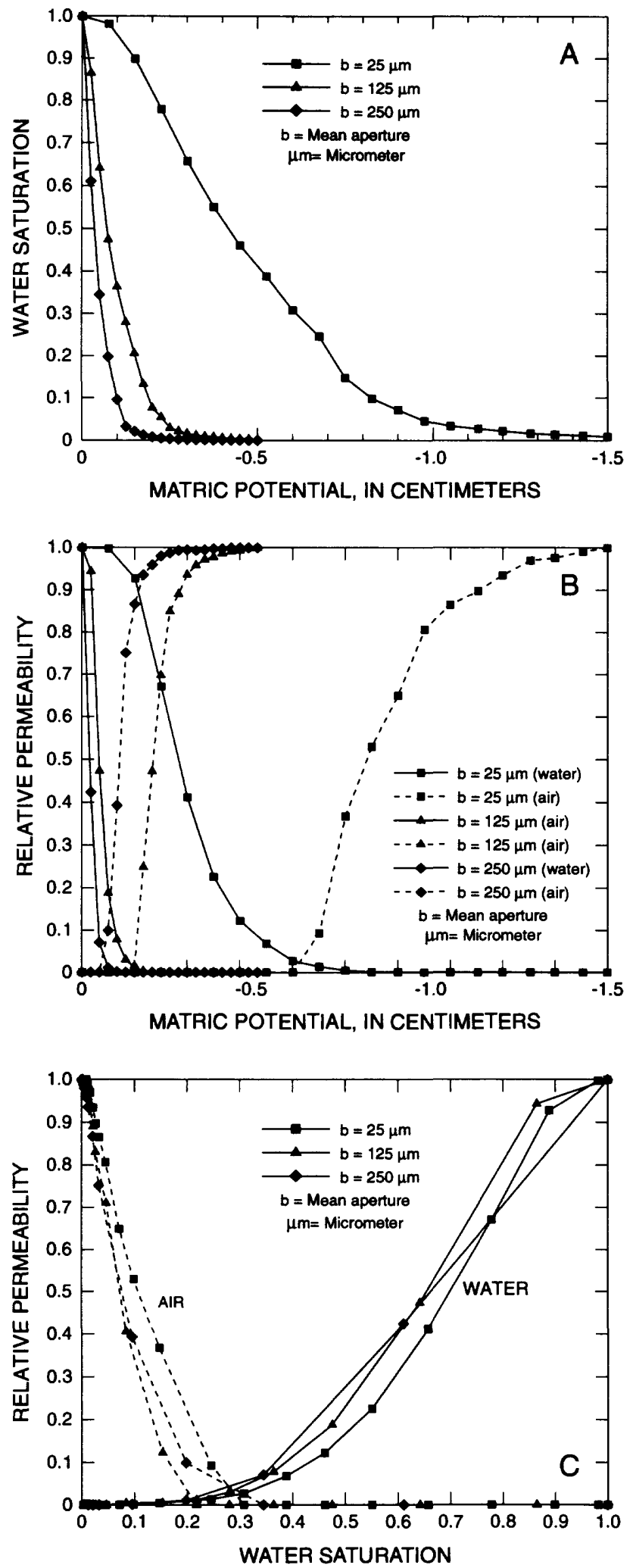

Figure 18. Average theoretical relations for 25-, 125-, and 250-micrometer fractures calculated for wetting conditions by aperture-scale numerical model VSFRAC on the basis of ten stochastic realizations: $(A)$ water saturation as a function of matric potential; $(B)$ water and air relative permeability as a function of matric potential; and $(C)$ water and air relative permeability as a function of water saturation. and 21B show the output from VSFRAC for the moisture characteristic and water permeability results along with the fitted curves for the 2.5-, 25- and $250-\mu \mathrm{m}$ fractures. The fitting parameters, goodness-of-fit, and other information for the fractures are listed in table 6.

To generalize these results and account for the probability that fractures within the block might not have average apertures identical to one of those for which properties were generated, empirical relations were developed between van Genuchten (1980) parameters $n$ and $\alpha$, and hydraulic (pneumatic) aperture $b_{h}$, as functions of mean physical aperture $b_{m}$. These equations are presented as footnotes to table 6 . Fracture permeability can then be calculated as

$$
k=\left(b_{h}^{2} / 12\right)\left(b_{h} / b_{m}\right)
$$

which was developed by equating Darcy's law with the cubic law and allowing for the possibility that flow aperture and mean physical aperture are different.

Some additional comments about the values in table 6 are necessary. As described previously, the macroscopic hydrologic characteristics will be somewhat sensitive to assumptions about aperture variance and the spatial correlation structure of aperture within the block. Additionally, the macroscopic hydrologic properties of a fracture depend on whether the fracture is wetting or drying (fig. 16A and 16B). All numerical results summarized by table 6 were developed under conditions in which the fracture was wetting.

The ratios of $b_{h} / b_{m}$ determined from the numerical results were used with an empirical equation developed by Barton (1982) for a variety of rock types that relates hydraulic and average physical apertures to surface roughness. As reported by Schrauf and Evans (1986), this equation is

$$
b_{h}=b_{m}^{2} / J R C^{2.5}
$$

where aperture is expressed in micrometers. Joint roughness coefficients (JRC's) were calculated for values of $b_{h}$ and $b_{m}$ for each fracture, as listed in table 6 . JRC values reflect the roughness of the fracture surface against a standard roughness profile and range from 2 (very smooth) to 20 (very rough). No JRC values were recorded for fractures in the block, but Throckmorton and Verbeek (1995), in summarizing fracture data collected over many years for Yucca Mountain, report 

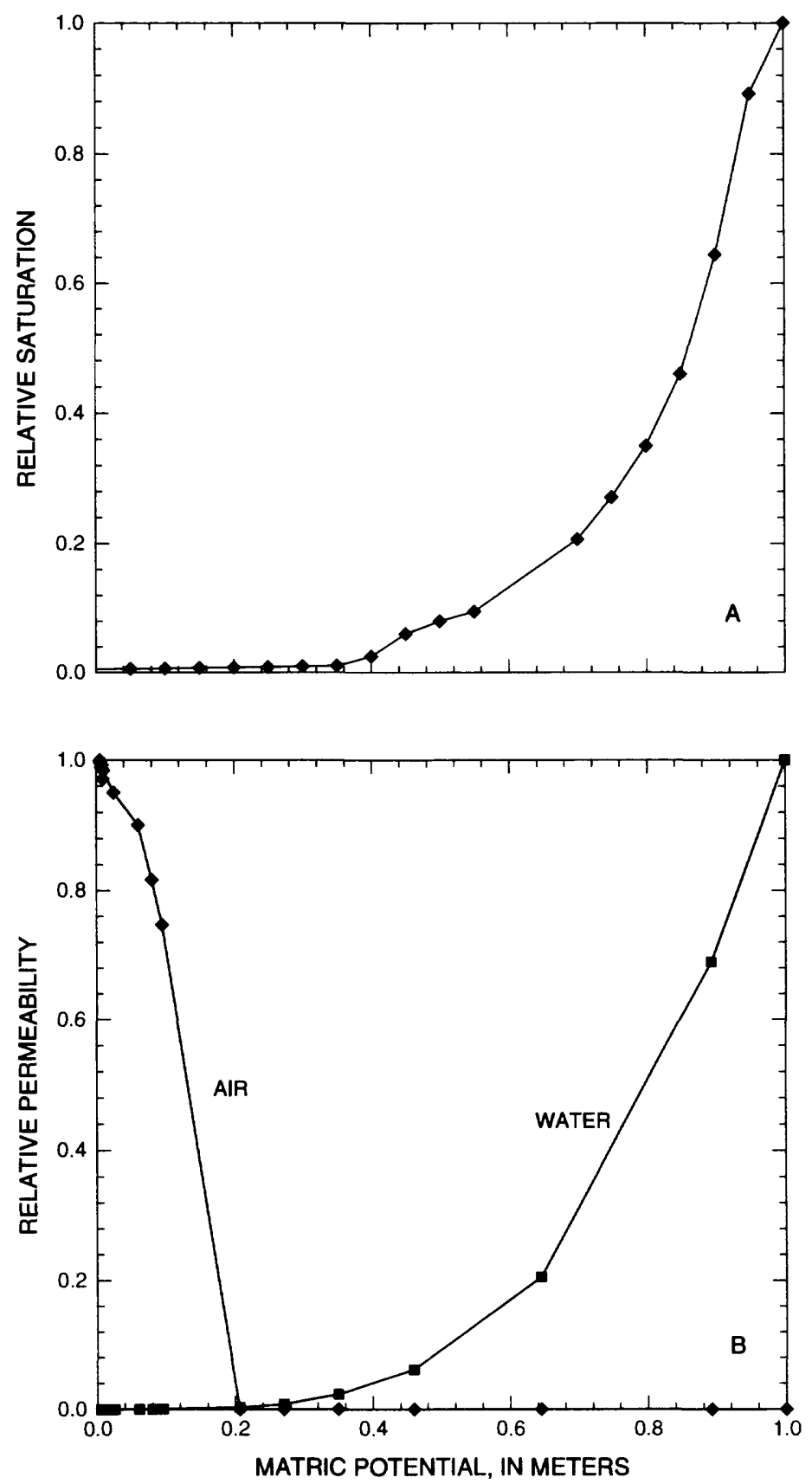

Figure 19. Theoretical relations calculated by the aperture-scale numerical model VSFRAC for a single realization of a 125-micrometer aperture fracture: (A) water saturation as a function of matric potential; and (B) air and water relative permeability as a function of water saturation. 


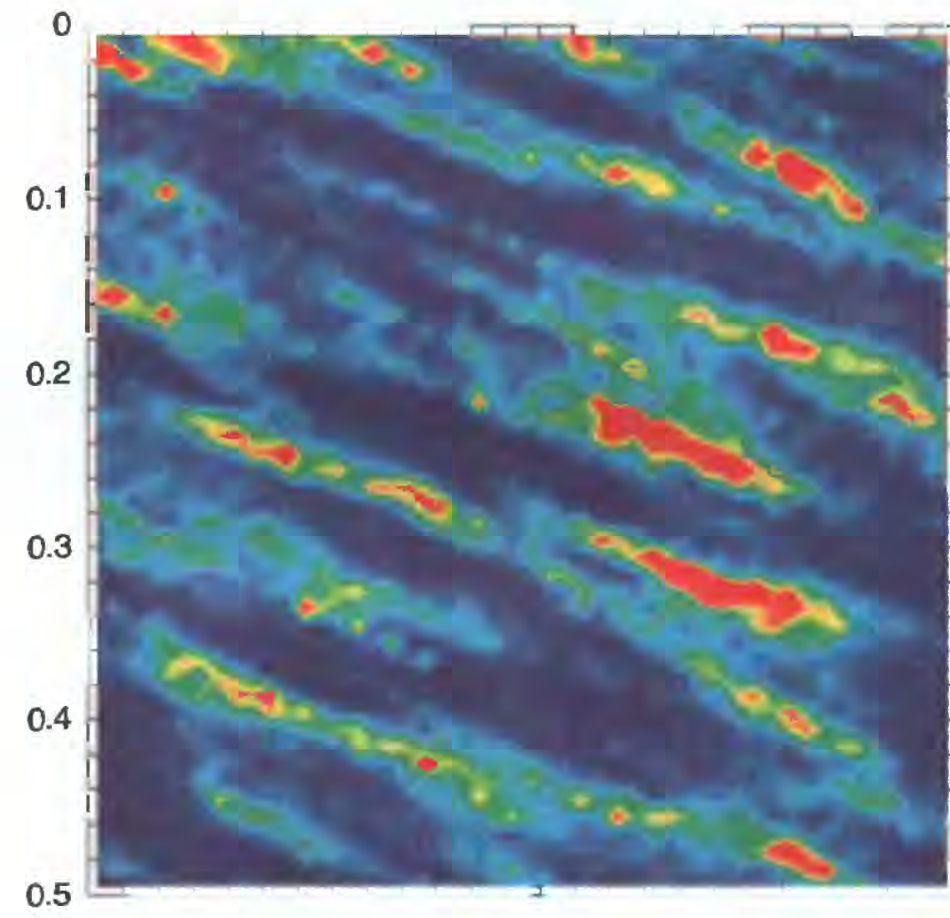

APERTURE,

IN MICROMETERS

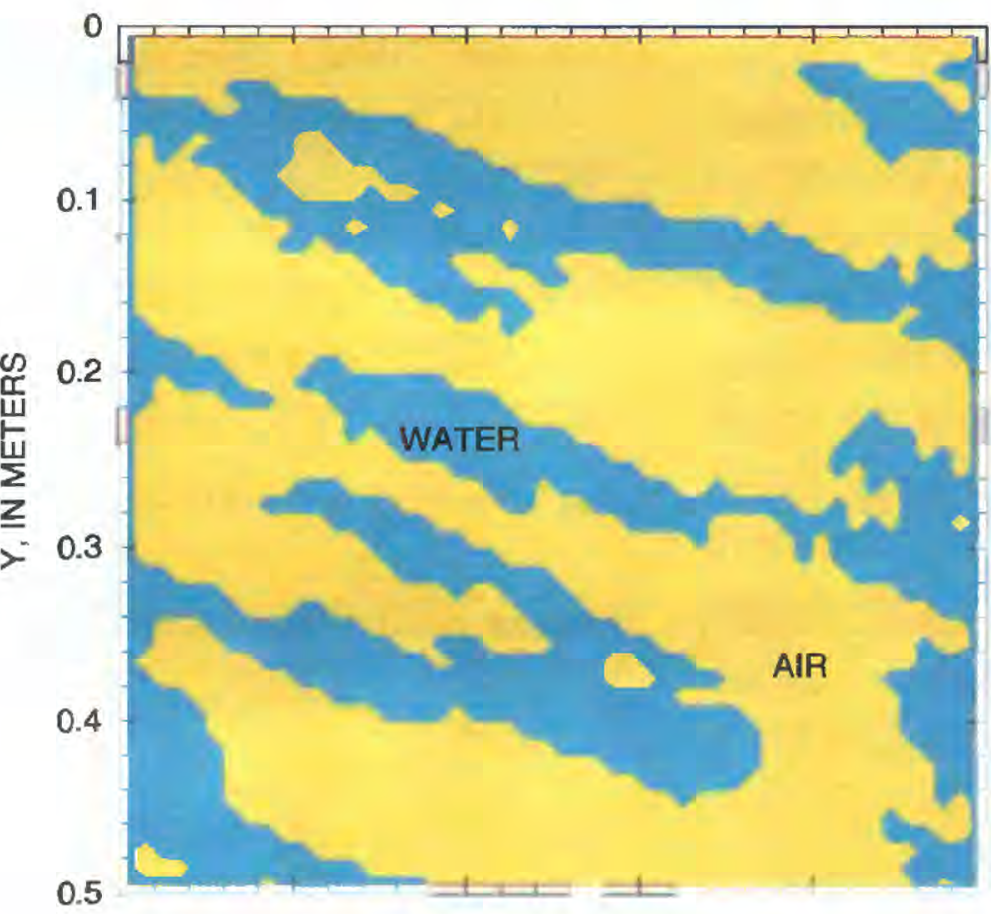

(B)

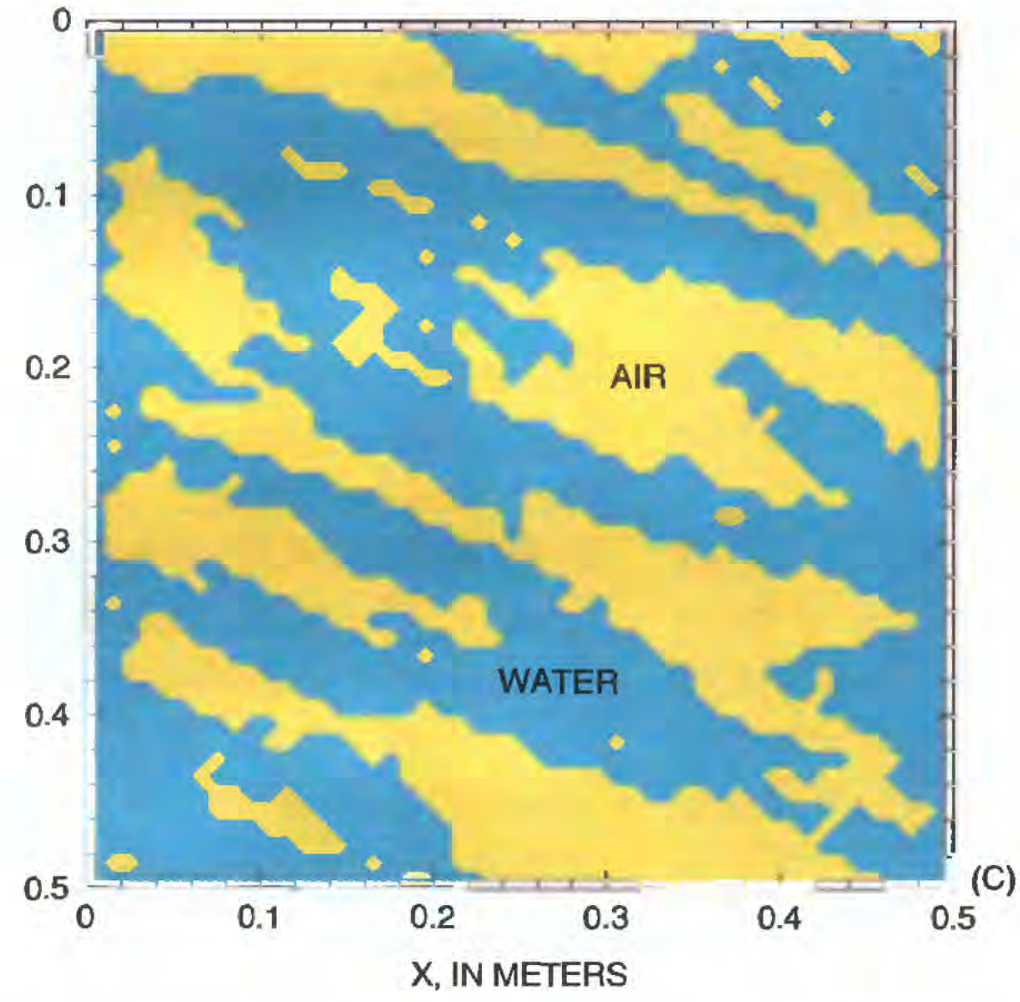

Figure 20. Aperture and phase distributions within the fracture characterized by the relations shown in figure 19: (A) aperture distribution; $(B)$ water and air distribution at a matric potential of -0.25 meter; and $(C)$ water and air distribution at a matric potential of -0.15 meter. 

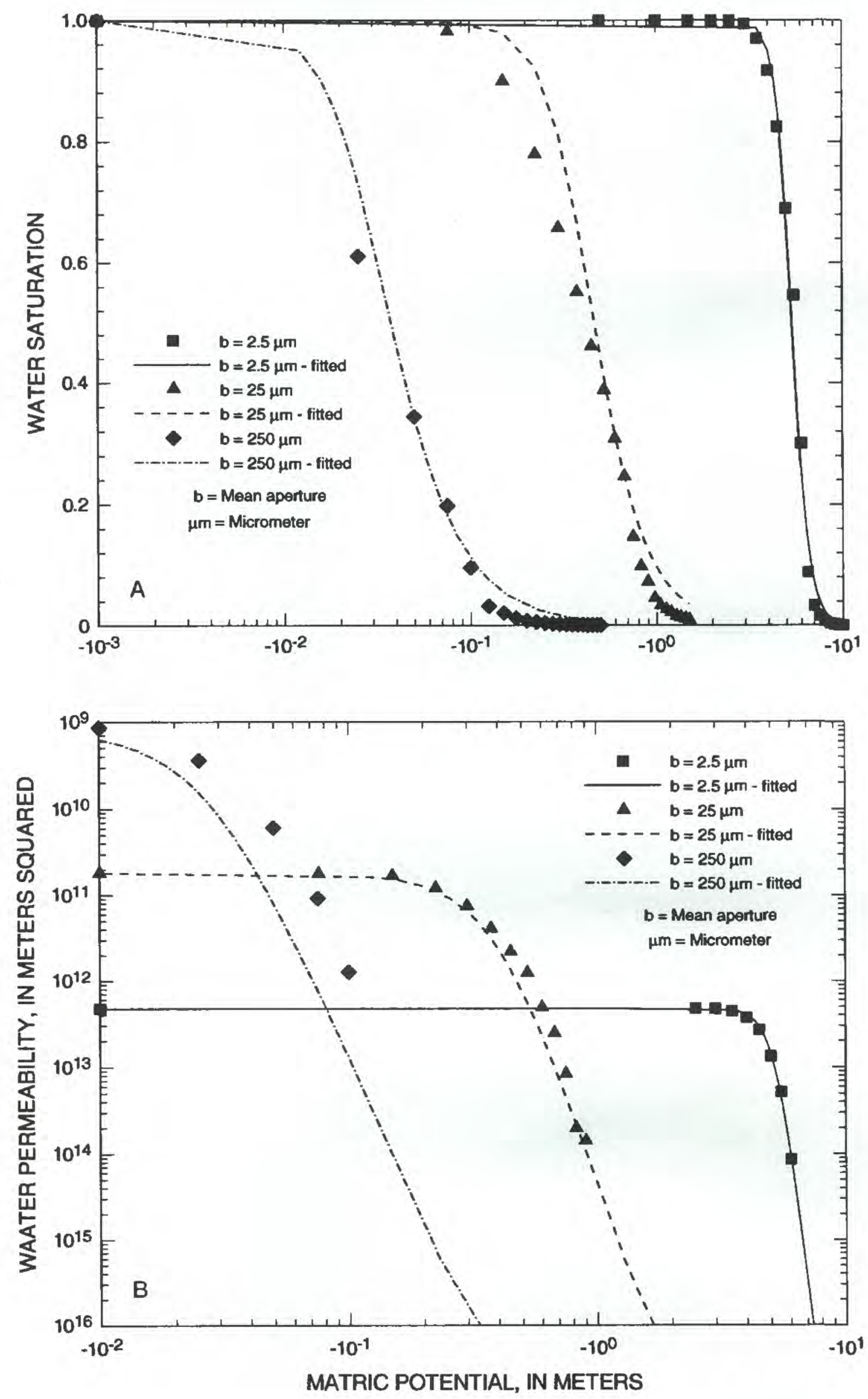

Figure 21. Fit of the van Genuchten function to estimates of fracture properties calculated by the aperture-scale numerical model VSFRAC: (A) saturation as a function of matric potential; and (B) water permeability as a function of matric potential. 
Table 6. Macroscopic hydrologic characteristics of hypothetical fractures considered by simulations in this report $\left[b_{m}\right.$, mean physical aperture; $\mu \mathrm{m}$, micrometer; $b_{h}$, mean hydraulic or pneumatic aperture; $k$, permeability; $\mathrm{m}^{2}$, square meter; $\alpha$, van Genuchten parameter related to the characteristic pore size; $m$, meter; $\mathbf{n}$, van Genuchten parameter related to dispersion of pore sizes; $m$, van Genuchten parameter $(m=1-1 / n)$; $\mathrm{S}_{\mathrm{lr}}$ residual water saturation; $\mathrm{S}_{\mathrm{gr}}$ residual air saturation; $\mathrm{r}^{2}$, goodness-of-fit; JRC, Joint Roughness Coefficient]

\begin{tabular}{rrcccccccc}
\hline $\begin{array}{c}\mathbf{b}_{\mathbf{m}} \\
(\mu \mathrm{m})\end{array}$ & $\begin{array}{c}\mathbf{1}_{\mathbf{b}_{\mathbf{h}}} \\
(\mu \mathrm{m})\end{array}$ & $\begin{array}{c}\mathbf{k} \\
\left(\mathbf{m}^{2}\right)\end{array}$ & $\begin{array}{c}{ }^{2} \boldsymbol{\alpha} \\
\left(\mathbf{m}^{-1}\right)\end{array}$ & ${ }^{\mathbf{3}_{\mathbf{n}}}$ & $\boldsymbol{m}$ & $\mathbf{S}_{\mathbf{l r}}$ & $\mathbf{S}_{\mathbf{g r}}$ & $\mathbf{r}^{\mathbf{2}}$ & JAC \\
\hline 2.5 & 2.42 & $4.748 \times 10^{-13}$ & 0.1887 & 10.204 & 0.90200 & 0.00 & 0.65 & 0.997 & 1.5 \\
25.0 & 17.62 & $1.824 \times 10^{-11}$ & 2.4456 & 3.5714 & 0.71999 & 0.00 & 0.70 & 0.992 & 4.2 \\
125.0 & 73.19 & $2.614 \times 10^{-10}$ & 14.577 & 2.9169 & 0.65716 & 0.00 & 0.78 & 0.981 & 8.6 \\
250.0 & 137.25 & $8.618 \times 10^{-10}$ & 33.723 & 2.7837 & 0.64076 & 0.00 & 0.65 & 0.962 & 11.6 \\
\hline
\end{tabular}

Regression equations developed from values in table 6 :

${ }^{1} b_{h}=0.5575 \times b_{m}\left(r^{2}=0.999\right)$.

${ }^{2} \alpha=0.1 \times b_{m}+1.35 \times 10^{-4} \times b_{m}{ }^{2}\left(r^{2}=1.000\right)$.

${ }^{3} n=2.7662+18.608 / b_{m}\left(r^{2}=1.000\right)$.

that cooling fractures have measured JRC values that range from 1 to 4 , with the mode at $\mathrm{JRC}=2$, and those of later tectonic fractures range from 3 to 18 , with the mode at JRC $=10$. JRC values were calculated for the hypothetical fractures in order to determine if their assumed roughness characteristics are consistent with what has been observed for fractures at Yucca Mountain, and whether their roughness characteristics were consistent with either a cooling or tectonic origin. The JRC values listed in table 6 are consistent with the rather broad range of values provided by field observations. It should be noted, however, that different surface roughnesses are implied for each of the fractures considered in table 6 , indicating that distinctly different types of fractures have been implicitly assumed.

\section{NUMERICAL SIMULATIONS}

\section{Simulation Approach}

As stated earlier, one principal purpose of this study is to investigate whether currently used concepts and models can explain the results of this block experiment or, if not, suggest what modifications may be required to these concepts or models. Because there are several aspects to this experiment, the overall model will be developed in stages. In the first stage, the imbibition tests described under "Rock Matrix" will be modeled to eliminate properties of the rock matrix as a significant source of uncertainty in the analysis of the block experiment. Next, the air-injection tests will be simulated in order to obtain estimates of transmissivity and aperture for fractures in the block. In the third stage, sand/rock-fracture interactions will be investigated in a geometrically simplified fracture system. The redistribution of water from the upper sand layer to the block following application of slugs of water will be examined in this stage. In the fourth and final stage, steady water movement through the fracture network of the block will be simulated in an attempt to reproduce the observed dependence of flow rates on matric potential along the upper boundary.

The numerical simulations were done with several different simulation codes. Numerical models of the imbibition experiments and of the water redistribution period of the block experiment were created with TOUGH2 (Pruess, 1991). TOUGH2 simulates the simultaneous transport of liquid, gas, and heat using the integrated finite-difference formulation of the equations governing those processes. Newton-Raphson linearization of the nonlinear governing equations for liquid and gas transport results in second-order convergence properties and numerical stability. Water is transported both as liquid and as vapor in the gas phase; air is transported both as a gas and as a dissolved component in the liquid phase. Dissolution of air in water is governed by Henry's law, and the water-vapor fraction of the gas phase is calculated from the steam tables based on the ambient temperature. Heat is transported by conduction and fluid advection, with latent heat being released or taken up during phase changes. Although the heat transport capability was not essential for the problems addressed in this report, the multiphase capability was deemed necessary to capture the effects of entrapped air in a newly saturated rock matrix. 
The air-injection tests were modeled with a version of MAFIC which simulates gas flow. The gas-flow version of MAFIC (Miller, 1992) is derived from an earlier version of MAFIC (Miller and others, 1994), which simulates the transport of water and tracer in water-saturated systems. The gas-flow version of MAFIC accounts for the large compressibility of gas through a pressure-squared linearization of the governing flow equation. Both versions of MAFIC use the finite-element method to discretize the flow domain. The advantage of these codes is that they are part of a package of codes that include FRACMAN (Dershowitz and others, 1994). FRACMAN can be used to create a fracture network either deterministically or on the basis of its statistical properties, and later, to generate a computation mesh and assign boundary conditions (including borehole sources and sinks) for MAFIC, which performs the flow and transport simulations. EDMESH (Lee and others, 1994) can be used to modify the computational mesh to provide additional refinement in areas of the model where it is needed, to remove deadend fractures, or to assign roughness characteristics to individual fractures.

The through-flow phase of the block experiment was modeled with the water-flow version of MAFIC (Miller and others, 1994). Although MAFIC (Miller and others, 1994) is a single-phase water-saturated flow simulator, unsaturated flow behavior for a series of steady-state simulations was approximated by adjusting user-prescribed transmissivities of the block fractures to reflect the reductions in transmissivity that accompany desaturation.

\section{Imbibition Tests}

As shown in table 3 , the cores used in the imbibition tests had diameters of either 2.52 or $4.14 \mathrm{~cm}$, and were of various lengths ranging from 2.25 to $7.10 \mathrm{~cm}$. Because the pore volume of the individual cores depends directly on the core lengths, the times required for the cores to fill to their maximum saturation values also increases with core length, assuming these maximum values, as well as other rock properties, are invariable. In fact, regression analysis indicated that for both series of imbibition tests shown in figure 11 , there was a weak $\left(r^{2}=0.25\right.$ to 0.30$)$ inverse relation between maximum saturation and core length. Therefore, to be able to directly compare the imbibition results for differentsized cores, the normalized cumulative volumes of water imbibed $\left(\mathrm{Q} / \mathrm{Q}_{\infty}\right)$ were plotted against the square root of normalized time $\tau$ (Zimmerman and others, $1990) . Q_{\infty}$ is the water volume that can ultimately be imbibed by the rock, given infinite time, and $\tau$ is a function of the intrinsic and unsaturated hydrologic properties of the rock, the ratio of the volume to wetted surface area of the rock, and time:

$$
\tau=2(\mathrm{n}+1) \mathrm{k}\left(\mathrm{S}_{\mathrm{ls}}-\mathrm{S}_{\mathrm{li}}\right)^{-\mathrm{m}} \mathrm{t} / \alpha \mathrm{n} \mu \phi\left[\mathrm{m}\left(\mathrm{S}_{\mathrm{ls}}-\mathrm{S}_{\mathrm{lr}}\right)\right]^{1 / \mathrm{n}}(\mathrm{V} / \mathrm{A})^{2}(8)
$$

$S_{1 i}$ is the initial saturation of the rock, $V$ is the rock volume, $A$ is the area across which imbibition occurs, and $\mu$ is the water viscosity, and other terms have been previously defined. Equation 8 requires that $\alpha$ has units of $\mathrm{Pa}^{-1}$. Zimmerman and others (1990) showed that when values of $Q / Q_{\infty}$ are plotted against $\tau^{0.5}$, the resulting curves are insensitive to matrix block shape or size or initial saturation. The values of the parameters used to calculate $\tau$ are those derived from the fitted van Genuchten function, as given in the "Rock Matrix" section. The resulting normalized water-uptake curves are described below.

To investigate whether observed differences in both the rates of imbibition and in maximum volumes imbibed could be explained simply by different entrapped air contents behind the wetting front, a series of numerical experiments that simulated imbibition into a 5.0-cm-tall core was performed with TOUGH2 (Pruess, 1991). In these simulations, $S_{1 s}$ ranged between 0.95 and 0.6 , and $\alpha$ varied from $\alpha_{d}$ to $\alpha_{\mathrm{w}}=2 \alpha_{\mathrm{d}}$. To enable direct comparison with the experimental data, the numerical results were expressed as normalized cumulative imbibition $\mathrm{Q} / \mathrm{Q}_{\infty}$ versus the square root of normalized time, $\tau^{0.5}$, based on the same parameter values used to normalize the experimental results. Figure 22 (A and B) show that both the maximum value of $Q / Q_{\infty}$ and the normalized sorptivity (the slope of the straight line portion of each curve) decrease with decreasing values of $S_{1 s}$. The normalized sorptivity decreases because, although the fillable porosity decreases, the rate of decrease in effective permeability $\left(\mathrm{kk}_{\mathrm{rl}}\right)$ is even greater. The maximum value of $\mathrm{kk}_{\mathrm{rl}}$ for each case is limited by the value of $\mathrm{k}_{\mathrm{rl}}$ at the corresponding value of $\mathrm{S}_{\mathrm{ls}}$, as described under "Rock Matrix." This is consistent with experimental results in soils (Constantz and others, 1988), where it has been shown that the existence of small amounts of entrapped air behind the leading edge of a wetting front can decrease infiltration rates by an order of magnitude or more. The use of $\alpha_{w}=2 \alpha_{d}$ resulted in decreases in the slopes of the straight-line portions of the curves when 
compared with the curves generated with $\alpha_{d}$ (compare $A$ and $B$ in fig. 22). This result occurred, in part, because initial conditions were specified as $\mathrm{S}_{\mathrm{li}}=0.01$, and the use of $\alpha_{w}$ resulted in the definition of initially smaller (by half) water potential gradients.

The normalized experimental data (fractured cores $\mathrm{S} 3$ and 14A omitted) were grouped on the basis of whether their early time behavior resembled the $S_{1 s}=0.90,0.80,0.70$ or 0.60 curves generated by TOUGH2. It was found that the early, straight-line portion of the experimental results generally followed the trajectory of the $S_{l s}=0.70$ or $S_{l s}=0.80$ curves generated by TOUGH2, although later time portions of the experimental data generally exhibited increasingly significant departures from these curves. Sample cores S2, S4, S5, S6, S7B and S10 had early time behavior similar to that followed by the $S_{1 s}=0.70$ curve (fig. 23A), whereas early time results for sample cores S1, S7A, S8, S9, S14B and S15A followed the $S_{1 s}=0.80$ curve (fig. 23B). Generally, the simulated curves generated using $S_{1 s}=0.70$ or 0.80 , and $\alpha_{d}$ to $\alpha_{w}=2 \alpha_{d}$ bounded the experimental results at early time but overestimated $\mathrm{Q} / \mathrm{Q}_{\infty}$ at later times. Exceptions to this generalization are the results for cores $\mathrm{S} 1$ and $\mathrm{S} 15 \mathrm{~A}$, which at late time continued to fill to values for $\mathrm{Q} / \mathrm{Q}_{\infty}$ of 0.85 to 0.90 . Because of their relatively short lengths, the maximum normalized time values for these cores are among the largest calculated. Interestingly, all cores in figure $23 \mathrm{~A}$ except $\mathrm{S} 10$ were oriented with their axes perpendicular to the compaction foliation, whereas in three of the cores (S8, S9, and S14B) in figure 23B, the compaction foliation was parallel to the core axis.

Several observations can be made about the variability observed in the imbibition tests. The first is that, although values of $S_{1 s}$ inferred from figure 11 ranged from 0.39 to 0.90 , figure $23 \mathrm{~A}$ and $23 \mathrm{~B}$ suggest that once differences in core lengths are considered, the actual range in the $S_{1 \mathrm{~s}}$ values is much narrower, perhaps 0.70 to 0.80 . The initial agreement between the data and simulation results at early time and divergence of results over a wide range of $\mathrm{Q} / \mathrm{Q}_{\infty}$ values indicates heterogeneities are encountered at different, perhaps random, stages in the filling process. Visual inspection of the core indicates that pumice fragments, which are aligned with their long axis parallel to the compaction foliation, might be responsible for the seemingly random departures from the numerical results, which were calculated assuming a homogeneous matrix. Pumice is generally thought to have substantial, but poorly connected pore space, which might explain the behavior of samples such as S1 and S15A, which followed the $S_{l s}=0.80$ curve until late time, when they filled to larger $Q / Q_{\infty}$ values of 0.85 to 0.90 . Blockage of flow along the core axis by these randomly located pumice fragments would help explain the erratic response of the cores when imbibition occurred through the core ends, and the much more uniform response of the same cores when submerged in water. The potential for obstruction of flow by pumice fragments is greater when flow is limited to a single direction (that is, along the core axis) and in cores with narrower diameter. Pumice fragments up to $20 \mathrm{~mm}$ in length were noted (core S4), but thickness of these fragments was $5 \mathrm{~mm}$ or less. Therefore, because the cross-sectional area of these fragments is greatest when the cores are aligned perpendicular to the compaction foliation, blockage of flow by pumice fragments may be more severe when cores are oriented in that way. Of the six cores that showed early time similarity to the modeled $S_{1 s}=0.70$ curve but departures from it at relatively small values of $\mathrm{Q} / \mathrm{Q}_{\infty}$ (fig. 23A), five were oriented perpendicular to the compaction foliation. Of the six cores which showed early time similarity to the modeled $\mathrm{S}_{\mathrm{ls}}=0.80$ curve (fig. $23 \mathrm{~B}$ ), three cores (S8, S9, and S14B) were oriented parallel to the compaction foliation. Although core S15A, which coincided with the $S_{1 s}=0.8$ curve at early time, was oriented perpendicular to the compaction foliation, its relatively large diameter $(4.14 \mathrm{~cm})$ may have made it less susceptible to blockage by pumice fragments than the smaller diameter $(2.52 \mathrm{~cm})$ cores. The evidence is therefore suggestive, although not conclusive, that core alignment with respect to compaction foliation, principally through its control of pumice fragment orientation, is affecting rates of water uptake by the cores.

To bound the possible effects of pumice fragments, numerical simulations were run with a single 6-mm-thick, low permeability ( 0.01 times that of the rock matrix) layer assumed to be located at various heights in the 5-cm-tall core. The resulting normalized imbibition curves (fig. 24) show that the location of these layers determines the $\mathrm{Q} / \mathrm{Q}_{\infty}$ values at which these simulation results diverge from those generated when uniform properties are assumed for the core: fragments located in the lower part of the core result in divergence at smaller $\mathrm{Q} / \mathrm{Q}_{\infty}$ values, whereas fragments located higher in the core result in divergence at larger $Q / Q_{\infty}$ values. The numerical results are bounding calculations in the sense that none of the actual cores is com- 

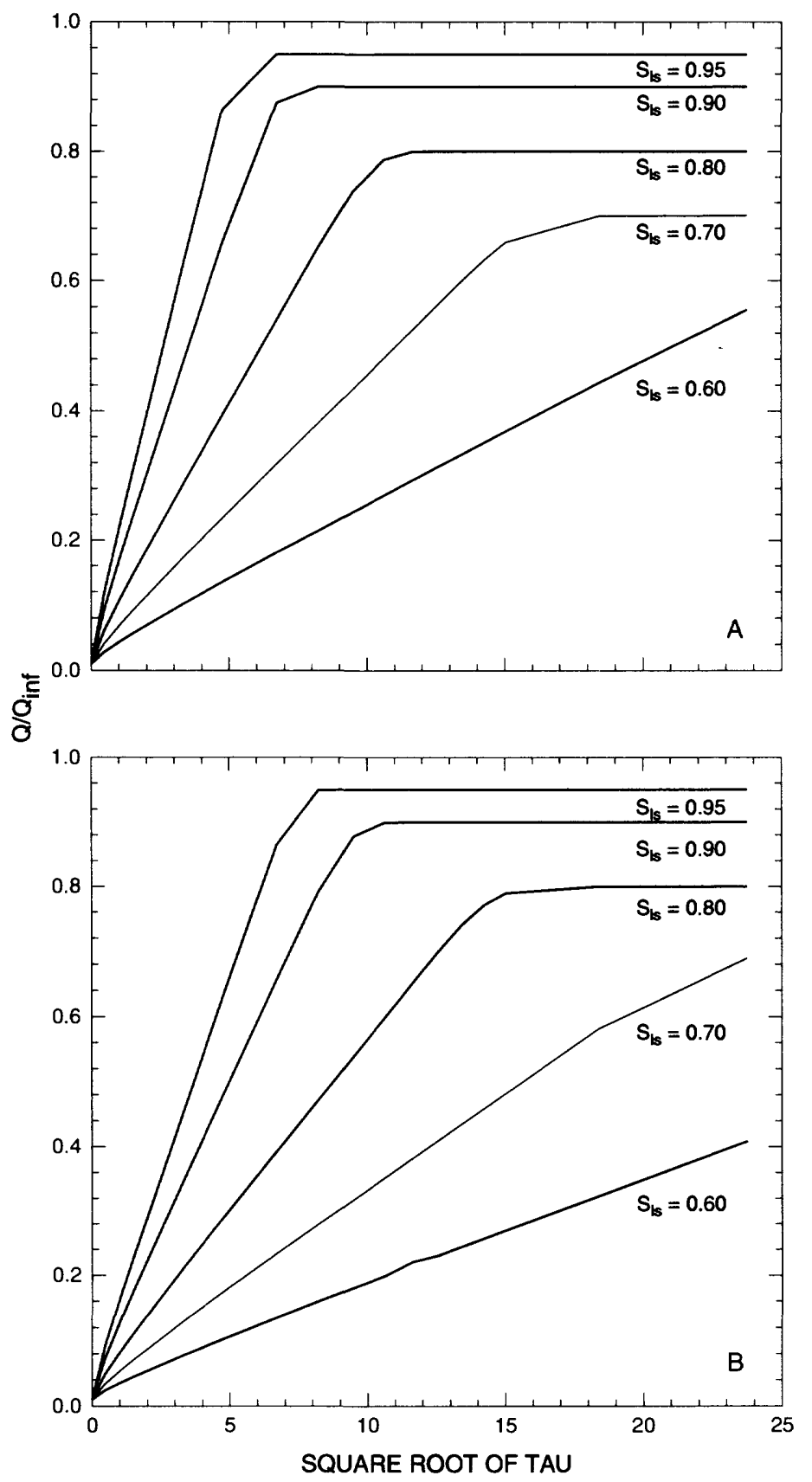

Figure 22. Normalized cumulative imbibition versus normalized time curves calculated using TOUGH2 for various values of $S_{1 s}$ assuming: (A) $\alpha=\alpha_{d}$; and (B) $\alpha=\alpha_{w}=2 \alpha_{d}$. 

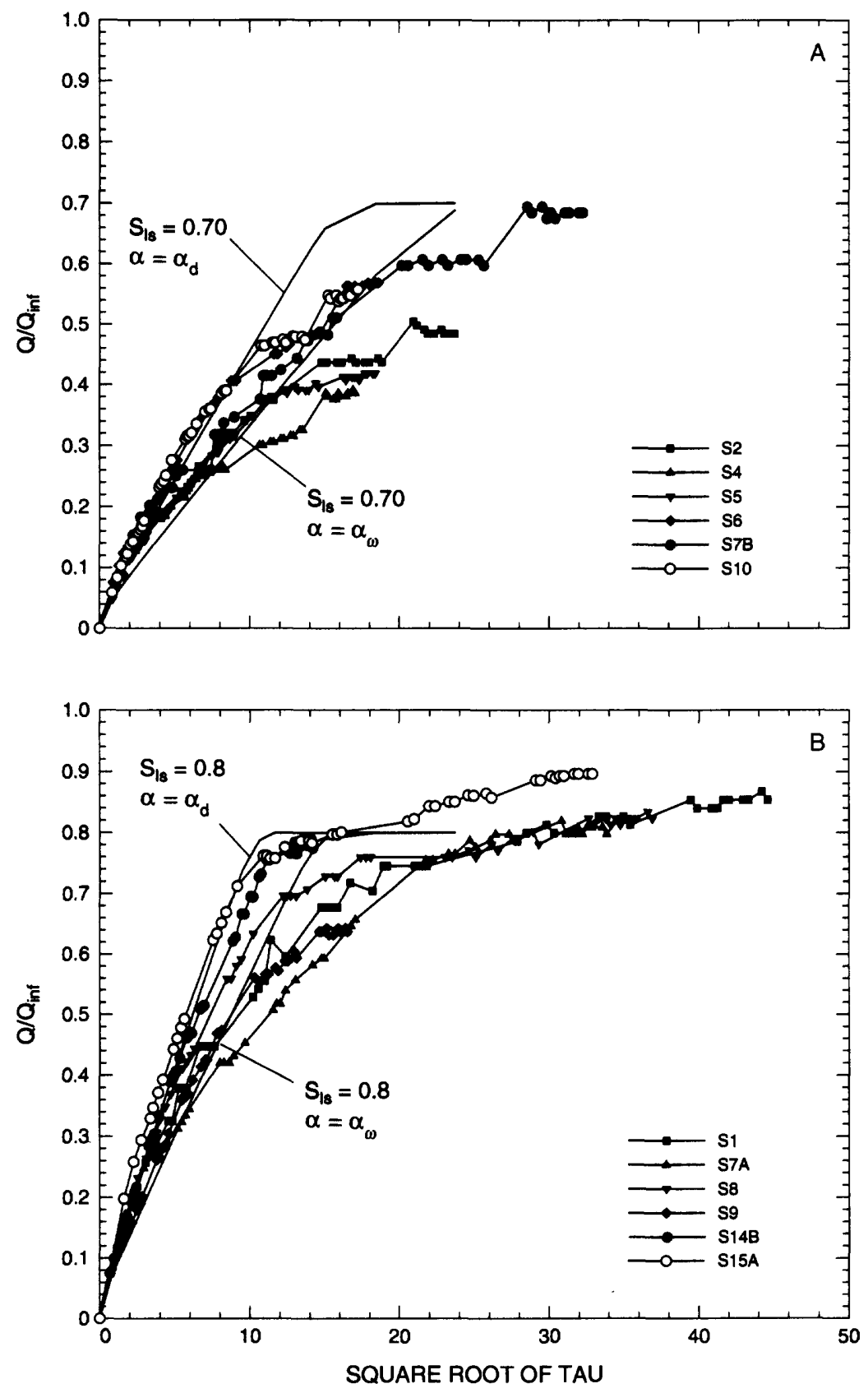

Figure 23. Normalized cumulative imbibition versus normalized time data for unfractured cores grouped on the basis of the similarity to early time results calculated by TOUGH2: (A) $S_{\mid \mathrm{s}}=0.70$; and (B) $S_{\mid \mathrm{s}}=0.80$. 
pletely bridged by a pumice fragment: at any distance along the core axes, only a fraction of the flow field is obstructed by pumice. However, because the true flow fields are partially obstructed at many locations by pumice fragments, departures from the uniform matrix case are generally smoother and more gradual than indicated by the curves shown in figure 24 .

The normalized imbibition curves for the fractured cores are shown in figure 25 . Core $S 3$ has a fracture parallel to its axis, whereas core S14A is bisected by an induced fracture perpendicular to its axis. The slope of the straight-line portion of the curve of sample S3 is greater than that observed for any other core, indicating that the fracture running along its length has enhanced its sorptivity. Water is pulled by capillarity into the fracture and enters the rock matrix through the walls enclosing the fracture, as well as through the bottom face. The normalized imbibition curve for S14A coincides with the numerically generated imbibition curve for $S_{I s}=0.80$ at early time, but because the fracture transverse to the core axis behaves as a capillary barrier, its response is very similar to that predicted for the case of a low permeability pumice fragment midway along the core (fig. 25). The effectiveness of the fracture as a barrier to flow is dependent on its saturation and water potential, however. At late time, the experimental data for S14A suggest that imbibition continues at an enhanced rate once these capillary barrier effects are overcome by raising the saturation of the fracture.

In summary, the experimental data and model calculations suggest that the measured matrix properties are reasonable for calculating water uptake during the block experiment, as long as permeability reductions resulting from the presence of entrapped air are considered. In general, this entrapped gas limits water saturation during wetting to approximately 0.70 to 0.80 . For a given value of $S_{I s}$, the use of $\alpha=\alpha_{d}$ to $2 \alpha_{d}$ resulted in simulated imbibition curves that effectively bounded the early time experimental data. Later time departures of the experimental data from simulated curves that were generated under the assumption of uniform matrix properties were attributed to the presence of pumice fragments. In small diameter cores.

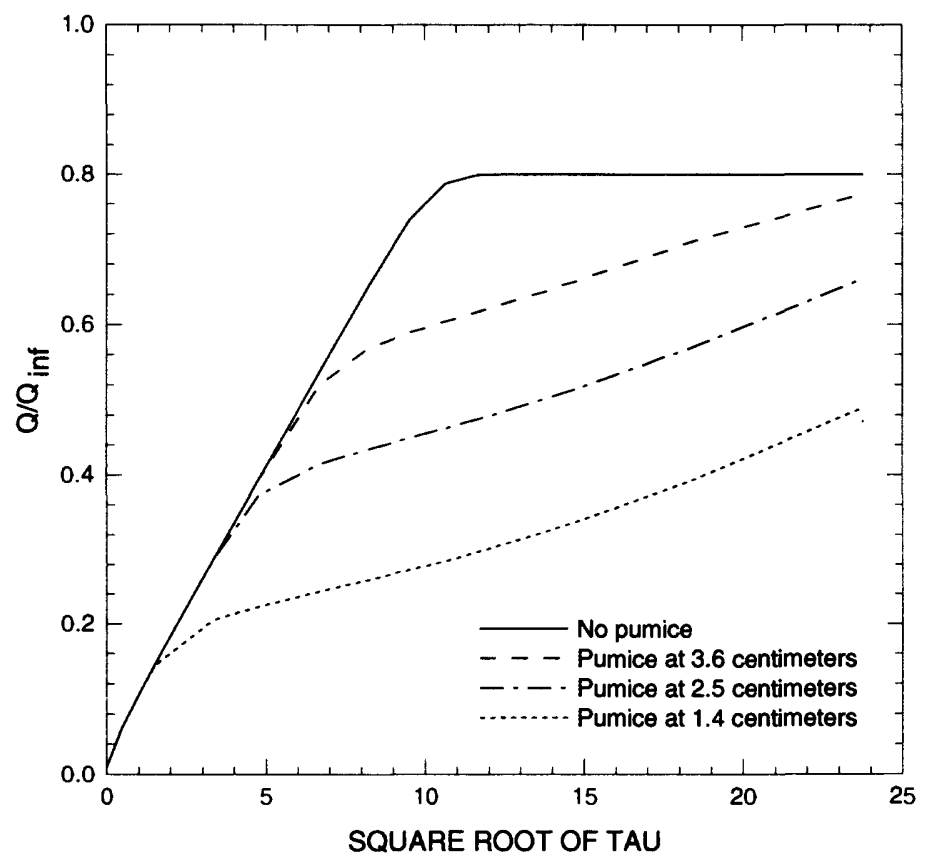

Figure 24. Normalized cumulative imbibition versus normalized time curves calculated using TOUGH2 for $S_{\mid s}=0.80$ and assuming low permeability pumice fragments located at various distances from the bottom of the core. 


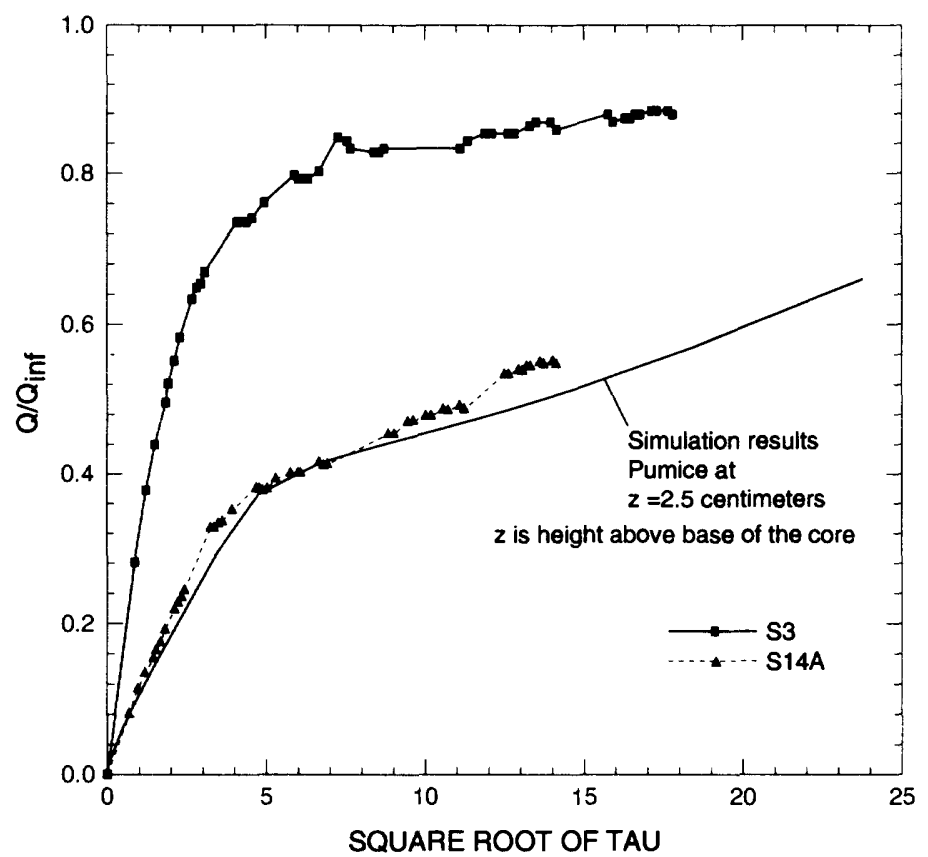

Figure 25. Normalized cumulative imbibition versus normalized time data of cores containing a fracture either parallel to (S3) or transverse to (S14A) the core axis.

$(2.52 \mathrm{~cm})$, these pumice fragments can obstruct a significant fraction of the cross-sectional area available for flow. However, their small size makes their probable effects on water movement in the block experiment negligible.

\section{Air-Injection Tests}

A subset of the air-injection tests listed in table 2 was used to determine properties of the fracture network. First, the overall geometry of the fracture network within the block was recreated with FRACMAN (Dershowitz and others, 1994) by adjusting the fracture locations and orientations until the simulated fracture traces matched those observed on the cut faces of the block (fig. 1). The actual calibration of the fracture transmissivities was done using a gas-flow version of the MAFIC flow and transport simulator for discrete fracture networks (Miller, 1992). The use of a numerical model rather than an analytical solution permits the possible influences of fracture heterogeneity, nonsymmetric or irregular boundaries, and the effects of intersecting fractures to be considered explicitly (see, for example, Smith and others, 1987).

Calibration of the fracture transmissivities $(\mathrm{T})$ required the use of data from only a subset of the air- injection tests listed in table 2 . That subset of tests was chosen to provide the most efficient means of gaining information about the pneumatic connections between boreholes while eliminating redundancy in information. Each air-injection test selected for analysis consisted of several constant flow-rate periods with steadystate pressures, separated by periods during which pressures were adjusting (fig. $2 \mathrm{~A}$ and B). For simplicity, however, analyses were done using only the steadystate pressures and flow rates recorded during the highest flow-rate period of each test. Steady-state pressure equilibrium for each constant flow-rate period of each air-injection test was generally rapidly achieved, except in matrix boreholes and relatively tight fractures. The high flow-rate periods of the tests created the strongest signals at the monitoring boreholes. These relatively strong cross-hole responses reduced the significance of small measurement errors and the impacts of barometric pressure changes that occurred during the course of the test.

In calibrating the properties of the fracture network, it was assumed that the pressure buildup at the injection borehole for a particular flow rate depended primarily on the local fracture transmissivity and aperture around the borehole, and only secondarily on the pneumatic properties of intersecting fractures. The cal- 
ibration strategy involved using injection data to determine local fracture transmissivities near each of the injection boreholes and iteratively cycling through the test simulations until updated estimates of fracture transmissivities of intersecting fractures no longer changed estimates of the local transmissivity of the fracture penetrated by the injection borehole. For each test in an iteration, the transmissivity values were prescribed and the pressure at the injection boreholes adjusted until the model reproduced the measured flow rates. All local transmissivity estimates were updated simultaneously at the end of each iteration on the basis of discrepancy between the measured and simulated pressures at the adjacent injection borehole. For those fractures that were intersected by more than one injection borehole (F1, F5), estimates of local transmissivities were assigned to the computational elements immediately adjacent to the injection boreholes, and the geometric mean transmissivity of the fracture was assigned to computational elements elsewhere throughout the fracture. For fractures intersected by only one injection borehole, the local transmissivity value was assigned to the entire fracture.

Table 7 lists the injection borehole, the fracture penetrated by the injection borehole, the test identification number, the final transmissivity estimates, the ratio between the simulated and observed injection borehole pressures for the final iteration, the estimated changes in transmissivity values (listed as a percent of the final values) necessary to resolve the remaining discrepancies between the observed and simulated injection borehole pressures, and the equivalent pneumatic (flow) apertures calculated from the transmissivities using the cubic law. The changes in fracture transmissivities estimated as necessary to resolve the remaining discrepancies between the observed and simulated injection borehole pressures were in all cases less than 5 percent, and in 5 of 8 cases less than 1 percent. These small values indicated that little would be gained by attempting to resolve the remaining discrepancies between the observed and simulated borehole pressures. Equivalent pneumatic apertures of 38.8, 53.1, and $49.5 \mu \mathrm{m}$ were calculated using the cubic law for fracture F1 at boreholes 1C, 1D, and 3A, respectively. Equivalent apertures for F5 of 26.8 and $25.9 \mu \mathrm{m}$ were estimated based on tests at boreholes $2 \mathrm{C}$ and $4 \mathrm{E}$. Other equivalent apertures calculated were $14.5 \mu \mathrm{m}$ for fracture F6, $20.2 \mu \mathrm{m}$ for fracture F2, and $59.1 \mu \mathrm{m}$ for fracture F3.
Figures 26 through 33 show the calculated pressure distributions for each of the eight injection tests listed in table 7 along with the finite element mesh containing 467 nodes and 820 elements used by MAFIC (Miller, 1992) for this set of simulations. For a given test, large pressure increases are generally restricted to the fractures intersected by the injection boreholes. Predicted pressure changes at the monitoring boreholes were less than a few tens of kilopascals and, except where the monitoring boreholes were located in the same fracture as the injection borehole, usually no more than several kilopascals. The subdued response at the monitoring holes, which was also reflected in the actual data, can be attributed to the proximity of the constant pressure boundary along the block surface. Much of the injected air moves toward the nearest side of the block because pressure gradients are largest in that direction. Under such conditions, there is less flowing air available to stress the fracture system, and the pressure responses at the monitoring boreholes are correspondingly weak. Although, for most injection tests, detectable pressure changes were simulated to occur at most of the monitoring boreholes, the proximity of the boundaries makes those changes relatively small and therefore more difficult to replicate accurately.

Table 2 indicates that the eight tests listed in table 7 do not capture all of the measured cross-hole responses and that additional combinations of injection/monitoring boreholes may be used to help evaluate the limitations of the model calibration. These additional cross-hole responses occurred in conjunction with tests in which borehole $3 \mathrm{~A}$ functioned as the injection borehole (injection/monitoring borehole combinations 3A-1C, 3A-1D, 3A-1E, 3A-1F, 3A-2A, and 3A$4 B)$. For these tests, the average response at the monitoring borehole was also calculated and compared with the simulated response. Figure 34 ( $\mathrm{A}$ and $\mathrm{B}$ ) shows the composite scatterplot between observed and simulated pressures for the eight injection tests listed in table 7 and the monitoring borehole data composited from other tests in table 2. Observed pressures above $110 \mathrm{kPa}$ indicate that a particular borehole was functioning as the injection borehole in that particular test. The proximity of the larger pressure values to the oneto-one line is not surprising given that, during model calibration, transmissivities were adjusted to replicate injection borehole pressures. Therefore, most of the model error is associated with gas pressures predicted at the monitoring boreholes (fig. 34B). Table $8 \mathrm{com}-$ 
Table 7. Summary of fracture properties based on calibration using air-permeability tests $\left[\mathrm{m}^{2} / \mathrm{s}\right.$, meter squared per second; $P_{\text {sim }}$, simulated pressure; $P_{\text {obs}}$, observed pressure; $T$, transmissivity; $\mu \mathrm{m}$, micrometer]

\begin{tabular}{ccccccc}
\hline $\begin{array}{c}\text { Injection } \\
\text { borehole }\end{array}$ & $\begin{array}{c}\text { Fracture } \\
\text { intersected }\end{array}$ & $\begin{array}{c}\text { Test } \\
\text { identification } \\
\text { number }\end{array}$ & $\begin{array}{c}\text { Fracture } \\
\text { transmissivity } \\
\left(\mathbf{m}^{2} / 8\right)\end{array}$ & Pslm $^{\text {s }}$ obs & $\begin{array}{c}\text { Predicted percent- } \\
\text { age } \\
\text { change in T, } \\
\text { from current } \\
\text { iteration }\end{array}$ & $\begin{array}{c}\text { Equivalent } \\
\text { pneumatic } \\
\text { aperture } \\
(\mu \mathrm{m})\end{array}$ \\
\hline 1A & F6 & P26341K3 & $2.5169 \times 10^{-09}$ & 0.997 & -0.57 & 14.5 \\
1C & F1 & P26391K4 & $4.7861 \times 10^{-08}$ & 0.998 & -0.37 & 38.8 \\
1D & F1 & P26791K1 & $1.2226 \times 10^{-07}$ & 0.988 & -3.22 & 53.1 \\
2A & F2 & P26291K2 & $6.7564 \times 10^{-09}$ & 1.002 & +0.40 & 20.2 \\
2C & F5 & P26191K1 & $1.5825 \times 10^{-08}$ & 0.997 & -0.65 & 26.8 \\
3A & F1 & P35290K4 & $9.9417 \times 10^{-08}$ & 1.016 & +4.11 & 49.5 \\
4A & F3 & P26391K1 & $1.6906 \times 10^{-07}$ & 1.001 & +0.41 & 59.1 \\
4E & F5 & P26191K4 & $1.4148 \times 10^{-08}$ & 1.005 & +1.21 & 25.9 \\
\hline
\end{tabular}

Geometric means:

$\mathrm{T}_{\mathrm{FI}}=8.3479 \mathrm{E}-08 \mathrm{~m}^{2} \mathrm{~s}$, with a corresponding equivalent pneumatic aperture of $46.7 \mu \mathrm{m}$.

$\mathrm{T}_{\mathrm{F5}}=1.4963 \mathrm{E}-08 \mathrm{~m}^{2} \mathrm{~s}$, with a corresponding equivalent pneumatic aperture of $26.4 \mu \mathrm{m}$.

pares observed $\left(\mathrm{P}_{\text {obs }}\right)$ and simulated $\left(\mathrm{P}_{\text {sim }}\right)$ gas pressures and lists the relative error $\left(\left(\mathrm{P}_{\text {sim }}-\mathrm{P}_{\text {obs }}\right) / \mathrm{P}_{\text {obs }} \times 100\right)$ at the injection and monitoring boreholes in each of the eight tests listed in table 7 . The relative uncertainties associated with different fracture pathways are reflected in table 8 and in figures $34 \mathrm{C}-\mathrm{H}$, which group the results for different injection-monitoring borehole pairs on the basis of the fracture in which the monitoring borehole is located. With some exceptions, the simulated pressures at monitoring boreholes located in fractures $\mathrm{F} 1$ (fig. 34C), F2 (fig. 34D), F3 (fig. 34E) and F4 (fig. 34F) do a reasonably good job of matching the observed pressures. In contrast, the simulated pressures at monitoring boreholes located in fractures F5 (fig. 34G) and F6 (fig. 34H) provide only a poor to fair match to the observed borehole pressures. The simulated pressures all overpredict the observed pressures in F6 at borehole 1A (fig. 34H). Of the six largest relative errors listed in table 8, three (the $2 \mathrm{C}-1 \mathrm{~F}, 2 \mathrm{C}-4 \mathrm{E}$, and $4 \mathrm{E}$ $2 \mathrm{C}$ injection-monitoring borehole pairs) involve borehole $2 \mathrm{C}$ in fracture $5 \mathrm{~F}$. The remaining three (the $3 \mathrm{~A}-1 \mathrm{~A}$, $1 \mathrm{C}-3 \mathrm{~A}$, and $3 \mathrm{~A}-1 \mathrm{C}$ injection-monitoring borehole pairs) involve borehole $3 \mathrm{~A}$ in fracture $\mathrm{Fl}$.

Regression of observed versus simulated gas pressures $\left(P_{\text {obs }}=-2.631 \mathrm{kPa}+0.997 \mathrm{P}_{\text {sim }}\right)$ had an $\mathrm{r}^{2}$ value of 0.972 . However, because most of the observed variance was associated with the injection boreholes. used in the calibration, inclusion of these boreholes in the regression does not allow an accurate assessment of the model's predictive capability. Exclusion of the injection boreholes and the injection-monitoring borehole pairs with the six largest relative errors from the analy- sis resulted in a different regression equation $\left(\mathrm{P}_{\mathrm{obs}}=\right.$ $\left.18.88 \mathrm{kPa}+0.784 \mathrm{P}_{\text {sim }}\right)$ and reduced $\mathrm{r}^{2}$ value $(0.53)$.

Discrepancies between the observed and simulated pressures at the monitoring boreholes can be attributed to the inability to characterize and simulate heterogeneity between boreholes, and the proximity of the cut faces of the block which function as constant pressure boundaries. These nearby constant pressure boundaries result in extremely steep pressure gradients, which in some cases can make observed borehole gas pressures more difficult to replicate accurately. However, another source of uncertainty in the model was the transmissivities assumed for the fractures that did not contain an injection borehole, especially fractures F4 and F8 (fig. 1). The results presented thus far have assumed that F4 and F8 were relatively nontransmissive $\left(\mathrm{T}=10^{-9} \mathrm{~m}^{2} / \mathrm{s}\right)$ compared with the other fractures. This assumption was based solely on visual inspection of the traces of these fractures on the cut faces of the block. The sensitivity of the results to transmissivity values assumed for F4 and F8 was tested by assigning fractures F4 and F8 the same transmissivities as F3 and $F 2$, respectively, a choice of values made on the basis of similarity of fracture orientations. The cases in which boreholes $2 \mathrm{C}, 3 \mathrm{~A}$, and $4 \mathrm{E}$ functioned as the injection wells were simulated with these new transmissivity values. The results for these simulations were nearly identical to the results obtained with $\mathrm{T}=10^{-9} \mathrm{~m}^{2} / \mathrm{s}$. Therefore, discrepancies between the observed and simulated pressures at the monitoring boreholes do not appear to be related to assumptions about the transmissivities or fractures F4 and F8. 
Figure 26.

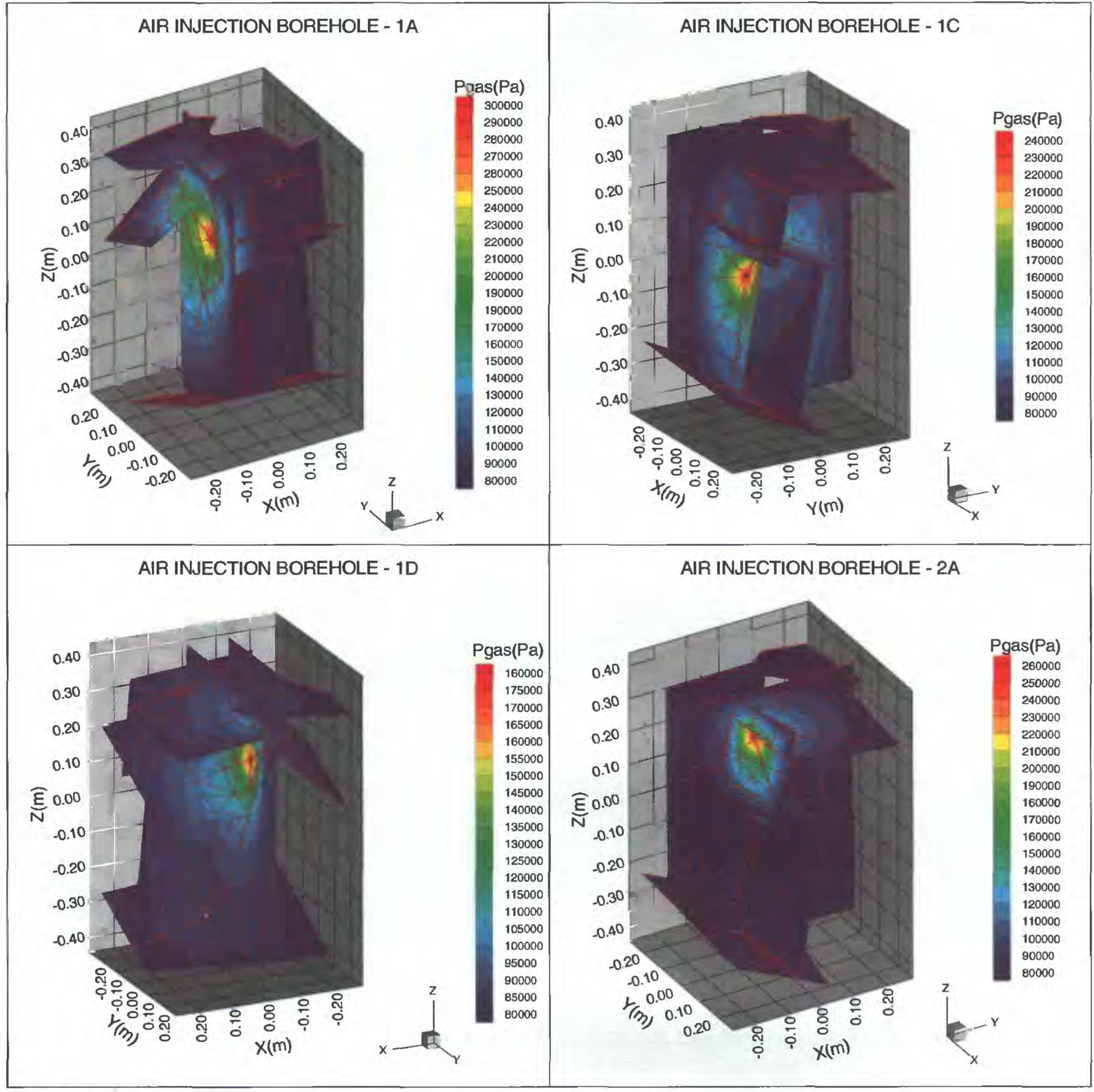

Figure 28.
Figure 27.

Figure 29.

Figures 26-29. Simulated steady-state gas-pressure distribution during injection into boreholes 1A, 1D, 1C, and 2A. 
Figure 30 .

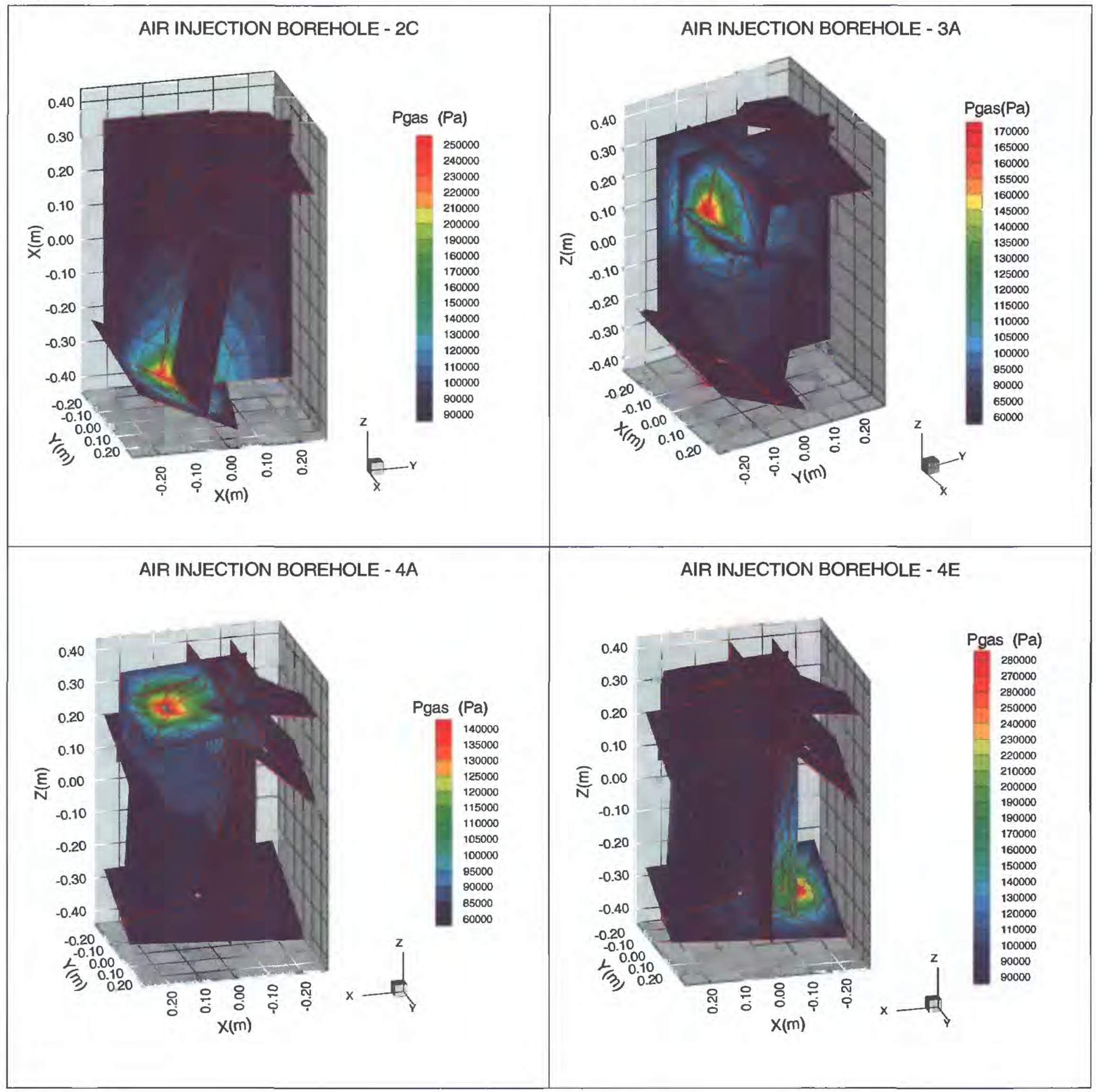

Figure 32.

Figure 33.

Figure 31 . 

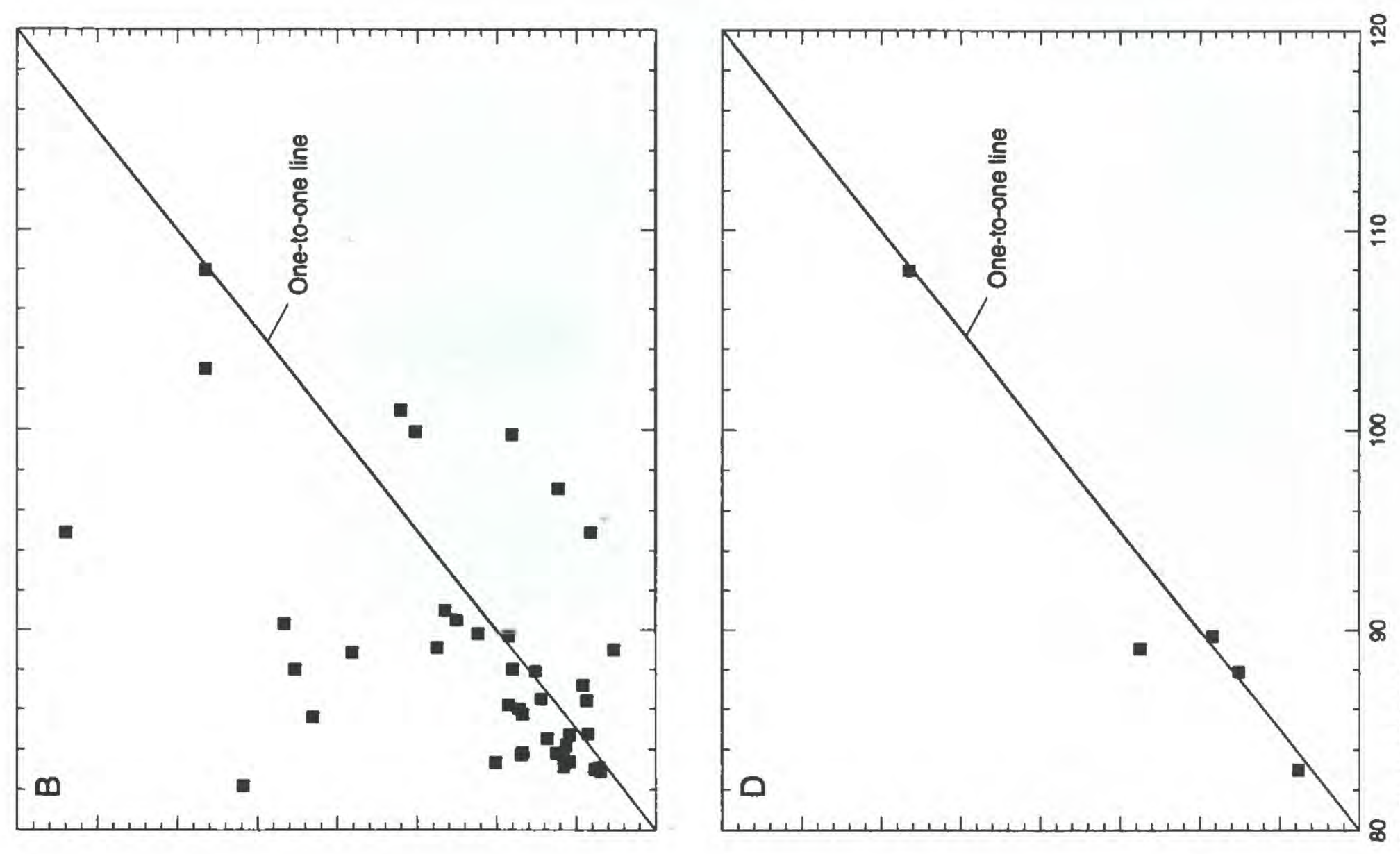

총

응

은

흗

을

可告

is

오 잉

들 뀸

ఫั

르드

을

문으

옹

일이

众동 일

응현

흔뜰등

㟧

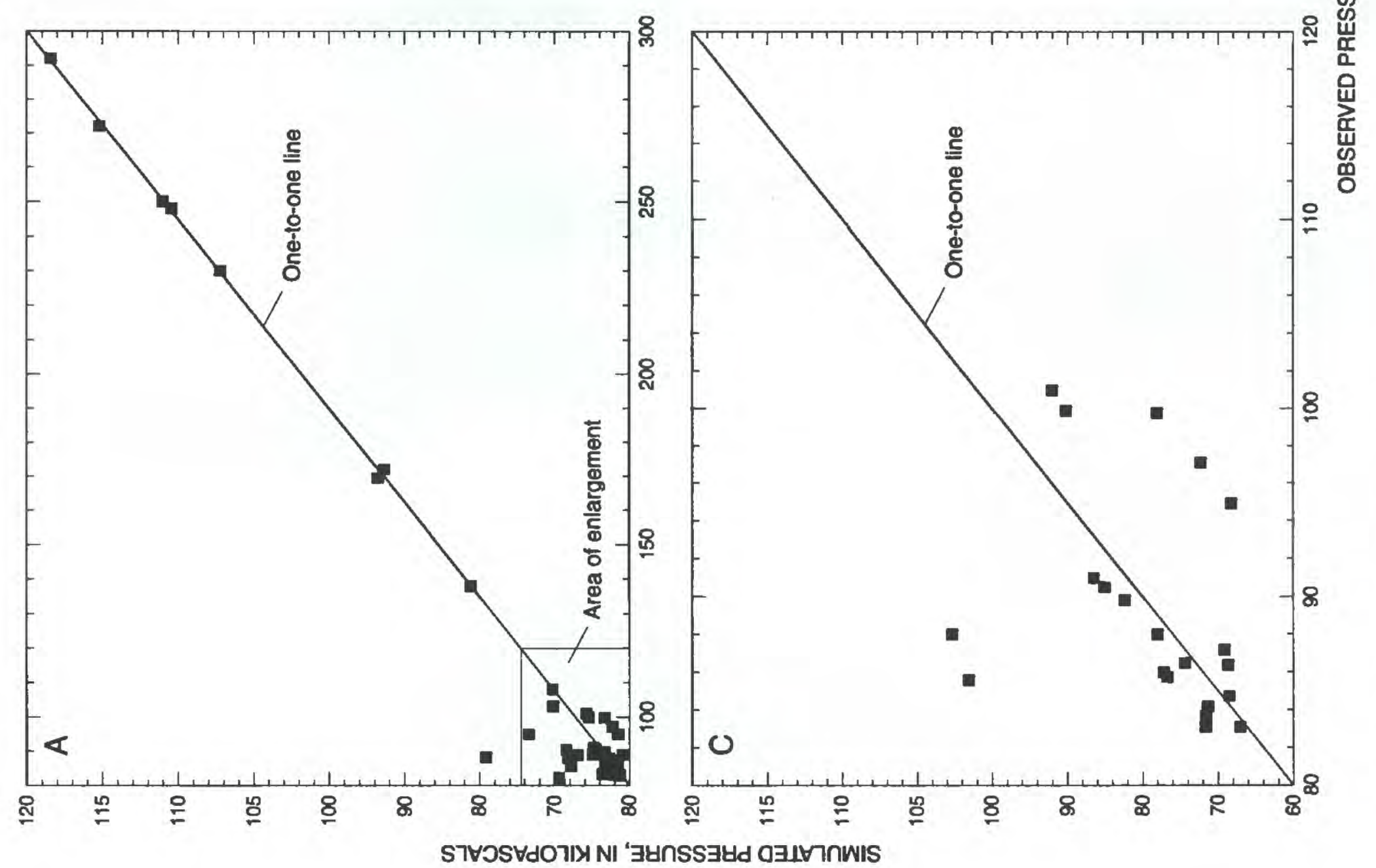

\%인

ᄃ ㅎํㅇ

응

드 몬

웡요

동

으을

은 응

岛응

․ㅗ은

흔

哓。

틀

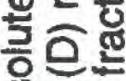

政

ऊu

ช 온

륭

员

으응

क 용

के

으 응

\%

흥으의

o. 동

过安

ㄷㅇㅇ

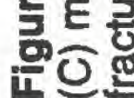



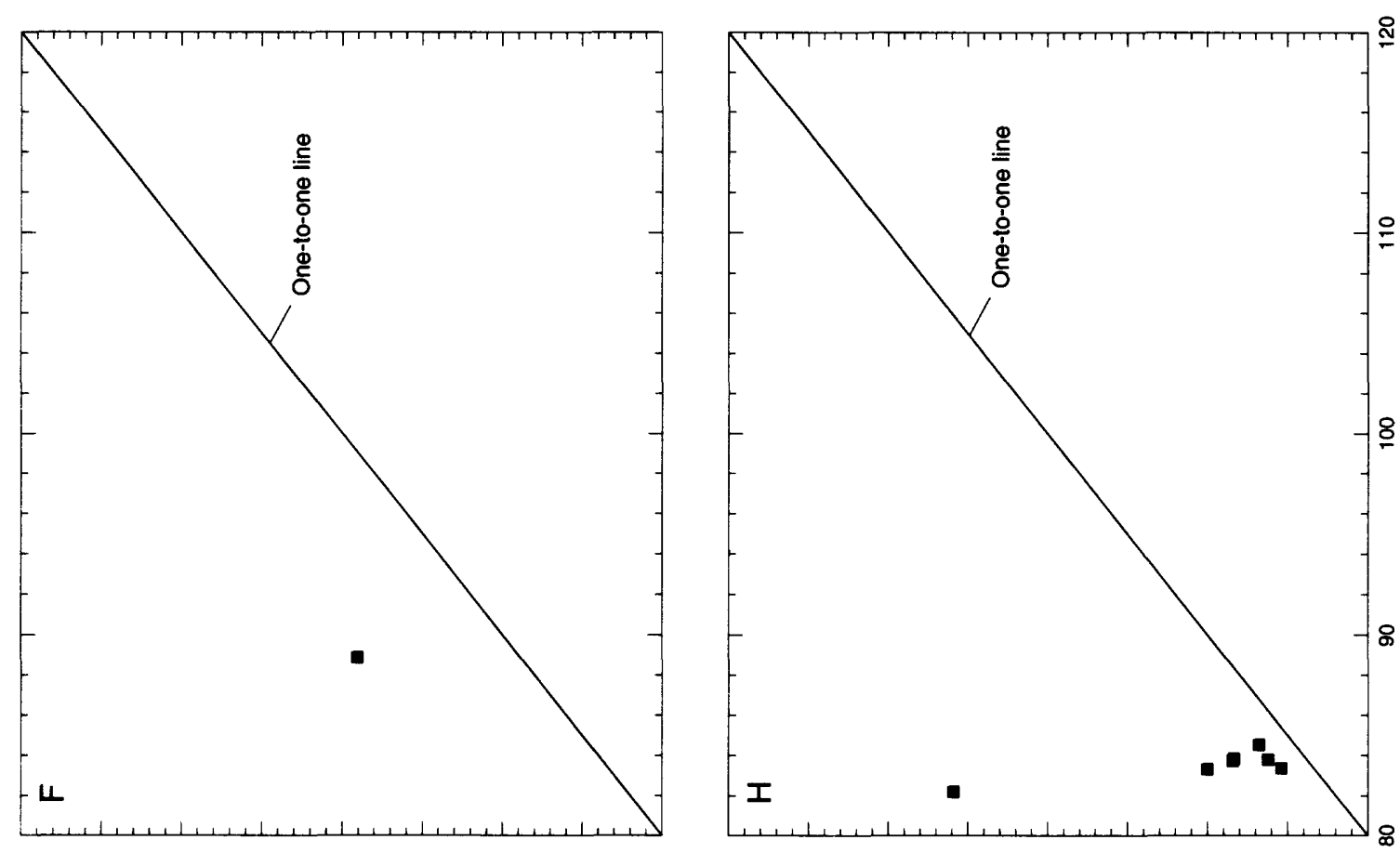

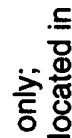

응 \$

뭉

뜨는

ळ்

8

응 윰

올

응

สั ญ్

든 응

응

o

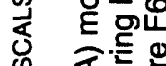

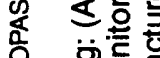

ํㄷ원

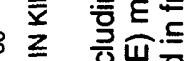

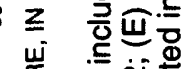

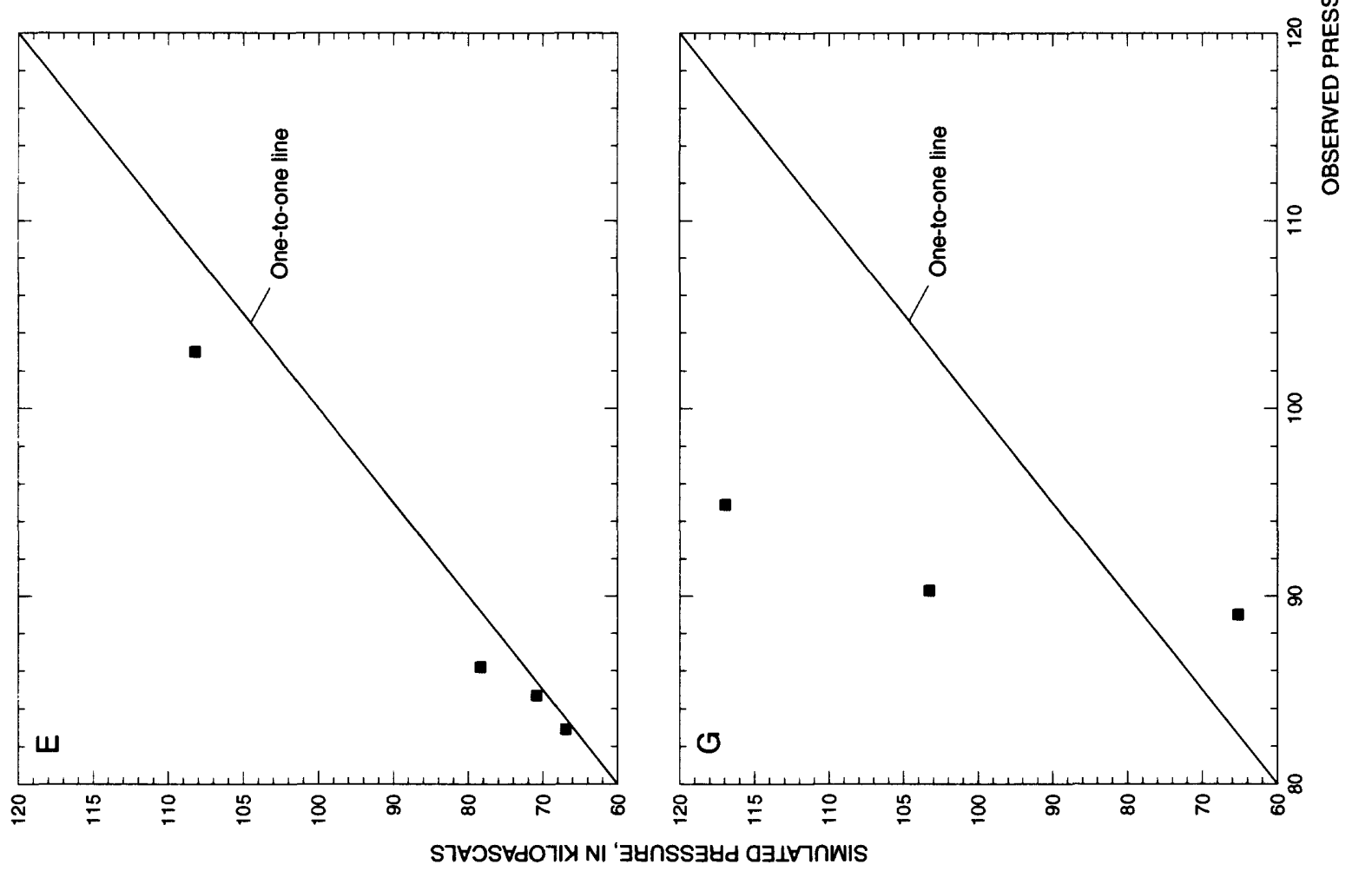

क्षे

$\Phi$ 인응

등 흥

은

$\Phi . \subseteq 9$

용

든

뭉을

\&

농응

的

흔

记

๙ั 응

통

흐ㅇㅡㅡ는

营

8

긍 응

융

응응

용

贾.

$>80$

象

즉 응 을

정응

过䜤

लि

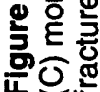


Table 8. Comparison of measured and simulated gas pressures for air-injection tests $\left[\mathrm{kPa}\right.$, kilopascal; $\mathrm{P}_{\text {sim }}$, simulated pressure; $\mathrm{P}_{\mathrm{obs}}$, observed gas pressure $]$

\begin{tabular}{|c|c|c|c|c|}
\hline $\begin{array}{l}\text { Test identification } \\
\text { number }\end{array}$ & Borehole & $\begin{array}{c}\text { Observed pressure } \\
\text { (kPa) }\end{array}$ & $\begin{array}{c}\text { Simulated pressure } \\
(\mathrm{kPa})\end{array}$ & $\begin{array}{c}\text { Relative error } \\
\left(P_{\text {sim }}-P_{\text {obs }}\right) / P_{\text {obs }} \times 100\end{array}$ \\
\hline \multirow[t]{6}{*}{ P26391K3 } & 1A (injection) & 292.0000 & 291.2400 & -0.2603 \\
\hline & $1 \mathrm{C}$ & 94.9000 & 84.0900 & -11.3909 \\
\hline & 1D & 83.1000 & 83.5490 & 0.5403 \\
\hline & $2 \mathrm{~A}$ & 83.0000 & 83.8600 & 1.0361 \\
\hline & $3 \mathrm{~A}$ & 83.1000 & 85.8000 & 3.2491 \\
\hline & $4 \mathrm{~A}$ & 82.9000 & 83.4800 & 0.6996 \\
\hline \multirow[t]{6}{*}{ P26391K4 } & $1 \mathrm{~A}$ & 83.3400 & 90.0500 & 8.0514 \\
\hline & 1C (injection) & 230.0000 & 229.6300 & -0.1609 \\
\hline & ID & 99.9000 & 95.0800 & -4.8248 \\
\hline & $2 \mathrm{~A}$ & 87.9000 & 87.5700 & -0.3754 \\
\hline & $3 A$ & 88.0000 & 102.6400 & 16.6364 \\
\hline & $4 \mathrm{~A}$ & 84.7000 & 85.4300 & 0.8619 \\
\hline \multirow[t]{6}{*}{ P26791K1 } & $1 \mathrm{~A}$ & 84.5300 & 86.7900 & 2.6736 \\
\hline & $1 \mathrm{C}$ & 101.0000 & 95.9900 & -4.9604 \\
\hline & 1D (injection) & 172.0000 & 169.8800 & -1.2326 \\
\hline & $2 \mathrm{~A}$ & 89.7000 & 89.2200 & -0.5351 \\
\hline & $3 \mathrm{~A}$ & 89.8000 & 91.1400 & 1.4922 \\
\hline & $4 \mathrm{~A}$ & 86.2000 & 89.2200 & 3.5035 \\
\hline \multirow[t]{6}{*}{ P26291K2 } & $1 \mathrm{~A}$ & 83.7300 & 88.4300 & 5.6133 \\
\hline & $1 \mathrm{D}$ & 85.7500 & 88.3400 & 3.0204 \\
\hline & $1 \mathrm{~F}$ & 87.2000 & 84.5900 & -2.9931 \\
\hline & 2A (injection) & 250.0000 & 250.4400 & 0.1760 \\
\hline & $3 \mathrm{~A}$ & 90.5000 & 92.5000 & 2.2099 \\
\hline & $4 \mathrm{~A}$ & 103.0000 & 108.2300 & 5.0777 \\
\hline \multirow[t]{6}{*}{ P26191K1 } & $1 \mathrm{~A}$ & 83.8000 & 86.2400 & 2.9117 \\
\hline & $1 \mathrm{D}$ & 84.2000 & 85.6500 & 1.7221 \\
\hline & $1 \mathrm{~F}$ & 88.1000 & 132.4700 & 50.3632 \\
\hline & 2C (injection) & 248.0000 & 247.2800 & -0.2903 \\
\hline & 4D & 83.8500 & 0.0000 & 0.0000 \\
\hline & $4 \mathrm{E}$ & 94.9000 & 116.9500 & 23.2350 \\
\hline \multirow[t]{11}{*}{ P35290K4 } & $1 \mathrm{~A}$ & 82.2000 & 105.9100 & 28.8443 \\
\hline & ${ }^{1} 1 \mathrm{C}$ & 85.6000 & 101.5100 & 18.5864 \\
\hline & $1 \mathrm{D}$ & 88.0000 & 88.9700 & 1.1023 \\
\hline & $1 \mathrm{E}$ & 99.7500 & 89.0500 & -10.7268 \\
\hline & ${ }^{1} 1 \mathrm{~F}$ & 97.1000 & 86.1500 & -11.2770 \\
\hline & ${ }^{1} 2 A$ & 89.0900 & 93.7500 & 5.2307 \\
\hline & 3A (injection) & 169.5000 & 172.1500 & 1.5634 \\
\hline & ${ }^{1} 4 \mathrm{~B}$ & 88.8800 & 99.0500 & 11.4424 \\
\hline & $4 C$ & 84.0000 & 0.0000 & 0.0000 \\
\hline & $4 \mathrm{D}$ & 82.6000 & 0.0000 & 0.0000 \\
\hline & $4 \mathrm{E}$ & 89.0000 & 82.6000 & -7.1910 \\
\hline \multirow[t]{5}{*}{ P26391K1 } & $1 \mathrm{~A}$ & 83.3600 & 85.4000 & 2.4472 \\
\hline & $1 \mathrm{C}$ & 83.7000 & 85.7900 & 2.4970 \\
\hline & $1 \mathrm{D}$ & 86.0000 & 88.5700 & 2.9884 \\
\hline & $2 \mathrm{~A}$ & 108.0000 & 108.2400 & 0.2222 \\
\hline & $3 \mathrm{~A}$ & 86.5000 & 87.2200 & 0.8324 \\
\hline
\end{tabular}

44 Numerical Simulation of Air- \& Water-Flow Experiments in a Block of Variably Saturated, Fractured Tuff from Yucca Mountain, Nevada 
Table 8. Comparison of measured and simulated gas pressures for air-injection tests-Continued

\begin{tabular}{|c|c|c|c|c|}
\hline $\begin{array}{l}\text { Test identification } \\
\text { number }\end{array}$ & Borehole & $\begin{array}{l}\text { Observed pressure } \\
\text { (kPa) }\end{array}$ & $\begin{array}{c}\text { Simulated pressure } \\
\text { (kPa) }\end{array}$ & $\begin{array}{c}\text { Relative error } \\
\left(P_{\text {sim }}-P_{\text {obs }}\right) / P_{\text {obs }} \times 100\end{array}$ \\
\hline & 4A (injection) & 138.0000 & 138.1800 & 0.1304 \\
\hline \multirow[t]{5}{*}{ P26191K4 } & $1 \mathrm{~A}$ & 83.8400 & 88.3500 & 5.3793 \\
\hline & $1 \mathrm{D}$ & 84.7500 & 84.2700 & -0.5664 \\
\hline & $1 \mathrm{~F}$ & 91.0000 & 93.2300 & 2.4505 \\
\hline & $2 \mathrm{C}$ & 90.3000 & 103.2900 & 14.3854 \\
\hline & 4E (injection) & 272.0000 & 273.4900 & 0.5478 \\
\hline
\end{tabular}

In summary, the air-injection tests were used to calibrate the transmissivities of fractures F1, F2, F3, F5, and F6 within the network model. Other fracture transmissivities were assigned on the basis of visual similarity to one of the tested fractures. The calibrated model explains 97.2 percent of the pressure variance observed in the subset of air-injection tests listed in table 7 , although this value decreased substantially when only the monitoring boreholes were considered.

\section{Slug Tests}

Information collected during and following the initial application of a slug of water to the sand layer overlying the block was used in this stage of the modeling to examine the hydrologic interactions between sand, rock matrix, and fractures. As discussed earlier, sand was placed over the block to provide a means of controlling the water potential at the upper surface of the block in the later, constant-flow-rate phase of the experiment. In this phase of the experiment, however, the sand layer provided an opportunity to investigate the factors controlling the movement of water from a porous, unfractured medium into an underlying fractured one. Similar hydrologic interfaces exist at Yucca Mountain, including those between alluvium and the moderately to densely welded Tiva Canyon Tuff, and between the upper nonwelded and densely welded vitric caprock subunits of the Topopah Spring Tuff. Therefore, the insights gained here may also help in understanding hydrologic processes at those material interfaces.

This phase of the experiment was itself modeled in stages using one- and two-fracture models. Sensitivity studies using one-fracture models were performed to illustrate the importance of understanding both the transmissive and capillary properties of fractures to modeling water movement across hydrologic interfaces between fractured and unfractured media. These models were intended primarily to provide generic understanding rather than a detailed numerical representation of the block experiment. A second set of simulations was performed using a two-fracture model. The two-fracture model attempted to capture slightly more of the fracture network geometry in order to facilitate a more direct comparison with the experimental results and was also used to perform additional sensitivity studies to examine the impacts of uncertainties in sand properties and air entrapment within fractures.

\section{Single-Fracture Models}

The modeling domain considered by the singlefracture models was $0.95 \mathrm{~m}$ tall, $0.5 \mathrm{~m}$ wide, and $0.5 \mathrm{~m}$ thick. The upper $0.10 \mathrm{~m}$ and lower $0.05 \mathrm{~m}$ of the domain consisted of sand. The material between these sand layers was rock matrix with a single vertical fracture along the midplane. Various fracture properties were assumed for different model runs, including those listed in table 6 for fractures with average apertures of $2.5,25.0,125.0$, and $250.0 \mu \mathrm{m}$. However, entrapped air within the fracture planes was not permitted (that is, $S_{1 s}=1.0$ ). Based on the simulation results for the imbibition experiments, the rock matrix was assigned a value of $S_{1 s}=0.70$, with other parameters identical to those described in the "Imbibition Tests" section. The slug of water applied to the upper sand layer was represented in the model by specifying an initial saturation of 0.99999 in the sand. Remaining initial conditions were $S_{1}=0.1$ for the rock matrix, $S_{1}=0.00001$ for the fracture, and $S_{1}=0.00001$ for the lower sand layer. The initial saturation of the rock matrix was estimated based on the water potential (approximately $-20,400 \mathrm{~m}$ ) corresponding to a relative humidity of 0.3 and temperature of $25^{\circ} \mathrm{C}$, and using the moisture- 
characteristic curves in figure 12 . Although the materials in the lower $0.85 \mathrm{~m}$ of the model domain were not initially in exact water-potential equilibrium, their initial saturations were nearly those that would have existed had such equilibrium been specified. The upper and lower boundaries and sides of the model domain were modeled as no-flow boundaries.

The simulation results for the single-fracture models, as well as for a block with no fractures, were compared in terms of cumulative inflow, rates of water uptake, and effect on matric potential in the overlying sand layer.

\section{Cumulative Inflow}

Simulation results obtained with the one-fracture models indicated that, in all cases, cumulative inflow from the upper sand layer into the block during the 100-day redistribution period was enhanced by the presence of a fracture, although the increases for the 2.5-, 125-, and 250- $\mu \mathrm{m}$ fracture cases relative to the no-fracture case were very small (fig. 35 ). For the case with a $25.0-\mu \mathrm{m}$ fracture, calculated cumulative inflow at the end of the 100-day redistribution period increased substantially, from $2.219 \mathrm{~L}$ in the no-fracture case to $7.675 \mathrm{~L}$. The differences in the rates of water uptake for the different fracture sizes can be explained by their permeability/matric potential relations relative to that of the sand (fig. 36). The 125- and 250- $\mu \mathrm{m}$ fractures are more permeable than the sand at matric potentials greater (less negative) than $-0.08 \mathrm{~m}$ and $-0.04 \mathrm{~m}$ (fig. 36), but become less permeable than the sand at smaller (more negative) matric potentials. It might be expected that, for these fractures, smaller rates of uptake at more negative values of water potential would be at least partially compensated for by much higher flow rates at larger matric potentials. However, when the matric potential at the sand/fracture interface is greater than these cross-over values, the smaller permeability of the sand limits the rate at which these fractures take up water. The $125-\mu \mathrm{m}$ fracture takes up slightly more water than the $250-\mu \mathrm{m}$ fracture because its permeability is greater at the relatively small matric potentials that prevail during most of the 100-day simulation period. Water uptake in the case with a $2.5-\mu \mathrm{m}$ fracture is nearly identical to that of the $250-\mu \mathrm{m}$ fracture, but in this case water uptake is limited by the small intrinsic permeability of the fracture relative to the sand. Although it, too, ultimately becomes more permeable than the sand, it does so at permeability values that are too small to make it a fac-

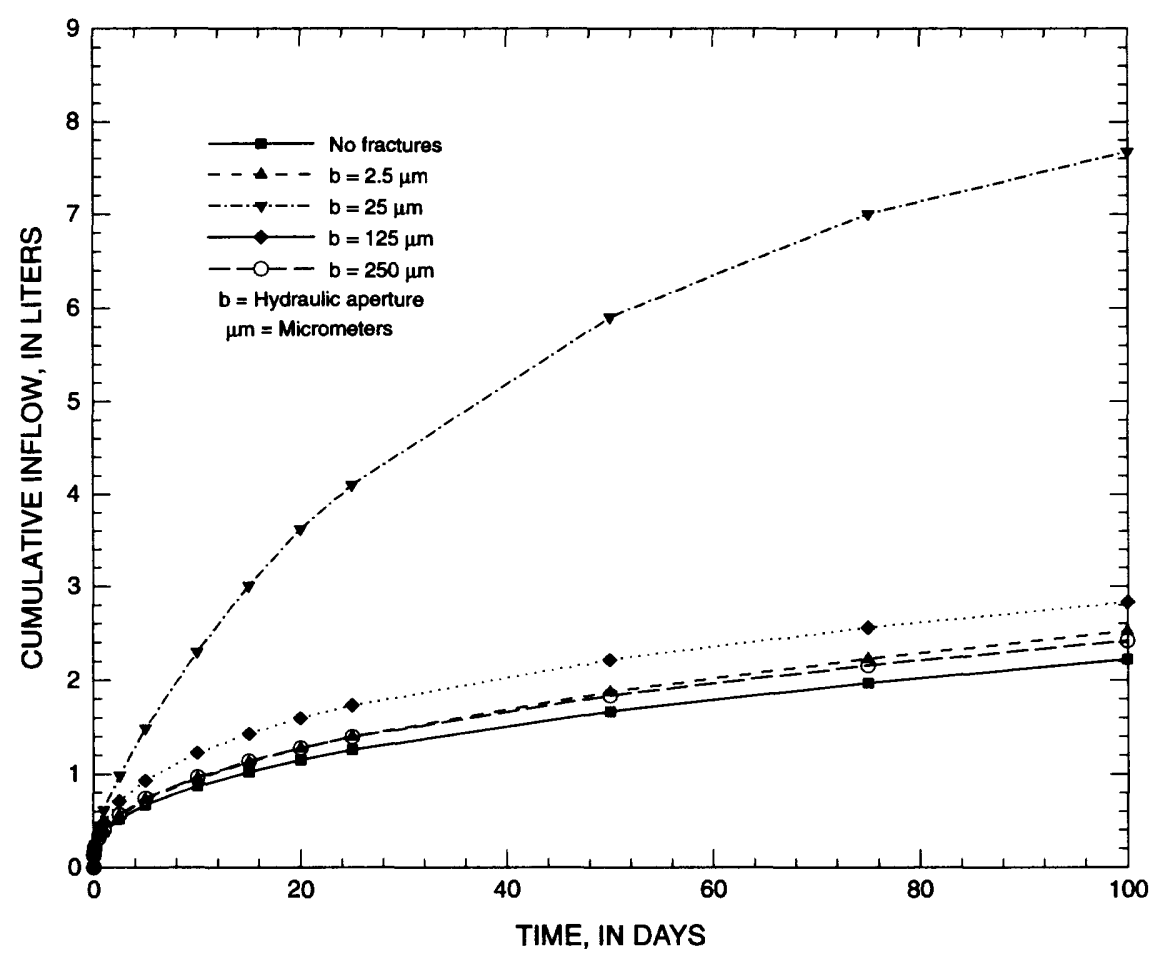

Figure 35. Sensitivity of model estimates of cumulative inflow during the first 100-day redistribution period to fracture size. 


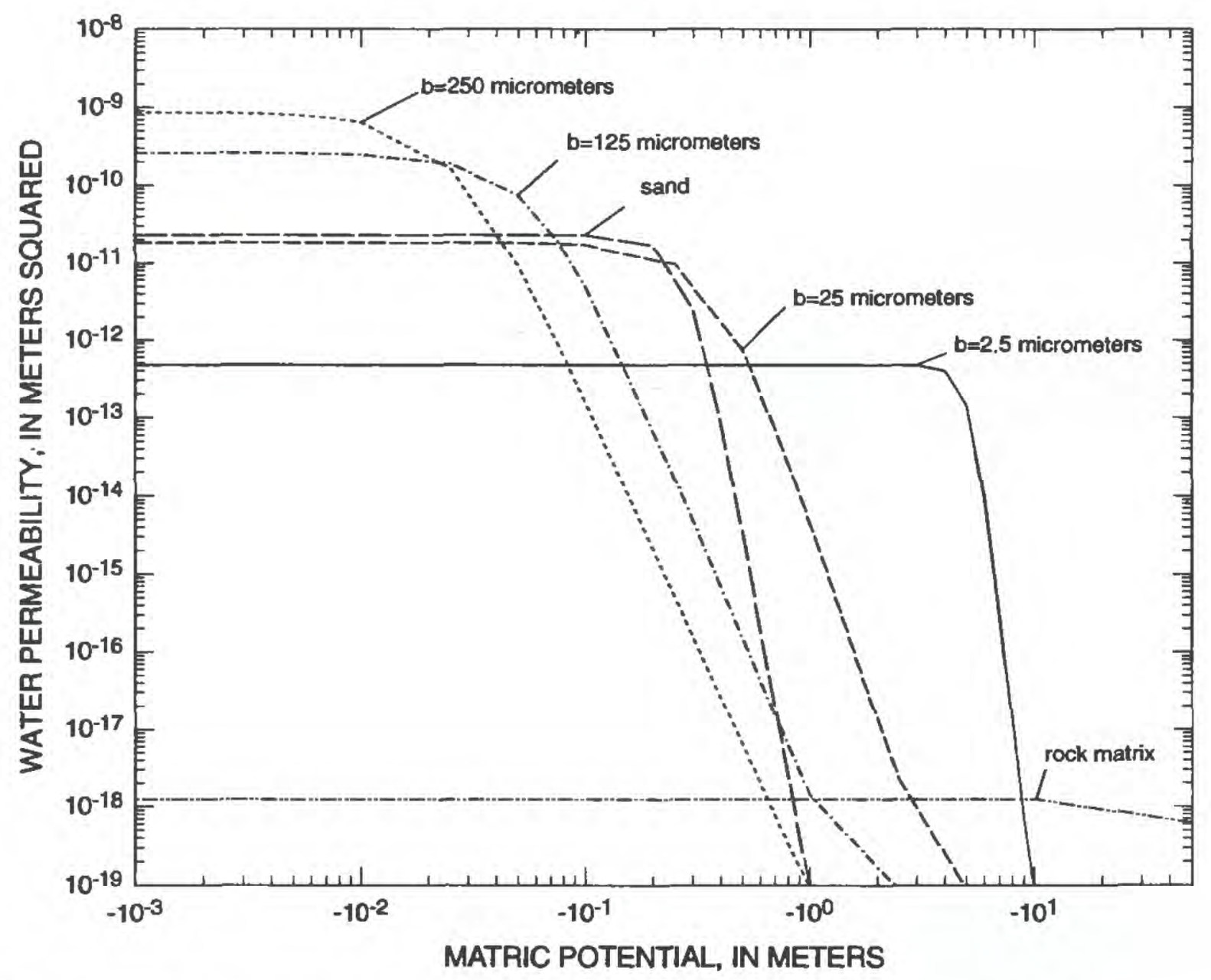

Figure 36. Water permeability/matric potential relations used in the model for fractures, sand, and rock matrix.

tor to overall water uptake. The substantial enhancement of cumulative uptake in the case of the $25-\mu \mathrm{m}$ fracture occurs because its permeability/matric potential relation is nearly identical to that of the sand over the range of potentials considered by the simulation. Thus, unlike the other fracture sizes considered, contrasts in permeability and capillary properties do not occur between the sand and the fracture. Flow from the sand to the fracture is not limited by either the intrinsic permeability of the sand or the capillary properties of the fractures, or, as in the case of the $2.5-\mu \mathrm{m}$ fracture, by the intrinsic permeability of the fracture itself. The ability of fractures to enhance water uptake by the rock matrix is thus directly tied to the hydrologic properties of the overlying material and cannot be predicted independent of those properties.

\section{Distribution of Saturation}

Patterns of wetting within the block during the redistribution period were plotted for selected cases. Figure $37(\mathrm{~A}-\mathrm{F})$ shows the simulated wetting pattern at $1,5,10,25,50$, and 100 days for the case involving the $25-\mu \mathrm{m}$ fracture. These saturation plots show that wetting along the fracture located along the midplane of the block results in a substantial advancement of the wetting front relative to the unfractured regions. The upper sand layer drains from the top down so that satu- ration and matric potential at the sand/rock interface are larger than at elevations higher in the sand layer. Water movement along the fracture continues until the lower boundary of the model domain is encountered. The lower sand layer slowly begins to wet with water supplied by the fracture, although water held by the matrix is not predicted to enter the sand because of the greater capillary attraction of the matrix for water. The increase in cumulative uptake (by a factor of 3.5 relative to the unfractured case) can be explained by the observation that wetting along both walls of the fracture, in addition to the upper surface, increases the area across which matrix imbibition occurs from 0.25 to $1.05 \mathrm{~m}^{2}$, assuming the entire fracture is wet. However, an increase in cumulative uptake by a factor less than four occurs because the entire fracture is not wet for the entire simulation period and because water moving downward from the top of the block interferes with water moving laterally from the fracture. In this partially converging flow field, cumulative uptake is not directly proportional to wetted surface area, as it would be in a linear flow field.

Figure $38(\mathrm{~A}-\mathrm{F})$ shows the simulated wetting pattern at $1,5,10,25,50$, and 100 days for the case involving the $125-\mu \mathrm{m}$ fracture. Although the early time wetting behavior (at 1 day) is similar to that observed for case with the 25- $\mu \mathrm{m}$ fracture, the depth to which water moves along the $125-\mu \mathrm{m}$ fracture does not 

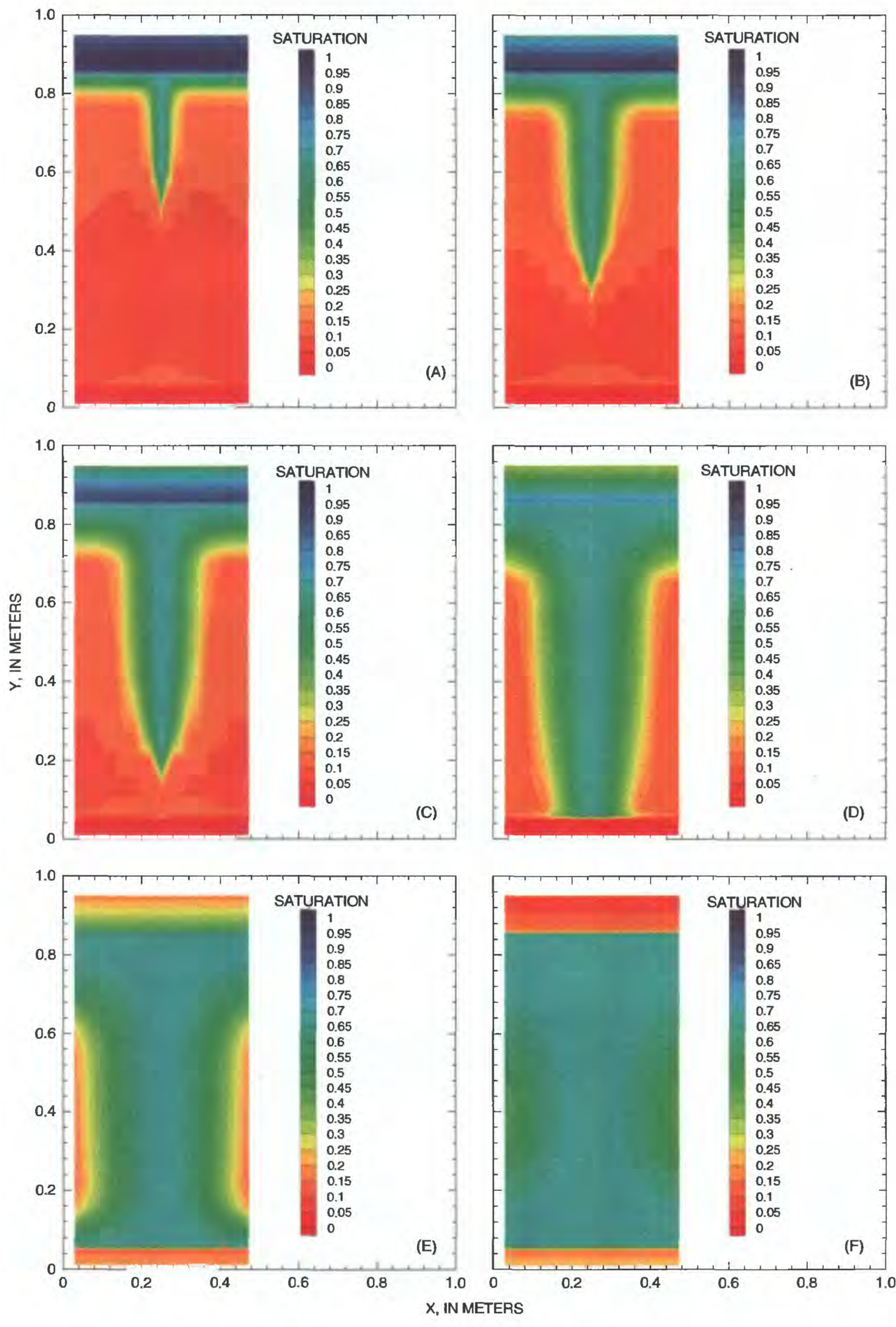

Figure 37. Simulated saturation distribution within an idealized block containing a single 25-micrometer fracture: (A) 1 day; (B) 5 days; (C) 10 days; (D) 25 days; (E) 50 days; and (F) 100 days.

48 Numerical Simulation of Air- \& Water-Flow Experiments in a Block of Variably Saturated, Fractured Tuff from Yucca Mountain, Nevada 

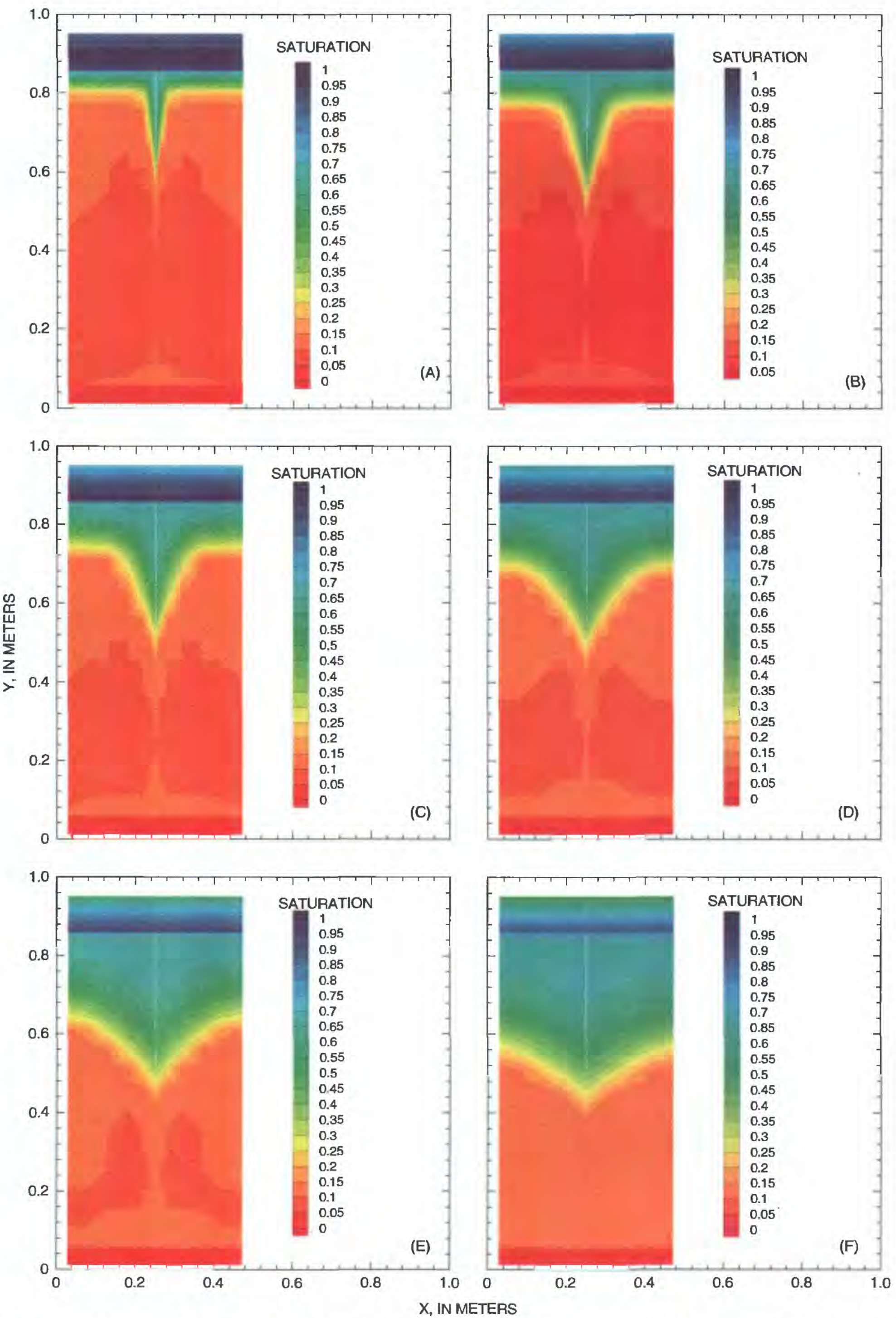

Figure 38. Simulated saturation distribution within an idealized block containing a single 125-micrometer fracture: (A) 1 day; (B) 5 days; (C) 10 days; (D) 25 days; (E) 50 days; and (F) 100 days. 
significantly increase after 5 days. After 5 days, as water entering the matrix across the sand/rock interface becomes the dominant fraction of water entering the block (see following paragraphs), the wetting front begins to become smoother. However, some evidence of the earlier contributions of water from the fracture remains, and the wetting front does not lose its uneven appearance altogether. The saturation distributions were not plotted for the 2.5- and 250- $\mu \mathrm{m}$-fracture cases. However, based on the similarity of their cumulative uptake curves to that of the 125 - $\mu \mathrm{m}$-fracture case, those saturation plots could be expected to evolve in a manner similar to those shown in figures $38 \mathrm{~A}-\mathrm{F}$.

\section{Rates of Inflitration}

Figure 39 shows the simulated flow rates from the sand to the block as a function of time for each fracture size, as well as for the matrix-only case. As suggested by the cumulative inflow curves (fig. 35), the uptake rates for the case with the $25-\mu \mathrm{m}$ fracture are higher than those for the other fracture sizes and matrix-only case. Comparison with the matrix-only case shows that, for this case, the $25-\mu \mathrm{m}$ fracture is the dominant source of water entering the block for the first 75 days or longer. In contrast, in the case of the $125-\mu \mathrm{m}$ fracture, the fracture contribution to inflow has become a minor component by 2.5 days, although it continues to augment inflow to a small degree until 25 days. Interestingly, the largest inflow rates identified (at 0.01 day) were similar in all cases $(2,413.0$ to $2,876.4 \mathrm{~cm}^{3} /$ day), suggesting that these early inflow rates were controlled by the properties of the sand. Because of the initially large matric-potential gradients across the sand/rock interface, the uptake rate calculated for the matrix-only case at $\mathbf{0 . 0 1}$ days is approximately one thousand times greater than what would be calculated on the basis of its intrinsic permeability and unit gradient assumptions.

\section{Equating Real to Hypothetical Fractures}

Although these simulations provide insight as to the possible factors governing water movement from the sand layer into the block, the schematic nature of the simulations prohibits direct comparison with experimental data. As attempts to replicate the experimental data in a literal sense, they are inadequate. However, if these simulations are viewed primarily as attempts to identify the consequences of underlying physical processes embedded in the model, some assessment can be made of their relevance by analyzing the available data to determine if the overall features predicted by the model are evident. Table 7 provided estimates of pneu-

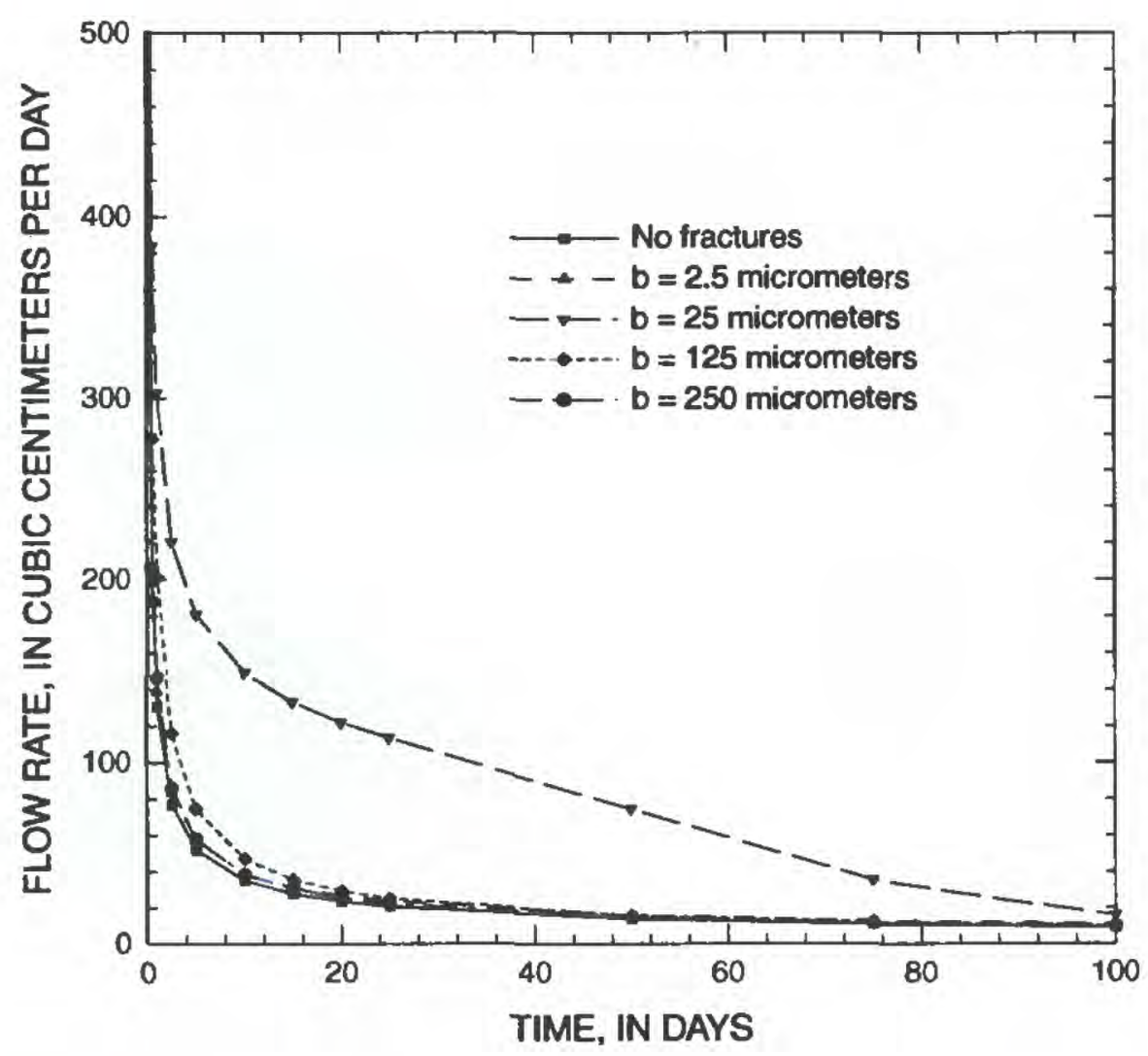

Flgure 39. Sensitivity of model estimates of rate of inflow to the block during the first 100-day redistribution period to fracture size. 
matic apertures for fractures intersected by the injection boreholes. Estimated apertures of fractures intersecting the upper surface of the block were $46.7 \mu \mathrm{m}$ for $\mathrm{F} 1$ (based on geometric mean transmissivity), $14.5 \mu \mathrm{m}$ for F6, and $20.2 \mu \mathrm{m}$ for F2. These values of aperture reflect the ability of the fractures to transmit fluids. The average physical apertures of these fractures and the variability of aperture about the mean are not known, and these parameters, rather than flow aperture, control the saturation-desaturation behavior of the fracture. If it is assumed, as for the model calculations used to compute the theoretical fracture properties (table 6), that mean physical aperture $b_{m}$ is roughly twice the hydraulic or pneumatic aperture $b_{h}$, then estimates for values of $b_{m}$ for $F 1(93.4 \mu \mathrm{m}), F 6(29.0 \mu \mathrm{m})$, and F2 $(40.4 \mu \mathrm{m})$ can be obtained. Thus, F1 might be anticipated to behave in a manner similar to what was observed for the $125-\mu \mathrm{m}$ fracture; F6, and to a lesser extent $F 2$, might be expected to produce a response similar to what was observed for the $25-\mu \mathrm{m}$ fracture.

\section{Two-Fracture Models}

In order to be able to make a more direct comparison between model results and observed data, a second numerical grid was created that incorporated two fractures: A $25-\mu \mathrm{m}$ fracture, located $0.125 \mathrm{~m}$ from the left boundary, and a $125-\mu \mathrm{m}$ fracture located $0.25 \mathrm{~m}$ from the left boundary. The $25-\mu \mathrm{m}$ fracture is intended to capture the effects of F6, whereas the $125-\mu \mathrm{m}$ fracture is meant to capture the effects of F1. Boundary and initial conditions for this simulation were similar to those used in the sensitivity study described previously.

\section{Cumulative Inflow}

The first point of comparison concerns the total amount of water that entered the block during the 100-day redistribution period. As discussed in the section "Moisture Redistribution Following Water Application," an estimated $4.5 \mathrm{~L}$ of water drained from the sand into the block during the 100 -day redistribution period.

The simulated cumulative inflow for the case with two fractures is shown in figure 40 , with results for the cases with single $25-\mu \mathrm{m}$ and $125-\mu \mathrm{m}$ fractures included for reference. The simulated cumulative inflow with both fractures of $6.28 \mathrm{~L}$ at 100 days overestimates the calculated cumulative inflow of 4.5 by 40 percent. The figure shows that the block with two fractures has the highest cumulative uptake before about 40 days, but that cumulative uptake at 100 days is actually $1.4 \mathrm{~L}$ less than the case involving just the $25-\mu \mathrm{m}$ fracture.

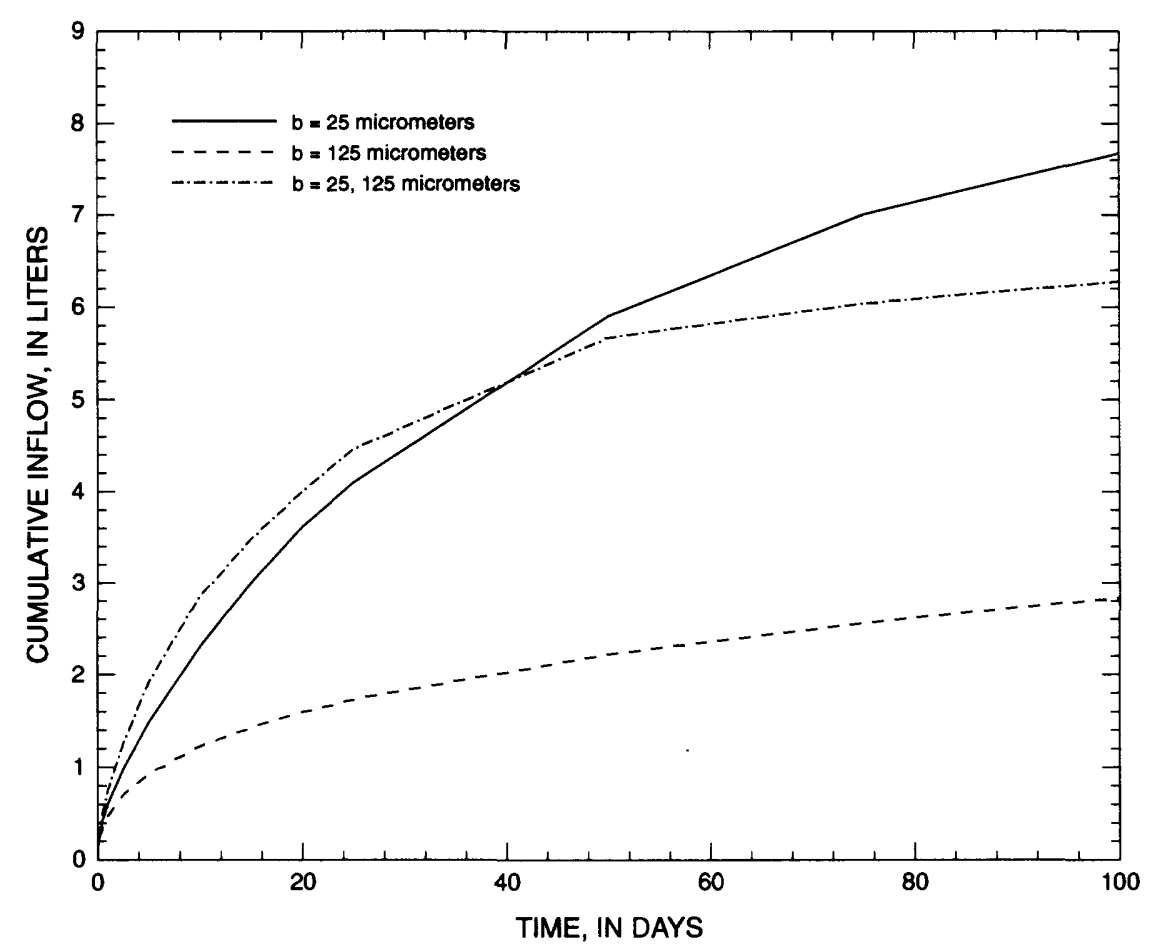

Figure 40. Model estimate of cumulative inflow during the first 100-day redistribution period into an idealized block containing both a $25-$ and 125 micrometer fracture. 


\section{Distribution of Saturation}

The somewhat counterintuitive result that cumulative uptake at 100 days is less in the two-fracture case than for the $25-\mu \mathrm{m}$-fracture case can be explained by examining the evolution of the saturation distribution for the multiple fracture case (fig. 41). As was observed in the simulations involving single fractures, the $25-\mu \mathrm{m}$ fracture at $x=0.125 \mathrm{~m}$ supplies a great deal more water than does the $125-\mu \mathrm{m}$ fracture at $\mathrm{x}=0.25 \mathrm{~m}$. However, the $125-\mu \mathrm{m}$ fracture along the midplane of the block acts as a capillary barrier that impedes the lateral spreading of the water emanating from the $25-\mu \mathrm{m}$ fracture. So, although the left half of the cross section fills quickly, the right half is shielded from the left by the relatively dry larger fracture. This phenomenon was observed experimentally (Glass and others, 1996) within a block of tuff bisected by a saw-cut, and suggested in this study by the results shown in figure 25 for core $14 \mathrm{~A}$, where imbibition along the core was slowed considerably by an induced fracture perpendicular to the core axis. In the simulation, the shielding provided by the larger aperture fracture is so effective that the right half wets by water rising from the sand layer at its base rather than by lateral moisture movement. In the model, the effectiveness of the $125-\mu \mathrm{m}$ fracture as a capillary barrier may be due, in part, to the assumption that relative permeability for each fracture is the same in directions both parallel and perpendicular to the fracture plane. Had different assumptions been made concerning directional relative permeabilities for the fractures, predicted capillary barrier effects associated with the $125-\mu \mathrm{m}$ fracture may have been less pronounced.

\section{Sand Layer Matric Potentiais}

Matric potentials measured by tensiometers in the upper sand layer form an additional basis for evaluating the results of the numerical models described above. The simulated and measured matric potentials $0.05 \mathrm{~m}$ above the sand-block interface are shown in figure 42 . The measured data show that matric potentials decreased rapidly within the days following water application but that these decreases slowed and asymtotically approached a value of approximately $-13 \mathrm{~cm}$ of water. The model results for the matrix-only, 2.5-, $125-$, and $250-\mu \mathrm{m}$-fracture cases displayed behavior generally similar to the data, although simulated values were more negative by about $11 \mathrm{~cm}$. The simulation results for these cases imply that, as discussed earlier, the larger fractures within the block had become non- transmissive as matric potential in the sand decreased so that at later times relatively small amounts of water were draining into the block. Conversely, the $25-\mu \mathrm{m}$ and multiple-fracture cases showed a continuous decline over the simulation period, reflecting continuous uptake by fractures throughout the redistribution period. For these cases, simulated matric potentials do not mimic very accurately either the overall shape or actual values of matric potential measured by the sandlayer tensiometers.

\section{Distribution of Matric Potential}

The last point of comparison involves the overall patterns of wetting simulated within the block. The distribution of matric potentials simulated for the multiple fracture case is shown in figure $43 \mathrm{~A}-\mathrm{F}$. These matric potentials correspond to the saturation distributions shown earlier for the same case (fig. 41). Contours in these figures are in 5-bar $\left(5.0 \times 10^{5} \mathrm{~Pa}\right)$ increments with a lower cutoff of -70 bars, the matric potential value below which the psychrometers used in the experiment are off-scale. For reasons already described, the model simulations predict more rapid wetting near the $25-\mu \mathrm{m}$ fracture located at $\mathrm{x}=0.125 \mathrm{~m}$, and slower wetting near the $125-\mu \mathrm{m}$ fracture located at $\mathrm{x}=0.25 \mathrm{~m}$. In the $125-\mu \mathrm{m}$ fracture, changes in matric potential are predicted to occur primarily as a result of lateral moisture movement from the smaller fracture, except within the upper 0.1 to $0.2 \mathrm{~m}$ where early water movement along the fracture, augmented by matrix flow from the block surface, has raised matric potentials above the -70 bar cutoff. In areas of the block shielded by the capillary barrier effects of large fractures, matric potentials at 100 days are not within measurement range of the psychrometers except where wet by matrix flow within the upper 15 to $20 \mathrm{~cm}$ of the block or, as a result of matrix imbibition of water from the lower sand layer, within the lower 10 to $15 \mathrm{~cm}$.

Figure 5, which shows the changes in matric potential in those psychrometers that responded to the application of the first slug, can be used to qualitatively evaluate some of the simulation results of the two-fracture case. The psychrometer data generally support the hypothesis that fractures estimated to have relatively small apertures on the basis of the air-injection tests $(F 2, F 6)$ were as important, or more, to water 

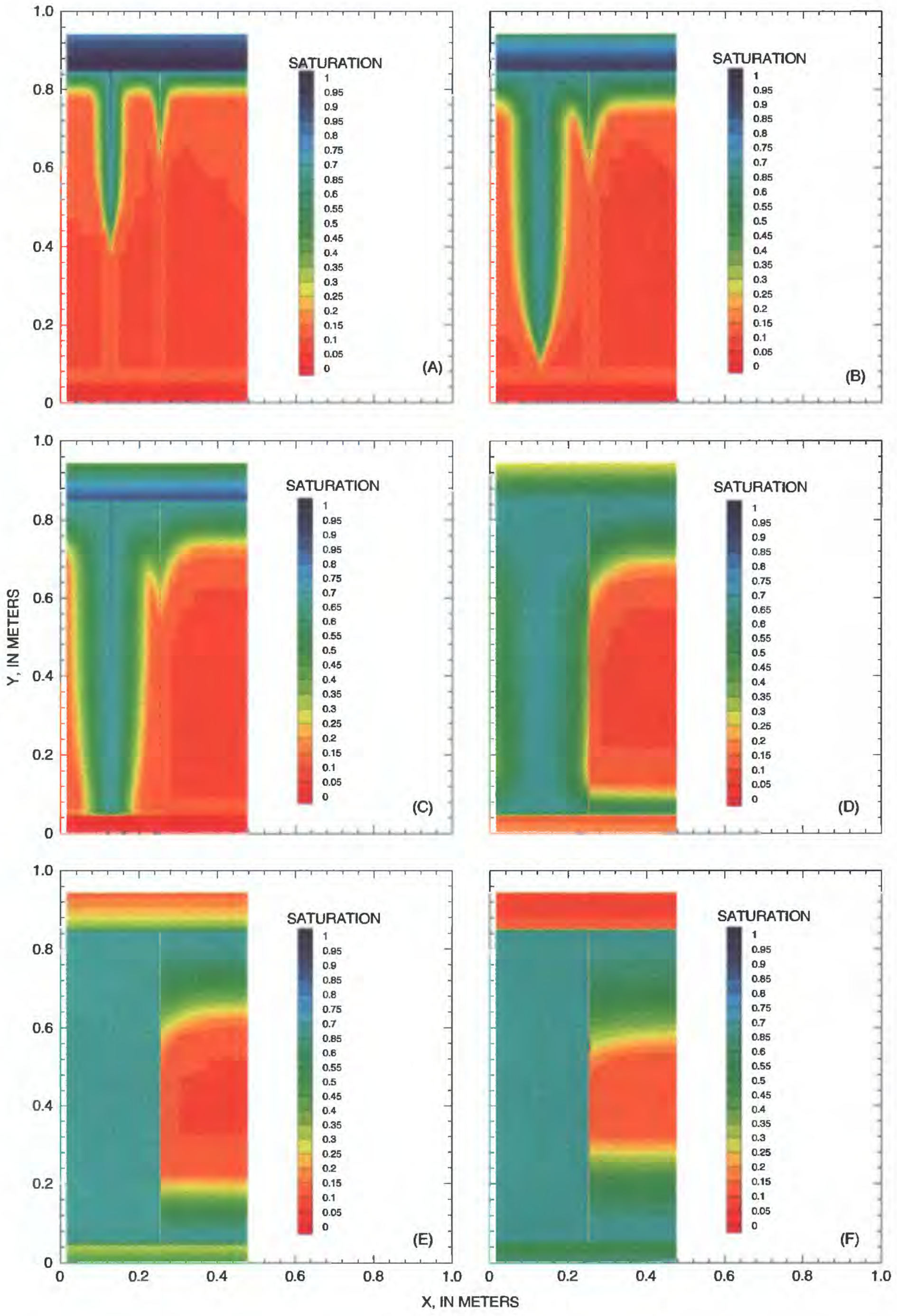

Figure 41. Simulated saturation distribution within an idealized block containing both a 25- and 125-micrometer fracture: (A) 1 day; (B) 5 days; (C) 10 days; (D) 25 days; (E) 50 days; and (F) 100 days. 


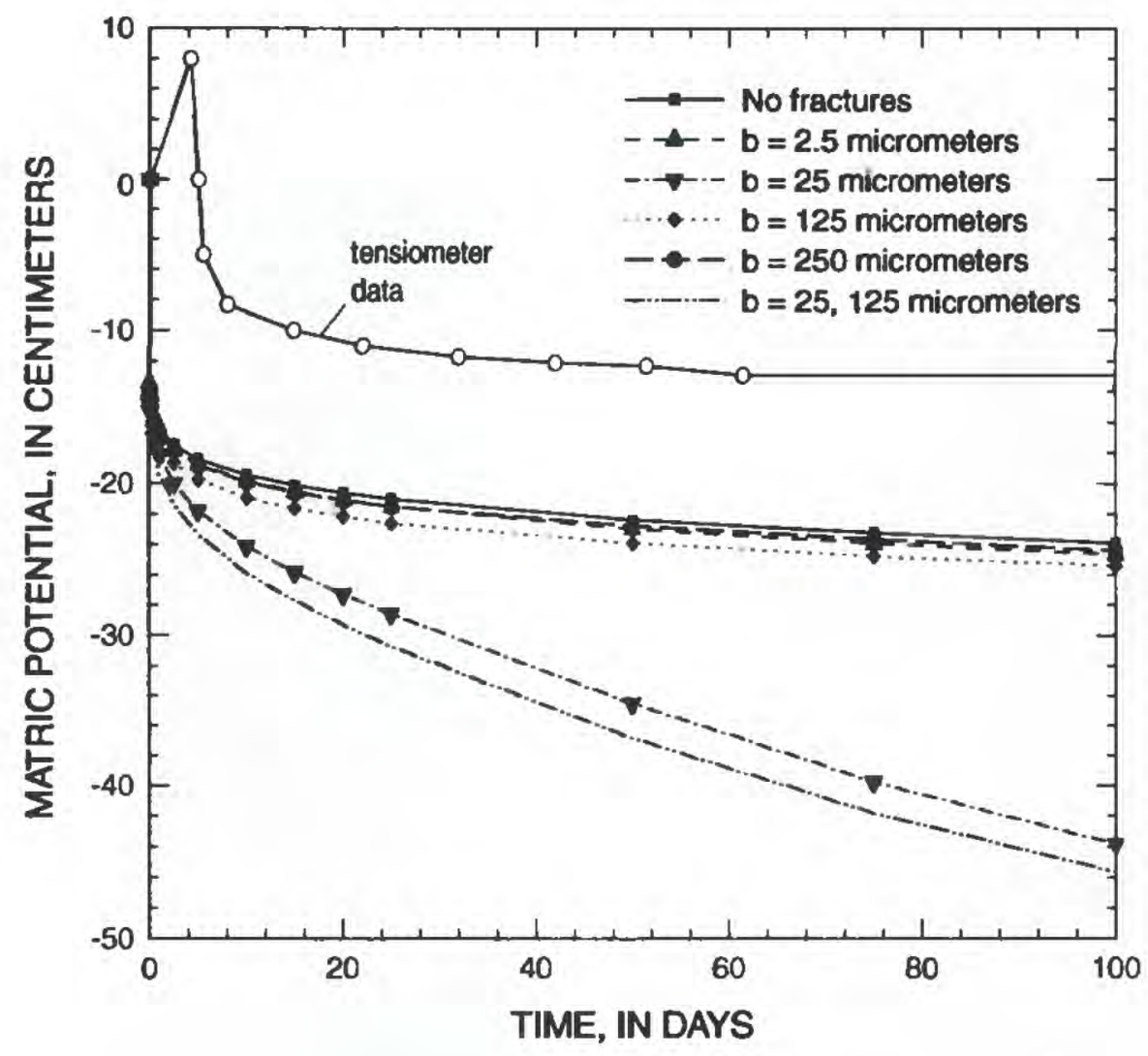

Figure 42. Sensitivity of model estimates of sand layer matric potential during the first 100-day redistribution period to fracture size.

uptake in this phase of the experiment than the larger aperture fractures (F1). Water movement from fracture F2 into fracture F3 is suggested by the early response of psychrometers in boreholes $2 \mathrm{~A}$ and $4 \mathrm{~A}$. And, although it straddles fracture $F 1$, the relatively early response of the psychrometer in borehole $3 \mathrm{~A}$ may be the result, in part, of its proximity to fracture F2, which is actually intersected at a very oblique angle by this borehole. Psychrometer 1D, which monitors F1, responds several days before the psychrometer in borehole $1 \mathrm{~B}$ (which straddles F6), contrary to what hypotheses developed from the simulations might suggest. However, the psychrometer in borehole ID may be sensing water introduced into the block through the F2 to F3 fracture pathway or water moving downward through the matrix, which by this time may have begun to affect psychrometers at the depth at which boreholes 1A, 1B, and 1D are located.

Thus, although somewhat ambiguous, the psychrometer data in figure 5 do not obviously contradict the hypotheses that large aperture fractures $(F 1)$ played a minor role in the uptake of water into the block in comparison with the smaller aperture fractures F2 and F6. However, equally important as the data shown in figure 5 is the fact that the rock in areas of the block never became wet enough to come into the measurement range of many of the psychrometers. For example, matric potentials at boreholes $1 \mathrm{C}, 1 \mathrm{E}$, and $1 \mathrm{~F}$ remained less than -70 bars throughout the 100 days following water application to the sand. This is clearly in contradiction to what the matric potential distributions for the two-fracture case would suggest (fig. 43), indicating that water uptake into the block is being significantly overestimated by the model. This further confirms what a comparison of the cumulative water uptake and sand-layer tensiometer data has already indicated.

It is not possible to evaluate other hypotheses suggested by the numerical model, such as the possible role of F1 as a capillary barrier to lateral moisture movement: fracture F2 cuts across F1 and may have introduced water on both sides of it, and F6 did not appear to transmit water to nearly the degree indicated by the simulations. Also, it is not possible from this data to evaluate the role of subhorizontal fractures as capillary barriers because boundary conditions imposed in the experiment appeared to result in at least some of them (F3, F4) transmitting water and thereby serving as local sources of water for the adjacent rock matrix. 

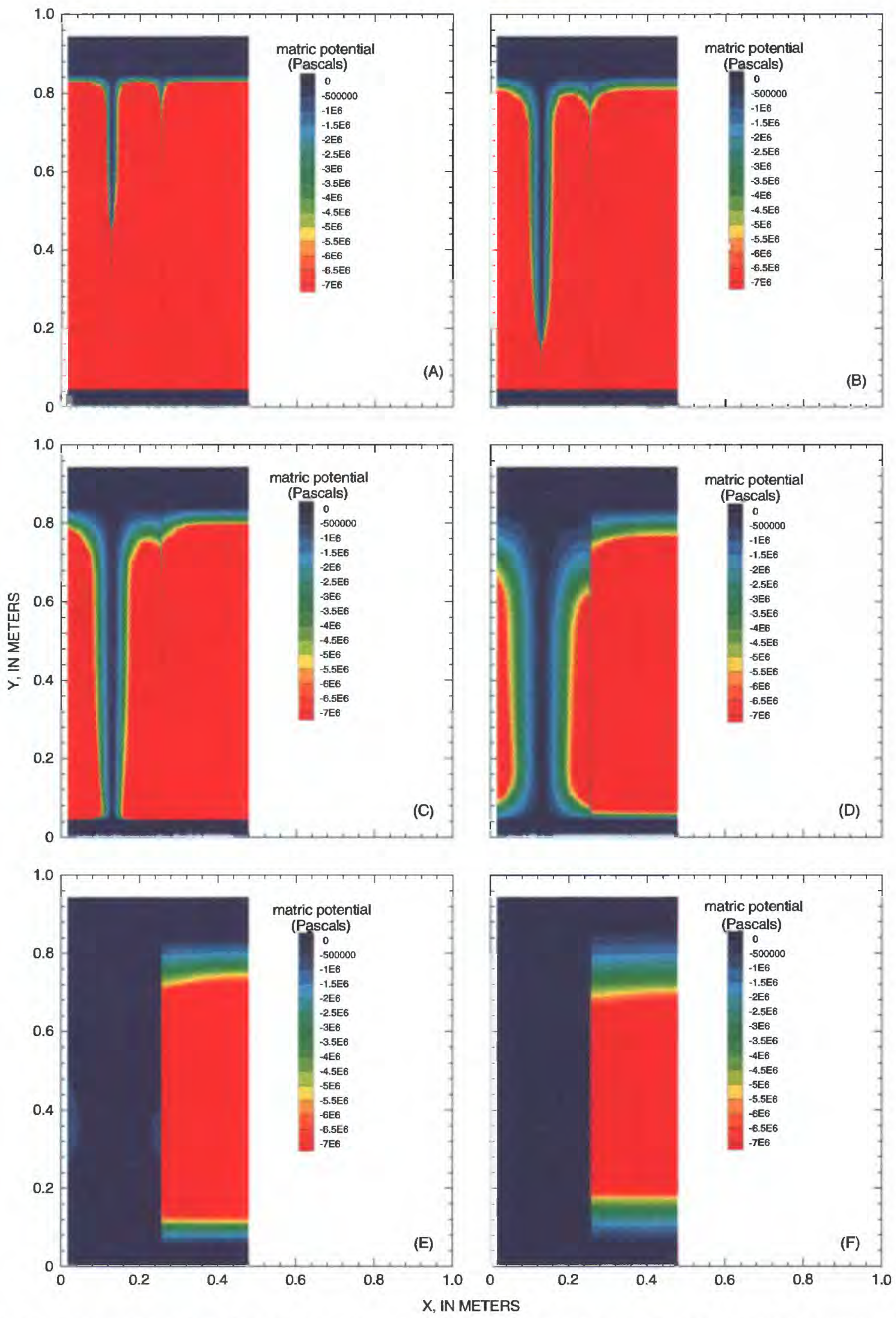

Figure 43. Simulated matric-potential distribution within an idealized block containing both a 25- and 125-micrometer fracture: (A) 1 day; (B) 5 days; (C) 10 days; (D) 25 days; (E) 50 days; and (F) 100 days. 


\section{Analysis of Assumptions in this Modeling Approach}

The task at this time is to identify, amidst all the uncertainties, those model parameters that can be justifiably changed, and when changed, would lead to a 40 -percent decrease in cumulative uptake by 100 days, allow the simulated matric potentials in the sand to stabilize at approximately $-13 \mathrm{~cm}$ of water, and permit simulated matric potentials to be consistent with values measured at analogous locations in the block.

Analysis of sources of error in the models described above is complicated because of the large number of idealizations and approximations that have been made. However, several idealizations and approximations may be particularly important. The fracture distribution in the model remains extremely schematic, and fracture properties, particularly under conditions of partial saturation, are educated guesses of as yet unmeasured, and perhaps unmeasurable, properties. In particular, the potential for air entrapment in newly wetted fractures, which earlier modeling with VSFRAC has suggested may be important, has not yet been considered.

Additionally, considerable uncertainty exists concerning the hydrologic properties of the sand. Values of permeability and parameters describing the moisture-retention characteristics of the sand layer were based not on measurements made from the sand layer itself, but on small samples packed to the same bulk density as the uncompacted sand layer. Relative permeability as a function of matric potential of the sand was inferred from that moisture-retention curve. Compaction of the sand during the redistribution period introduces additional uncertainty with regard to permeability values and moisture-retention characteristics used in the model.

The contrast in hydrologic properties between the sand and underlying fractures was shown earlier to have a strong influence on water movement into the block. To examine whether uncertainties in the hydrologic properties of the sand might be responsible for discrepancies between the simulated results and observed data, sand properties were varied by adjusting the $\alpha$ parameter of the moisture-characteristic function so that it was either one-half ( $\left.\alpha=\alpha_{\text {base case }} / 2\right)$ or twice $\left(\alpha=2 \alpha_{\text {base case }}\right)$ the value used in the base case $\left(3.4520 \mathrm{~m}^{-1}\right)$. Doubling the $\alpha$ parameter causes the sand to drain at approximately half the tension of the base case, whereas halving the $\alpha$ parameter causes the sand to drain at twice the tension of the base case.

The impact of altering the moisture-retention characteristics of the sand on cumulative inflow to the block is shown in figure 44 . Doubling the value of the $\alpha$ parameter resulted in greatly enhanced water uptake at early time, whereas halving the $\alpha$ parameter resulted

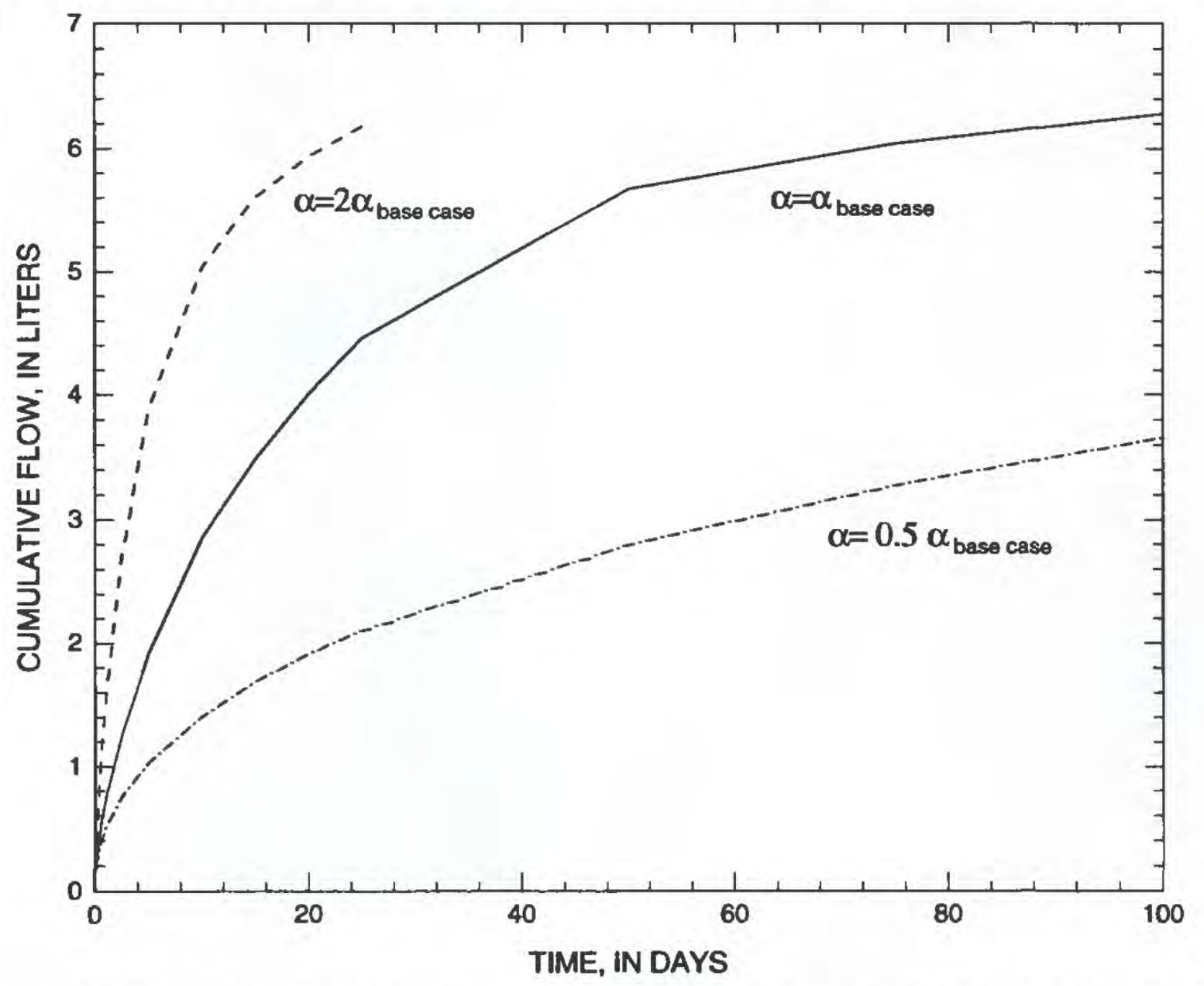

Figure 44. Sensitivity of model estimates of cumulative inflow into the block during the first 100 -day redistribution period to variations in sand properties. 
in a substantial decrease in cumulative uptake relative to the base case. The results for the $\alpha=2 \alpha_{\text {base case }}$ case greatly overestimate drainage from the sand and, correspondingly, wetting of the rock matrix. Simulated saturation distributions for this case indicate that the additional inflow, relative to the base case, entered the block through the $125-\mu \mathrm{m}$ fracture. Cumulative uptake at 100 days was reduced to $3.7 \mathrm{~L}$ when $\alpha$ was halved. Although simulated cumulative uptake at 100 days for this case is comparable to the value of $4.5 \mathrm{~L}$ estimated to have left the sand, simulated matric potentials in the sand (fig. 45) are unrealistically small relative to the measured matric potentials during this period.

The final simulation of this phase of the experiment examined the impact of assuming large residual gas saturations in the fractures, as suggested by aperture-scale simulations described earlier (fig. 18C) and the values for $\mathrm{S}_{\mathrm{gr}}$ listed in table 6 . Because fracture permeability was greatly reduced by entrapped air, the calculated cumulative inflow to the block and sand-layer matric potentials were quite similar to the matrix-only, and single 2.5- and 250.0- $\mu \mathrm{m}$-fracture cases described earlier.

\section{Slug Test Modeling Summary}

In summary, sensitivity analyses showed that drainage from the sand and associated water uptake by the block were strongly influenced by contrasts in the permeability/matric potential relations assumed for the sand and underlying fractures. Given the measured properties of the sand, fractures with mean physical apertures of $25 \mu \mathrm{m}$ were predicted to be more important for water uptake than either smaller $(2.5-\mu \mathrm{m})$ or larger (125- and $250-\mu \mathrm{m}$ ) fractures. The relatively small intrinsic permeability of the narrower fractures, and capillary characteristics that inhibited water entry into the larger fractures, resulted in simulated values of cumulative water uptake for those cases that were only slightly larger than for the matrix-only case. Matric potentials measured by borehole psychrometers during this phase of the experiment revealed a pattern of wetting that was consistent with these concepts. Fractures F2 and F6, which were estimated on the basis of airinjection tests and aperture-scale modeling to have average physical apertures of 40.4 and $29.0 \mu \mathrm{m}$, showed earlier and more pronounced wetting than $\mathrm{F} 1$, which had an estimated average physical aperture of $93.4 \mu \mathrm{m}$. A two-fracture model was created that attempted to capture the combined effects of fractures

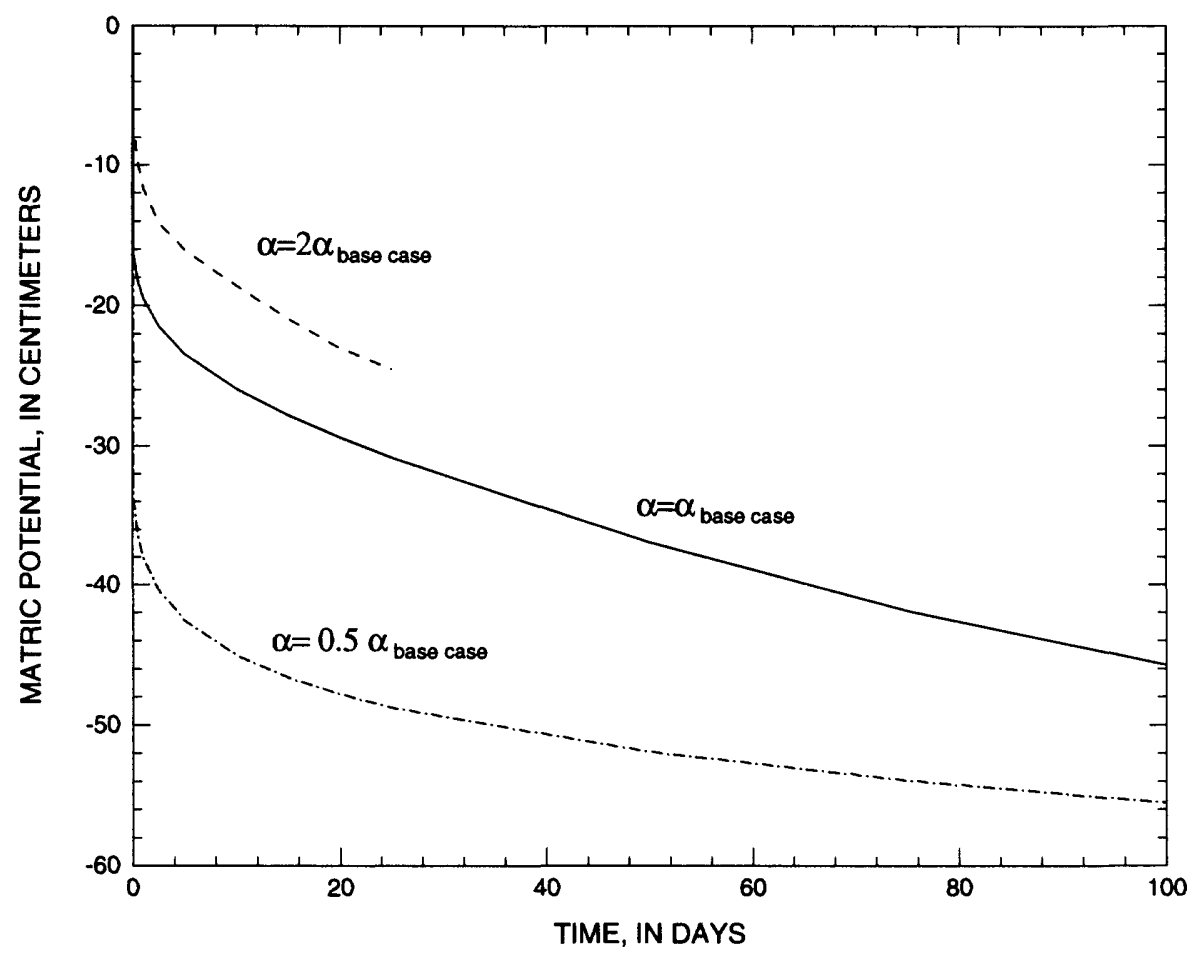

Figure 45. Sensitivity of model estimates of sand layer matric potential during the first 100-day redistribution period to variations in sand properties. 
F1, F2, and F6. This model overestimated the calculated cumulative water uptake by the block at 100 days by 40 percent, and produced corresponding overestimates and underestimates of matric potential in the rock matrix and overlying sand layer, respectively. The model predicted that lateral movement of moisture introduced into the block through the smaller aperture fracture could be blocked by capillary barrier effects associated with a parallel, larger aperture fracture. These effects were not indicated by the borehole psychrometric data, possibly because water uptake through fracture F6 was far less than predicted for the $25-\mu \mathrm{m}$ fracture in the model. Measured sand layer matric potentials were underestimated in all cases, although the matrix-only, and single 2.5-, 125-, and $250-\mu \mathrm{m}$ - fracture cases replicated the gradual decrease in matric potential to a near-constant value. In contrast, the single $25.0-\mu \mathrm{m}$ and two-fracture (25.0- and 125.0$\mu \mathrm{m})$ cases predicted continuous decreases in sand-layer matric potentials over the entire 100 -day simulation period. Although the simulations suggested many interesting and complex interactions, some of which could be at least qualitatively supported by the data, the models could not simultaneously reproduce the observed cumulative inflow and the measured matric potentials in both the sand layer and rock matrix. Incorporation of large residual gas saturations into assumed fracture properties in the two-fracture model resulted in considerable decreases in fracture permeability, so that cumulative water uptake by the block and simulated saturation and matric potential distributions were similar to that of the matrix-only case. Possible sources of error in these models include (1) the schematic nature of the fracture network, (2) inaccurate estimates of fracture aperture and hydrologic properties, and (3) inadequate characterization of the sand layer properties, combined with compaction of the sand layer during the experiment.

\section{Through-Flow Tests}

The through-flow simulations were intended to demonstrate that the relation between water-flow rate and matric potential of the rock (fig. 9A-C) could be predicted reasonably well, given a knowledge of the fracture geometry, fracture transmissivities estimated on the basis of the air-injection tests, and insights about the unsaturated hydrologic behavior of fractures developed from numerical simulations of multiphase fluid movement in single, variable-aperture fractures (figs. 16-21).
Because of its small permeability $(\mathrm{k}=$ $1.24 \times 10^{-18} \mathrm{~m}^{2}$ ), the rock matrix of the block is predicted to conduct only $0.064 \mathrm{~cm}^{3} /$ day of water under steady, saturated conditions with a unit hydraulic gradient. Therefore, nearly all of the observed flow through the block may be attributed to flow through the fracture network. For this reason and for simplicity, simulations of this aspect of the experiment considered only fractures in the absence of a permeable matrix. As described earlier, the geometry of the fractures within the block was recreated using FRACMAN (Dershowitz and others, 1994), and estimates of the transmissivities of those fractures were obtained using a trial and error fit to the air-injection-test data. Because this phase of the experiment does not require that boreholes be present to inject or withdraw fluids, the MAFIC (Miller, 1994) mesh used in the through-flow simulations is somewhat simpler than the mesh required to simulate the air-injection tests. The mesh used in the through-flow simulations had only 350 nodes and 631 elements.

Preliminary attempts to predict flow behavior of the fracture network under partially saturated conditions using TOUGH2 were suspended after convergence problems forced consideration of an alternative, less rigorous approach. In this alternative approach, steady unsaturated flow behavior was approximated with MAFIC (Miller, 1994), a single-phase (liquid water) simulator, by adjusting the transmissivities of the fractures to reflect the transmissivity reductions that accompany desaturation. These reductions were made using the relative permeability/matric potential curves estimated for the individual fractures, based on information contained in tables 6 and 7 and the average matric potential assigned to the block as a whole. In other words, in order to approximate the effects of variable saturation, fracture transmissivities in the MAFIC input file were manually adjusted at each of six average matric potentials selected to encompass the range of matric potentials imposed in the experiment. The apertures used to estimate the unsaturated fracture transmissivities in MAFIC were twice as large as those listed in table 7, in accordance with the observation from both experiments (Schrauf and Evans, 1986) and the numerical simulations described earlier that mean physical aperture is roughly twice the equivalent hydraulic or pneumatic aperture calculated from the cubic law. Table 9 lists the transmissivity values for individual fractures at each matric potential considered. For these six simulations, total heads 
Table 9. Summary of effective transmissivities of fractures at matric potentials considered by the MAFIC simulations $\left[b_{m}\right.$, mean physical aperture; $b_{h}$, equivalent hydraulic aperture; $\mu \mathrm{m}$, micrometer; $T$, transmissivity; $\psi$, matric potential; m, meter; $\mathrm{m}^{2} / \mathrm{s}, \mathrm{meter}$ squared per second]

\begin{tabular}{cccccccc}
\hline $\begin{array}{c}\text { Fracture } \\
\text { identification }\end{array}$ & $\begin{array}{c}b_{m}\left(=2 \times b_{h}\right) \\
(\mu \mathrm{m})\end{array}$ & $\begin{array}{c}T(\psi=0.0 \mathrm{~m}) \\
\left(\mathrm{m}^{2} / \mathrm{s}\right)\end{array}$ & $\begin{array}{c}T(\psi=-05 \mathrm{~m}) \\
\left(\mathrm{m}^{2} / \mathrm{s}\right)\end{array}$ & $\begin{array}{c}T(\psi=-0.10 \mathrm{~m}) \\
\left(\mathrm{m}^{2} / \mathrm{s}\right)\end{array}$ & $\begin{array}{c}T(\psi=-0.15 \mathrm{~m}) \\
\left(\mathrm{m}^{2} / \mathrm{s}\right)\end{array}$ & $\begin{array}{c}T(\psi=-0.20 \mathrm{~m}) \\
\left(\mathrm{m}^{2} / \mathrm{s}\right)\end{array}$ & $\begin{array}{c}T(\psi=-0.25 \mathrm{~m}) \\
\left(\mathrm{m}^{2} / \mathrm{s}\right)\end{array}$ \\
\hline F1 & 93.4 & $8.3479 \times 10^{-08}$ & $4.3786 \times 10^{-08}$ & $7.3429 \times 10^{-09}$ & $9.8584 \times 10^{-10}$ & $1.7362 \times 10^{-10}$ & $4.0965 \times 10^{-11}$ \\
F2 & 40.4 & $6.7564 \times 10^{-09}$ & $6.3017 \times 10^{-09}$ & $4.8409 \times 10^{-09}$ & $2.9066 \times 10^{-09}$ & $1.3939 \times 10^{-09}$ & $5.8232 \times 10^{-10}$ \\
F3 & 118.2 & $1.6906 \times 10^{-07}$ & $5.5211 \times 10^{-08}$ & $4.3660 \times 10^{-09}$ & $4.2965 \times 10^{-10}$ & $6.8793 \times 10^{-11}$ & $1.5797 \times 10^{-11}$ \\
${ }^{1} \mathrm{~F} 4,{ }^{1} \mathrm{~F} 8$ & $21: 4$ & $1.0000 \times 10^{-09}$ & $9.9802 \times 10^{-10}$ & $9.6594 \times 10^{-10}$ & $8.9428 \times 10^{-10}$ & $7.7935 \times 10^{-10}$ & $6.3087 \times 10^{-10}$ \\
F5 & 52.8 & $1.4963 \times 10^{-08}$ & $1.2981 \times 10^{-08}$ & $7.6239 \times 10^{-09}$ & $3.0388 \times 10^{-09}$ & $9.7751 \times 10^{-10}$ & $3.0592 \times 10^{-10}$ \\
F6 & 29.0 & $2.5169 \times 10^{-09}$ & $2.4389 \times 10^{-09}$ & $2.2125 \times 10^{-09}$ & $1.7966 \times 10^{-09}$ & $1.2770 \times 10^{-09}$ & $7.9375 \times 10^{-10}$ \\
${ }^{1} \mathrm{~F} 7,{ }^{1} \mathrm{~F} 9$ & 2.1 & $1.0000 \times 10^{-12}$ & $1.0000 \times 10^{-12}$ & $1.0000 \times 10^{-12}$ & $1.0000 \times 10^{-12}$ & $1.0000 \times 10^{-12}$ & $1.0000 \times 10^{-12}$ \\
\hline
\end{tabular}

' Designates that apertures and associated hydrologic properties were based on visual similarity to other fractures.

along the upper and lower boundaries were set to +1.4 and $+0.6 \mathrm{~m}$ in order to have a unit gradient across the approximately $0.8-\mathrm{m}$-tall block. The sides of the block were treated as no-flow boundaries, an assumption that can be justified by considering the nearly identical inflow and outflow rates of the block (fig. 9A). The nearly identical inflow and outflow rates indicate that very little water exited from the block along its sides during the partially saturated phase of the experiment when the water was held under tension in the rock.

Figure 46 shows the measured and simulated flow rates through the block. The comparison between the measured and simulated flow rates is surprisingly good, especially in view of all the uncertainties involved in determining fracture transmissivities from the airpermeability data and in inferring the unsaturated hydrologic behavior of the fractures from these transmissivity estimates. Where available, inflow and outflow data generally coincide with model simulations. The steady saturated flow rate through the block under a unit gradient was predicted to be $1,486.9 \mathrm{~cm}^{3} /$ day. The corresponding intrinsic permeability of the block in the direction of flow is $7.02 \times 10^{-15} \mathrm{~m}^{2}$. Although the steady, saturated flow rate through the block was not measured, extrapolation through the last seven data points of the log-linear plot of flow rate versus matric potential (fig. 9A) resulted in an estimate of $1,780 \mathrm{~cm}^{3} /$ day at $0 \mathrm{~cm}$ potential. The flow rate calculated by the model differs from that estimate by -16.5 percent.

The most prominent difference between the measured and simulated flow rates occurs at $\psi=-25.0 \mathrm{~cm}$, where the model does not reflect the abrupt decrease in flow evident in the data about $\psi=-21.0 \mathrm{~cm}$. Examination of the fracture transmissivity values in table 9 suggests that at $\psi=-25.0 \mathrm{~cm}$, most of the flow in the model occurs along the F6-F5 and F2-F4-F8-F5 fracture pathways. Transmissivity values were not measured in F4 or F8, and aperture estimates for these fractures were based on a visual comparison with F2. Different apertures could have been assumed for one or both of these fractures which, given the assumptions of the model, would have resulted in a decrease in simulated flow rates at $\psi=-21.0 \mathrm{~cm}$, with little change in flow rate at larger values of $\psi$. For instance, had F4 been modeled as having the properties of $\mathrm{F} 3$, its transmissivity at $\psi=-25.0 \mathrm{~cm}$ would be approximately $1 / 100$ th of the value originally assumed, and flux through the F2-F4-F8-F5 pathway would be correspondingly reduced. Flow rates at larger water potentials would not be significantly different than those already simulated because other fractures along this pathway (F8) would continue to limit flow.

The generally successful comparison between the measured and simulated flow rates suggests that the observed decreases in measured flow rates with decreasing water potentials probably resulted from partial desaturation of the fractures rather than clogging by bacteria or mineral deposition, or desaturation of the sand-layer.

\section{EXTRAPOLATION OF RESULTS TO THE FIELD SCALE}

This experiment was unusual in that measurements of inflow to and outflow from the block could be made to evaluate estimates of flux that were made on the basis of measured or inferred matrix and fracture hydrologic properties, monitoring of moisture status within the block with instrumented boreholes, and numerical modeling. Although other types of support- 


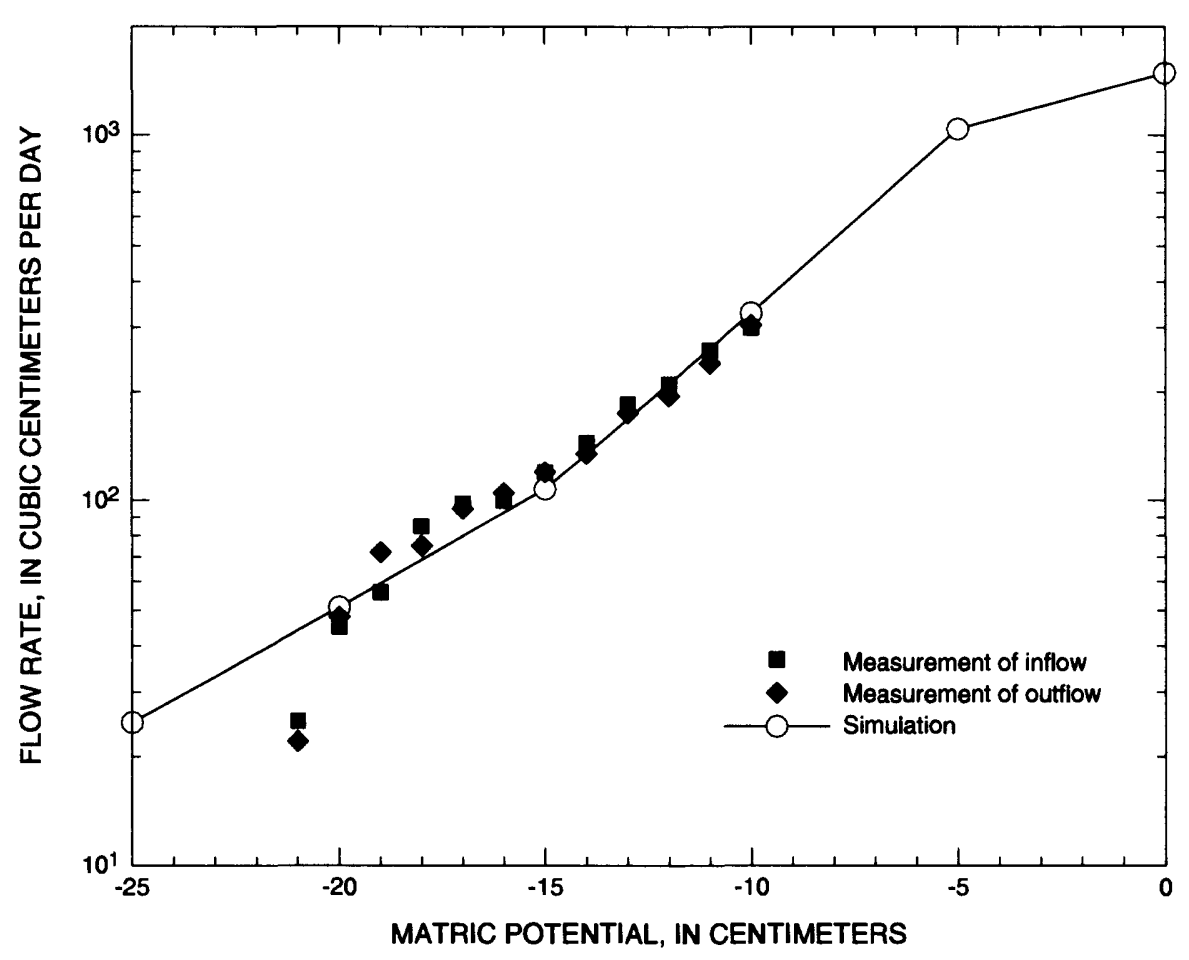

Figure 46. Comparison between measured and simulated water fluxes through the block as a function of matric potential.

ing information may exist at the field scale, direct measurements of flux will not be available to confirm estimates made on the basis of similar but less complete data. Such estimates can be made as part of studies intended to characterize natural infiltration, as well as those associated with the surface-based, deep borehole-monitoring program. Successful comparisons between measured fluxes and model simulations under carefully monitored, well-characterized conditions such as those described in this study can promote confidence that those field estimates have some basis and that the underlying physical processes are being adequately addressed. Of course, field-scale flux estimates would be subject to much greater uncertainty because the geometry and properties of the fracture network would be far less well known. Moreover, model results indicated that the fracture network went from full saturation to near complete drainage as matric potential went from 0 to $-1 \mathrm{~m}$. Saturation changes in the rock matrix over this small range in matric potential would not be detectable with current technology, and these values of matric potential are above the measurement limit of psychrometers presently in use in instrumented boreholes. Estimates of fracture flux from in-situ field measurements would therefore be qualitative at best.
Although the block experiment and the modeling are part of the developmental work being done in preparation for underground testing and analysis, aspects of this work have more general implications. In particular, the hydrologic interactions between unsaturated, fractured welded tuff and the overlying porous sand are relevant to infiltration studies. These interactions support the hypotheses that water potential at the alluviumbedrock contact essentially controls the flux of water across that interface. Also, the large, entrapped-air saturations that apparently occurred during imbibition experiments into the oven-dried cores indicated that similar phenomena might occur where rock has been dried to a significant degree, such as at the ground surface by solar radiation or, potentially, deeper underground by waste-generated heat.

Theoretical relations describing steady, multiphase fluid movement in single fractures were developed for this study. These relations rely on the assumption that local aperture values, through a capillary and an accessibility criterion, govern the spatial distribution and subsequent movement of fluid phases within a rough fracture. Although, in general, this approach appears to be reasonable, it currently lacks a firm experimental basis. Recent data from visualization experiments performed on roughened glass plates indicate a potential for gravity-driven wetting front insta- 
bilities to occur when flux through a fracture is less than can be transmitted under the existing gravitational gradient or at the cessation of stable infiltration

(Nicholl and others, 1993a,b). These effects were qualitatively replicated by a pore-scale invasion model that included the effects of gravity (Glass, 1993). Moreover, visual observations of the walls of the underground Exploratory Studies Facility (ESF) at Yucca Mountain suggest that fluid movement in at least some fractures is controlled by other criteria. Near-surface fractures may be filled with porous carbonate filling or with clay that may either have had a detrital origin or was precipitated in place. Some fractures at depth are several centimeters wide. Cooling fractures may have anastomosing tubular structures on otherwise extremely planar surfaces that formed during the escape of hot gases soon after the ashflow was deposited. Conceptual models different from those described in this report are needed to describe the movement of fluids in these types of fractures.

Not all the experimental data could be considered in this analysis. For instance, only a very small subset of the air-injection-test data was analyzed. And, for a given test, only the largest flow rates recorded during that test were considered. It was assumed for analysis purposes that flow in the fractures was laminar and that no turbulence or fracture dilation occurred as a result of the high gas pressures involved. Similarly, air-injection tests performed after the block had been significantly wetted were not analyzed to see if estimates of fracture transmissivity were altered by the presence of water in the injected or intersecting fractures. Finally, to investigate how subsequent water pulses interact with earlier ones, different tracers were added to the water in the first and second redistribution periods and at the beginning of the intended constant flow-rate part of the test. These data could not be analyzed prior to preparation of this report.

\section{IMPLICATIONS FOR EXPLORATORY STUDIES FACILITY TESTING}

One of the purposes of performing this prototype test was to help finalize the experimental design and analysis methods prior to the initiation of similar (but larger scale) tests proposed for the ESF. The experimental design of the ESF tests needs to reflect the information obtained from the test results and analyses described in this report.
1. The results of imbibition experiments summarized in this report were sensitive to the presence of pumice fragments, particularly when the pumice fragments were aligned with their largest dimensions perpendicular to the core axis. Future imbibition tests need to utilize cores whose diameters are large relative to the size of these pumice fragments in order to prevent their occurrence from dominating the test results.

2. Significant uncertainties were associated with the unsaturated hydrologic properties of the upper sand layer in this experiment, in part because its properties were inferred from measurements made on smaller, similarly packed samples. If sand is similarly used in an ESF test, the relative permeability and moisture-retention characteristics of the sand need to be characterized in situ. One method for doing this would be to monitor, concurrently, both water potentials and moisture content in the sand at various depths and locations during the redistribution period (Watson, 1966). In addition to providing in-situ data on the hydrologic properties of the sand, these measurements yield information on the time-varying rates at which water moves across the sand/rock interface, information that was not available for this phase of the prototype experiment.

3. Except where air-injection tests resulted in different aperture estimates, no information about aperture variability was available for individual fractures in the block. Therefore, aperture variations assumed in the aperture-scale model VSFRAC to develop hydrologic properties for fractures of various sizes were not constrained by fracture-specific data. Similarly, mean average apertures $b_{m}$ in the block were estimated from flow apertures $b_{h}$, using the observation that in the numerical simulations, $b_{m}$ was approximately twice $b_{h}$. Rasmussen (written commun., 1995) recently developed a theoretical relation between $b_{m}, b_{h}$, and aperture variability, $\sigma_{\text {ln } b}^{2}$, using the expected (or mean) values, $E\left(b_{m}\right)$ and $E\left(b_{h}\right)$ :

$$
\sigma_{\ln b}^{2}=2 b_{m}^{2} \ln \left[E\left(b_{m}\right) / E\left(b_{h}\right)\right]
$$

If site-specific data from Yucca Mountain allow equations of the form of equation 7 to be derived, estimates of $b_{m}$ can be made from the flow aperture $b_{h}$ and the easily measured joint roughness coefficients (JRC's), and aperture variability $\sigma_{\text {ln b }}^{2}$ can be estimated using equation 9.

4. The air-injection-testing matrix (table 2) succinctly summarizes those combinations of injection and monitoring boreholes for which data had been collected. Creation of such a table prior to testing could 
optimize testing by eliminating redundancy or gaps in information.

Similarly, the following analytical tools and methods need further development or improvement.

1. As implemented, MORPH (Dial, 1992) creates triangular TOUGH2-compatible integrated finite difference (IFD) cells directly from the corresponding finite elements. This approach may be simple, but it may not be as accurate or as numerically stable as meshes with higher order differencing schemes. An alternative approach might be to retain finite element (FE) nodes as the centers of future IFD cells and define the cell volumes by identifying the fracture areas implicitly associated with each FE node by using the concept of the "patch." IFD cell internodal distances are readily calculated from a knowledge of FE nodal coordinates, and IFD intercell areas can be calculated by determining the intersections of the perpendicular bisectors of the finite element sides.

2. If improved TOUGH 2 mesh design does not result in the numerical stability necessary to complete truly unsaturated or multiphase flow calculations, alternative methods for approximating the impact of desaturation, such as described in the "Through-Flow Tests" section, could be used with MAFIC rather than TOUGH2 to take advantage of the transport capability of MAFIC and the greater ease for graphically displaying the results of models that use finite-element meshes.

\section{SUMMARY}

The results of a multistage experiment involving a block of fractured, welded tuff were used to investigate if those results could be explained with models and concepts currently used to simulate unsaturatedzone water movement at Yucca Mountain, Nevada, the potential location of a high-level nuclear-waste repository. Aspects of the experiment were modeled with varying degrees of success.

Imbibition experiments using cores of various lengths and diameters were adequately described by models using independently measured permeabilities and moisture retention characteristics, provided that permeability reductions resulting from the presence of entrapped air were considered. Entrapped gas limited maximum water saturations during imbibition to approximately 0.70 to 0.80 of the fillable porosity values determined by vacuum saturation. Hysteretic effects were further approximated by varying the van
Genuchten parameter $\alpha$ between $\alpha_{d}$ and $2 \alpha_{d}$, where $\alpha_{d}$ is the value determined from the fitted drainage curve. Model results for this range of $\alpha$ produced simulated imbibition curves that effectively bounded the early time experimental data. Later time departures of the experimental data from the simulated curves were attributed to the presence of pumice fragments which inhibited water movement.

Analysis of air-injection tests with the MAFIC code produced estimates of transmissivities for fractures F1, F2, F3, F5, and F6 within the block. Transmissivities for other fractures were assigned on the basis of visual similarity to one of the tested fractures. The calibrated model explained 53 percent of the observed pressure variance at the monitoring boreholes (with results for 6 outliers excluded) and 97.2 percent of the pressure variance (including monitoring and injection boreholes) observed in the subset of air-injection tests examined. Discrepancies between simulated and observed pressure responses are attributed to the presence of uncharacterized and unmodeled heterogeneity between boreholes, and the proximity of constant pressure boundaries which resulted in steep pressure gradients that made replication of the observed cross-hole pressures difficult.

Attempts to model moisture redistribution from a saturated sand layer overlying the block resulted in many insights into the factors affecting this process. Single-fracture models predicted that fractures whose permeability and capillary characteristics most closely matched that of the overlying sand would be most important to water uptake by the block. For large-aperture fractures, water uptake at early time was limited by the intrinsic permeability of the sand and, at later times, by the small relative permeability of the fracture. In the case of small-aperture fractures, water uptake was limited by the small intrinsic permeability of the fractures themselves. For large-aperture fractures, simulated sand-layer matric potentials declined to near constant values as a result of capillary barrier effects at the sand/ rock interface, indicating that similar declines in matric potential observed during the experiment may have been influenced by such processes. A two-fracture model indicated that capillary barrier effects associated with large-aperture fractures could hydraulically isolate portions of the block from the actively flowing fractures, resulting in a decrease in water uptake relative to the corresponding single-fracture models. Although these simulations provided considerable insight, none could simultaneously match all of the data for this period, which included measured matric 
potentials in both the overlying sand layer and rock matrix, and an estimated cumulative drainage from the sand at 100 days of $4.5 \mathrm{~L}$. Discrepancies are attributed to uncertainty in the hydrologic properties of the upper sand layer, which were estimated from smaller, similarly packed samples and which were affected by compaction during the course of the experiment. The schematic model representation of the fracture network also undoubtedly contributed to the observed discrepancies.

The through-flow tests provided an opportunity to compare model-based estimates of flux based on indirect indicators, such as intrinsic permeability and matric potential, with direct measurements of flux collected over a range of matric potentials. The simulated steady fluxes were generally in very close agreement with measured fluxes, thereby lending support to the validity of the measurements themselves, the analytical methods that were used to make those estimates, and the processes that were hypothesized as causing the decline in measured flow rates. Failure of the throughflow model to predict the abrupt decrease in measured flow rates at matric potentials between -0.20 and -0.25 $m$ suggests that discrepancies between modeling and experimental results previously noted for the moistureredistribution stage of the experiment may have also resulted from incomplete or inaccurate characterization of the fracture apertures.

\section{REFERENCES CITED}

Barton, N.R., 1982, Modeling rock joint behavior from in situ block tests-Implications for nuclear waste repository design: Battelle Memphis Institute, Columbus, Ohio, Office of Nuclear Waste Isolation Technical Report ONWI-308.

Chekuri, V.S., Tyler, S.W., and Fordham, J.W., 1994, The role of fracture coatings on water imbibition into unsaturated tuff: Proceedings of the 5th Annual International High-Level Radioactive Waste Management Conference, Las Vegas, Nev., May 22-26, 1994, p. 1891-1896.

Ciesnik, M., Curtis, J., Flint, A.L., Hampson, D., and Thamir, F., 1994, Yucca Mountain Project Hydrologic Investigation Program, Unsaturated Zone Hydrology: SCP 8.3.1.2.2.4.2a, Prototype Percolation Test, Basic Data Report on Welded Tuff Core Experiments, Data Tracking Number (DTN): GS941108312242.002, $100 \mathrm{p}$.

Constantz, J., Herkelrath, W.N., and Murphy, F., 1988, Air encapsulation during infiltration: Soil Science Society of America Journal, v. 52, p. 10-16.
Dershowitz, W., Lee, G., Geier, J., Hitchcock, S., and LaPointe, P., 1994, FRACMAN Version 2.4 - Interactive discrete feature data analysis, geometric modeling and exploration simulation: User documentation, Redmond, Wash., Golder Associates Inc., 171 p.

Dial, B.W., 1992, MORPH Version B1.0 - MAFIC to VTOUGH/TOUGH input converter, user documentation: Alameda, Calif., Golder Associates Inc., 12 p.

Edlefsen, N.E., and Anderson, A.B., 1943, Thermodynamics of soil moisture: Hilgardia, v. 15, no. 2, p. 31-298.

Foltz, S.D., Tidwell, V.C., Glass, R.J., and Sobolik, S.R., 1993, Investigation of fracture-matrix interactions Preliminary experiments in a simple system: Proceedings of the 4th Annual International High-Level Radioactive Waste Management Conference, Las Vegas, Nev., April 26-30, 1993, p. 328-335.

Glass, R.J., 1993, Modeling gravity-driven fingering in rough-walled fractures using modified percolation theory: Proceedings of the 4th Annual International HighLevel Radioactive Waste Management Conference, Las Vegas, Nev., April 26-30, 1993, p. 2042-2052.

Glass, R.J., Tidwell, V.C., Flint, A.L., Peplinski, W., and Castro, Y., 1994, Fracture-matrix interactions in Topopah Spring Tuff - Experiment and numerical analysis: Proceedings of the 5th Annual International High-Level Radioactive Waste Management Conference, Las Vegas, Nev., May 22-26, 1994, p. 1905-1914.

Glass, R.J., Tidwell, V.C., and Nicholl, M.J., 1996, Challenging and improving conceptual models of isothermal flow in unsaturated fractured rock, through exploration of small-scale processes: SAND-1824, Albuquerque, N. Mex., Sandia National Laboratories, $43 \mathrm{p}$.

Haldeman, W.R., Chuang, Y., Rasmussen, T.C., and Evans, D.D., 1991, Laboratory analysis of fluid flow and solute transport through a fracture embedded in porous tuff: Water Resources Research, v. 27, no. 1, p. 53-65.

Healy, R.W., and Kwicklis, E.M., 1991, Modeling of flow and solute transport through a variable aperture partially saturated fracture: Abstract, in U.S. Geological Survey Open-File Report 91-125, 39 p.

Hillel, Daniel, 1980, Fundamentals of soil physics: New York, Academic Press, 364 p.

Kwicklis, E.M., and Healy, R.W., 1993, Numerical investigation of steady liquid water flow in a variably saturated fracture network: Water Resources Research, v. 29, no. 12 , p. 4091-4102.

Kwicklis, E.M., Thamir, F., Healy, R.W., Boughton, C.J., and Anderton, S., 1993, Numerical and laboratory investigations of transient and steady-state flow in a fractured core, in Evans, D.D., and Nicholson, T.J., eds., Flow and transport through unsaturated fractured rock related to high-level radioactive waste disposal: Proceedings of Workshop V, Tucson, Ariz., Jan. 7-10, 1991, U.S. Regulatory Commission Report NUREG/CP-0040, 232 p. 
Lee, G., Dershowitz, W., and Geier, J., 1994, EDMESH mesh editor and stochastic field generator for fracture network and continuum flow and transport codes -Version B1.30, User documentation: Seattle, Wash., Golder Associates Inc., 47 p.

Luckner, L., van Genuchten, M.T., and Nielsen, D.R., 1989, A consistent set of parametric models for the two-phase flow of immiscible fluids in the subsurface: Water Resources Research, v. 25, no. 10, p. 2187-2193.

Miller, I., 1992, MAFIC Version B2.0 - Matrix/fracture interaction code with solute transport, user manual: Redmond, Wash., Golder Associates Inc., 58 p.

Miller, I., Lee, G., Dershowitz, W., and Sharp, G., 1994, MAFIC Version B1.4 - Matrix/fracture interaction code with solute transport, user documentation: Redmond, Wash., Golder Associates Inc., 79 p.

Montazer, Parviz., and Wilson, W.E., 1984, Conceptual hydrologic model of flow in the unsaturated zone, Yucca Mountain, Nevada: U.S. Geological Survey Water-Resources Investigations Report, 84-4345, 55 p.

Nicholl, M.J., and Glass, R.J., 1994, Wetting phase permeability in a partially saturated horizontal fracture: Proceedings of the 5th Annual International High-Level Radioactive Waste Management Conference, Las Vegas, Nev., May 22-26, 1994, p. 2007-2019.

Nicholl, M.J., Glass, R.J., and Nguyen, H.A., 1993a, Smallscale behavior of single, gravity-driven fingers in an initially dry fractures: Proceedings of the 4th Annual International High-Level Radioactive Waste Management Conference, Las Vegas, Nev., April 26-30, 1993, p. 2023-2032.

1993b, Wetting front instability in an initially wet unsaturated fracture: Proceedings of the 4th Annual International High-Level Radioactive Waste Management Conference, Las Vegas, Nev., April 26-30, 1993, p. 2061-2070.

Persoff, P., and Pruess, K., 1993, Flow visualization and relative permeability measurements in rough-walled fractures: Proceedings of the 4th Annual International High-Level Radioactive Waste Management Conference, Las Vegas, Nev., April 26-30, 1993, p. 2033-2041.

Peters, R.R., Klavetter, E.A., George, J.T., Gauthier, J.H., 1987, Measuring and modeling water imbibition into tuff, in Evans, D.D., and Nicholson, T.J., eds., Flow through unsaturated, fractured rock: American Geophysical Union Monograph 42, p. 99-106.

Pruess, K., 1991, TOUGH2-A general-purpose numerical simulator for multiphase fluid and heat flow: LBL-29400, Berkeley, Calif., Lawrence Berkeley Laboratory, $102 \mathrm{p}$.

Pruess, K., and Tsang, Y.W., 1990, On two-phase relative permeability and capillary pressure of rough-walled rock fractures: Water Resources Research, v. 26, no. 9, p. 1915-1926.
Rasmussen, T.C., Evans, D.D., Sheets, P.J., and Blanford, J.H., 1993, Permeability of Apache Leap Tuff -Borehole and core measurements using water and air: Water Resources Research, v. 29, no. 7, p. 1997-2006.

Reitsma, S., and Kueper, B.H., 1994, Laboratory measurement of capillary pressure-saturation relationships in a rock fracture: Water Resources Research, v. 30, no. 4, p. 865-878.

Schrauf, T.W., and Evans, D.D., 1986, Laboratory studies of gas flow through a single natural fracture: Water Resources Research, v. 22, no. 7, p. 1038-1050.

Smith, L., Mase, C.W., and Schwartz, F.W., 1987, Estimation of fracture aperture using hydraulic and tracer tests, in Farmer, I.W., Daemen, J.J.K., Desai, C.S., Glass, C.E., and Neuman, S.P., eds., Rock Mechanics: Proceedings of the 28th U.S. Symposium, University of Arizona, Tucson, June 29-July 1, 1987, A.A. Balkema (publ.), Rotterdam, Neth., p. 453-463.

Thamir, Falah, Kwicklis, E.M., and Anderton, S., 1993, Laboratory study of water infiltration into a block of welded tuff: Proceedings of the 4th Annual International HighLevel Radioactive Waste Management Conference, Las Vegas, Nev., April 26-30, 1993, p. 2071-2080.

Thamir, Falah, Kwicklis, E.M., Hampson, David, and Anderton, S., 1994, Observations of water movement in a block of fractured, welded tuff: Proceedings of the 5th Annual International High-Level Radioactive Waste Management Conference, Las Vegas, Nev., May 22-26, 1994, p. 2020-2029.

Thoma, S.G., Gallegos, D.P., and Smith, D.M., 1992, Impact of fracture coatings on fracture/matrix interactions in unsaturated porous media: Water Resources Research, v. 28 , no. 5 , p. $1357-1367$.

Throckmorton, C.K., and Verbeek, E.R., 1995, Joint networks in the Tiva Canyon and Topopah Spring tuffs of the Paintbrush Group, southwestern Nevada: U.S. Geological Survey Open-File Report 95-2, 47 p.

van Genuchten, M.T., 1980, A closed form equation for predicting the hydraulic conductivity of unsaturated soils: Soil Science Society of America Journal Proceedings, v. 44, no.5, p. 892-898.

Wang, J.S.Y., and Narasimhan, T.N., 1985, Hydrologic mechanisms governing fluid flow in a partially saturated, fractured, porous medium: Water Resources Research, v. 21, no. 12, p. 1861-1874.

Watson, K.K., 1966, An instantaneous profile method for determining the hydraulic conductivity of unsaturated porous materials: Water Resources Research, v. 2, no. 4, p. 709-715.

Zimmerman, R.W., Bodvarsson, G.S., and Kwicklis, E.M., 1990, Absorption of water into porous blocks of various shapes and sizes: Water Resources Research, v. 26, no. 11 , p. 2797-2806. 